\title{
Consumer preferences for food products and production systems
}

\section{Empirical analysis of choice behaviour and attitudes}

\author{
Dissertation \\ zur Erlangung des Doktorgrades \\ der Fakultät für Agrarwissenschaften \\ der Georg-August-Universität Göttingen
}

vorgelegt von

Daniela Weible

geboren in Bietigheim-Bissingen

Göttingen, im September 2014 
D7

1. Referent: PD Dr. Martin Banse

2. Korreferent: Prof. Dr. Roland Herrmann

Tag der mündlichen Prüfung: 20. November 2014 


\section{Contents}

Summary i

Zusammenfassung iv

1 Introduction 1

1.1 Research question and objective . . . . . . . . . . . . . . . . . . 1

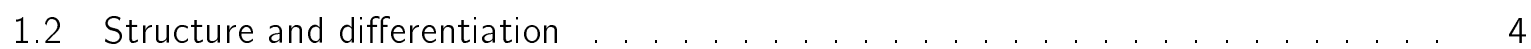

1.3 Summary of the contributions and synthesis of results $\ldots \ldots \ldots \ldots$

2 Articles included as part of the dissertation 12

2.1 How do political, individual and contextual factors affect school milk demand? Empirical evidence from primary schools in Germany . . . . . . . . . . . . . . . 12

2.2 Gender-driven food choice: Explaining school milk consumption of boys and girls . 24

2.3 Youths' preferences for milk products at school: How product attributes and perceived body image affect choices . . . . . . . . . . . . . . . . . . . . 46

2.4 Does the society perceive its own responsibility for modern pig production? . . . . 68

\begin{tabular}{lll}
\hline 3 & Concluding discussion & 76
\end{tabular}

\begin{tabular}{ll}
\hline References & 86
\end{tabular}

\begin{tabular}{lll}
\hline Appendix A & Further Publications & 93
\end{tabular}

\begin{tabular}{lll}
\hline Appendix B & Curriculum Vitae & 96
\end{tabular}

\begin{tabular}{ll}
\hline Appendix Danksagung & 97
\end{tabular} 


\section{Summary}

Nowadays, consumers face a huge range of products when buying food. A high density of information regarding content, origin and production of food is available. Hence, people can not only choose the ingredients or nutrients which they are going to eat but also the system in which food is produced. The abundance of options in the food market is a response to specific consumer needs and the available information creates transparency. Critical discussions about production systems can have positive effects (e. g., improved animal husbandry), too. However, one can also find negative effects of modern food production, such as information overload, unhealthy dietary patterns associated with chronic diseases or environmental problems. Altogether, the choices people make regarding food relate to several concerns and problems, which affect not only individual well-being but also societal welfare. Thus, a better knowledge of consumer preferences and understanding of reasons for people's consumption behaviour is of great interest. For example, appropriate strategies to encourage healthy lifestyles or to improve the acceptance of contemporary agriculture can only be developed if the factors underlying unhealthy diets or the criticism towards modern production systems are known.

In general, research on consumer behaviour focuses on the analysis of people's behaviour in terms of the purchase or consumption of goods. Choice behaviour allows the capture of people's preferences and the identification of these determinants that drive their decisions. In the context of food, however, empirical studies have shown that consumer intentions are not always reflected in their purchasing behaviour. Thus, consumers' preferences should be analysed from different perspectives.

This dissertation takes up these points and examines consumer preferences for food by analysing choice behaviour and attitudes. Preferences for food products, product attributes as well as production systems are empirically studied, exemplified by two topics: school milk and animal husbandry. Regarding these two areas, the main objectives are (i) to increase the knowledge and understanding of consumer preferences and (ii) to provide implications and recommendations for governments, policy-makers and research in particular. In sum, this dissertation combines four articles contained in chapter 2 that cover findings of three different studies.

The study presented in sections 2.1 and 2.2 is the first study on pupils' school milk demand that provides such a comprehensive demand model. Children's choices regarding school milk products are of interest because childhood is seen as being decisive for dietary habits in later years. Healthy lifestyles are adopted early-on in life and thus, children and young people receive high attention in scientific research and public health policies. Snacks offered at schools, such as school milk, provide an important setting: first, to analyse determinants of children's behaviour, second, to influence dietary habits of children. However, until now, little is known about children's preferences for school milk. The schools analysed in the study are located in North Rhine-Westphalia, Germany. Data covers 7,336 pupils in grades 2 to 4 . In addition to pupils, the study also includes their parents, teachers, school milk managers and school principals. Based on the theory of multilevel analysis, 
individual factors as well as the family and school context are considered at four levels: price, pupils, class and school level.

Section 2.1 presents derived results and recommendations for future school milk policies. Although the price setting (i. e., the availability of subsidies) is of importance for the school milk demand, only slightly more pupils will order school milk if prices are higher subsidized. Even when it is free of charge, not all pupils choose school milk (at a maximum of $81 \%$ ). Individual factors such as children's consumption habits at home, socio-demographics or their attitude towards milk significantly affect choices. The declining interest in school milk with increasing age is in accordance with results from the literature, as other dairy products (e.g., cheese) become more and more important for this age group. There are also indications for socialisation and role modelling effects, as parents and teachers significantly influence or model children's choices for school milk. Due to the influence of behaviour and attitudes of pupils and their immediate environment, the results implicate that policy-making has to go beyond price politics and adjust school food policies. For example, policy decisions should take information and communication activities in the field of nutrition concerning children, parents, teachers, and other school personnel into account. The evidence for a positive effect of a broader range of available milk flavours shows the necessity for modifications or the extension of the current product range.

Section 2.2 contributes to insights to the role of gender in food preferences using the example of school milk among German primary school children. In addition to the empirical analysis, it also covers a literature review on the role of parents, peers, teachers and the school environment in children's consumption behaviour. Findings of a multilevel analysis confirm that food choices of boys and girls are generally driven by both, identical and differing factors. Taste, habits and the attitude towards milk influence both, boys and girls. However, girls are only affected by their parents' and teachers' consumption behaviour. In contrast to girls, boys seem to be more price sensitive and influenced by attitudes of their immediate environment. The implications emphasize the necessity of considering individual factors as well as the social and physical environments of the child when explaining children's preferences for food. Although results are limited to consumption behaviour for school milk, they could be also used for the development of new or for improvements of existing school food programmes.

The suitability of available school milk products to meet older children's preferences is analysed in section 2.3. In particular, the question whether pupils already care about nutritional aspects is addressed. Through an online-survey, stated preference data is captured by a choice experiment among 500 youths aged 15-18 in Germany. The article compares children who always choose existing milk products to those who also choose products not yet available in schools. Within a nested Logit model it is confirmed that youths prefer a wider range of school milk products, including drinking yoghurt as an option among others. The results indicate that youths are aware of fat and sugar content and their effects on health and weight. However, this awareness cannot be observed directly in the product attributes which they choose. Although cross tables that were conducted before the analysis indicate strong gender effects, the influence of gender could not derived from model results which might be superposed by other effects. As expected, children care about prices. However, the study shows a low level of price sensitivity which might be the result of the small differences in product prices. Derived recommendations for school-based intervention programmes stress the importance of allowing children to choose between different milk products. An active choice between several options is essential to create an environment in which dietary 
habits can be formed.

With respect to the topic of animal husbandry, public attention and debates are increasingly focusing on the conditions in modern production systems. It seems that particularly controversially discussed pig production faces lower societal acceptance and developed in a way that no longer matches society's expectations and needs. However, concerns, priorities and expectations are rarely known in detail. Previous studies only touched upon these as their main topic lay somewhere else, e. g., either on animal welfare or on food and food quality.

Therefore, section 2.4 provides detailed insights into attitudes towards modern pig production from society's point of view. The study comprises two parts: A qualitative part in which the perceptions, opinions, responsibility and expectations of about 60 people in three German cities are captured in focus groups. And it consists of a quantitative part to receive a picture of current attitudes in society with an online-survey of about 1500 participants. Qualitative findings show participants' attention to the following topics: space available per pig is considered as insufficient and not species-appropriate, frequency of medications as too high and the prophylactic use of antibiotics as problematic. Although a generally negative or critical attitude is present, a very diverse picture of perception, attitudes and expectations regarding pig production exists in German society. These findings are confirmed by results of the quantitative part. Three segments of people of comparable size are identified with enormous differences regarding their attitudes towards modern pig production: the groups of "opponents", "tolerating" and "moderates".

Overall, children's choice behaviour is complex and influencing factors cover market-related, socio-demographic, psychological and sociological aspects. Indications for socialisation and role modelling effects of parents and teachers are particularly found. Nutritional and health aspects are also relevant for children's decisions. In regard to pig production, the main point of criticism is the available space per pig. Although a basic negative or critical attitude is present, a very diverse picture of perceptions, attitudes and expectations exists. In general, three population groups with differing attitudes regarding pig production are identified. In conclusion, empirical findings show that the combination of methodological approaches is beneficial to gain detailed insights into consumer preferences. Choice analyses of revealed and stated preference data are used to identify a huge range of factors that influence children's behaviour regarding school milk products. Moreover, qualitative and quantitative methods are used to explore and identify attitudes towards modern pig production from a societal point of view. Finally, the empirical studies in this dissertation consider consumers not only from the perspective of decision-makers or purchasers but also in their role as citizens or part of society. 


\section{Zusammenfassung}

Titel: Verbraucherpräferenzen für Lebensmittel und Produktionssysteme der Landwirtschaft - Eine empirische Analyse des Entscheidungsverhaltens und der Einstellungen

Konsumenten stehen beim Kauf von Lebensmitteln einer großen Anzahl an Produkten gegenüber. Eine hohe Dichte an Informationen bezüglich der Zutaten, Herkunft oder des Produktionsverfahrens sind verfügbar. Dadurch können Konsumenten nicht nur über Inhalts- und Nährstoffe der Produkte entscheiden, sondern auch über das System, in dem Nahrungsmittel produziert werden. Durch die Fülle an Möglichkeiten werden spezifische Bedürfnisse von Konsumenten bedient und die verfügbaren Informationen tragen zur Transparenz bei. Auch können kontroverse Diskussionen über Produktionssysteme positive Effekte haben (z. B. durch verbesserte Bedingungen in der Tierhaltung). Jedoch sind auch negative Effekte der modernen Lebensmittelproduktion zu beobachten, wie Umweltprobleme, Informationsfluten oder ungesunde Ernährungsgewohnheiten, die im Zusammenhang mit chronischen Erkrankungen stehen. Letztendlich beeinflussen Entscheidungen rund um die Lebensmittelwahl nicht nur das individuelle Wohl, sondern auch das Gesellschaftliche. Ein besseres Verständnis der Präferenzen von Verbrauchern und den Bestimmungsgründen sind daher von großem wissenschaftlichen Interesse. Geeignete Strategien zur Förderung gesunder Lebensstile oder für eine verbesserte Akzeptanz der heutigen Landwirtschaft können nur dann entwickelt werden, wenn diejenigen Faktoren identifiziert sind, die zu ungesunden Ernährungsweisen oder zu einer starken Kritik an modernen landwirtschaftlichen Produktionsverfahren führen.

In der Konsumentenverhaltensforschung liegt der primäre Fokus auf der Analyse von Verhalten, d. h. auf der Erklärung von Kauf- oder Konsumentscheidungen. Anhand des Entscheidungsverhaltens lassen sich die Triebkräfte des Verhaltens und somit auch die Präferenzen von Verbrauchern identifizieren. Im Kontext von Lebensmitteln zeigen empirische Studien aber auch, dass sich Absichten von Konsumenten nicht immer im Kaufverhalten wiederspiegeln. Das heißt, eine umfassende Betrachtung von Verbraucherpräferenzen ist notwendig, um diese zu durchdringen.

Die Dissertation greift diese Punkte auf und analysiert Verbraucherpräferenzen sowohl anhand des Entscheidungsverhaltens als auch anhand von Einstellungen. In verschiedenen empirischen Studien werden Präferenzen für Produkte, Produktattribute und für Produktionssysteme der Landwirtschaft am Beispiel der Schulmilch und der Tierhaltung untersucht. Das Ziel der Arbeit ist es, (i) einen Beitrag zum Wissen und der Erklärung von Verbraucherpräferenzen zu leisten, und (ii) daraus Implikationen und Empfehlungen für Regierungen, Politiken und insbesondere die Wissenschaft abzuleiten. Die Dissertation besteht aus vier wissenschaftlichen Beiträgen, die auf Ergebnissen von drei verschiedenen Studien beruhen und in Kapitel 2 aufgeführt werden.

Die dem Kapitel 2.1 und 2.2 zugrundeliegende Studie ist die erste im Bereich der Nachfrage von Schülern nach Schulmilch, die die Entwicklung eines so umfangreichen Nachfragemodells ermöglicht. Dem Ernährungs- und Entscheidungsverhalten von Kindern und Jugendlichen wird in der wissenschaftlichen Forschung und in Gesundheitspolitiken große Aufmerksamkeit geschenkt, da sich in der Kindheit Ernährungsgewohnheiten ausbilden bzw. diese erlernt werden. Der Schulkon- 
text erlaubt es, individuelle Konsumentscheidungen von Schülern zu untersuchen und die an den Schulen angebotenen Zwischenmahlzeiten (wie z. B. Schulmilchprodukte), können Einfluss auf die Ausbildung der Ernährungsgewohnheiten nehmen. Über die Präferenzen für Schulmilchprodukte ist jedoch wenig bekannt. Die im Rahmen der Studie erfassten Schulen befinden sich in NordrheinWestfalen, wobei Daten über die Schulmilchbestellungen von 7.336 Schülern aus den Klassen 2-4 vorliegen. Zusätzlich zu den Informationen über die Schüler umfasst der Datensatz Informationen über Eltern, Lehrer, Schulmilchkoordinatoren und Schulleiter. In einer Multilevelanalyse werden sowohl individuelle Merkmale der Kinder als auch Merkmale der Familie und des Schulkontextes einbezogen. Das Modell berücksichtigt dabei vier Level bzw. Ebenen: die Preis-, Schüler-, Klassenund Schulebene.

Die Ergebnisse in Kapitel 2.1 zeigen, dass der Produktpreis (d.h. die Verfügbarkeit einer Subvention) Einfluss auf die Nachfrage hat, wobei der Anteil der Schüler, die bei einer stärkeren Subventionierung der Preise zusätzlich Schulmilch bestellen, relativ gering ist. Sogar bei einer kostenlosen Abgabe wählen nicht alle Schüler Schulmilch (maximal $81 \%$ ). Einen signifikanten Einfluss auf die Nachfrage haben zudem individuelle Faktoren, wie Konsumgewohnheiten zuhause, sozio-demografische Merkmale oder Einstellungen gegenüber Milch. Ein abnehmendes Interesse an Schulmilch mit steigendem Alter bestätigt bestehende Ergebnisse aus der Literatur, da andere Milchprodukte (z. B. Käse) zunehmend wichtiger für diese Altersgruppe werden. Weiterhin liefern die Ergebnisse Hinweise auf Sozialisationseffekte und Rollenvorbilder (role modelling), da Einstellungen und Verhalten der Eltern und Lehrer die Entscheidungen der Kinder signifikant beeinflussen. Die Ergebnisse lassen darauf schließen, dass eine reine Preispolitik im Kontext der Schulverpflegung nicht ausreichend ist, wenn es das Ziel ist, die Konsumgewohnheiten und das Ernährungsverhalten von Kindern nachhaltig zu beeinflussen. Darüber hinausgehende Maßnahmen sind erforderlich. Beispielsweise könnten im Bereich Ernährung Informations- und Kommunikationsmaßnahmen für Schüler, Eltern und Lehrer in Erwägung gezogen werden. Positive Effekte einer breiteren Produktpalette weisen zudem darauf hin, dass eine Modifikation und Erweiterung der Schulmilchproduktpalette zu empfehlen ist.

Die Analyse der Präferenzen für Schulmilch in Abhängigkeit des Geschlechtes steht im Kapitel 2.2 im Vordergrund. Zudem wird ein Literaturüberblick zur Rolle der Eltern, Gleichaltrigen, Lehrern und Schulen für das Konsumverhalten von Kindern gegeben. Die Ergebnisse der Analyse zeigen, dass identische und unterschiedliche Faktoren die Schulmilchnachfrage von Jungen und Mädchen bestimmen. Beide Geschlechter werden von Gewohnheiten, Geschmack und ihrer Einstellung beeinflusst, wohingegen sich das Konsumverhalten der Eltern und Lehrer nur auf die Mädchen auswirkt. Dagegen zeigt sich, dass die Jungen preissensibler sind und ihr Handeln maßgeblich von den Einstellungen der Personen aus ihrem Umfeld geprägt wird. Neben den Faktoren des Individuums sind Faktoren des sozialen und physischen Umfeldes bei der Erklärung von Verbraucherpräferenzen von Bedeutung. Zwar beziehen sich die Ergebnisse lediglich auf Schulmilchprodukte, jedoch können sie auch im Hinblick auf die Entwicklung von neuen oder für die Verbesserung von existierenden Schulverpflegungsprogrammen wichtige Implikationen liefern.

Das Kapitel 2.3 gehört ebenfalls zu dem Themenbereich der Schulmilch. Es werden Präferenzen von jungen Erwachsenen für bestimmte Produktattribute analysiert. Insbesondere die Fragen, ob die am Markt existierenden Schulmilchprodukte überhaupt (noch) den Präferenzen dieser Altersgruppe entsprechen und ob Ernährungsaspekte eine Rolle bei der Entscheidung spielen, werden thematisiert. Die notwendigen Informationen werden mittels einer Online-Befragung mit etwa 500 
Jugendlichen im Alter von 15-18 mithilfe eines Choice Experiments erfasst. Diejenigen Kinder, die immer das bereits am Markt existierende Schulmilchprodukt wählen, werden mit den Schülern verglichen, die sich für die nicht am Markt verfügbaren Produkte entscheiden. Ergebnisse des Nested Logit-Modells zeigen, dass eine breitere Produktpalette, die auch Trinkjoghurt als eine mögliche Alternative beinhaltet, von den Jugendlichen präferiert wird. Weiterhin sind sich die Jugendlichen über den Fett- und Zuckergehalt und die Auswirkungen auf Gesundheit und Körpergewicht bewusst. Dieses Wissen spiegelt sich aber nicht in der Wahl der Produktattribute wieder. Wie erwartet, hat der Preis einen signifikanten Einfluss auf die Entscheidung der Jugendlichen. Ein Einfluss des Geschlechts kann jedoch in dieser Analyse nicht bestätigt werden. Die Ergebnisse lassen darauf schließen, dass die Möglichkeit, zwischen verschiedenen Produkt(attribut)en wählen zu können, wichtig für den Erfolg von schulbasierten Interventionsprogrammen ist.

In Bezug auf die Tierhaltung ist das Wissen und Verständnis der Verbraucherpräferenzen ebenfalls von großem Interesse. Über die heutige Landwirtschaft und Lebensmittelproduktion wird in der Öffentlichkeit und den Medien häufig kritisch diskutiert. Besonders davon betroffen sind die Bedingungen in modernen Tierhaltungssystemen. Die gesellschaftliche Wahrnehmung und Vorstellungen scheinen weit von der Realität entfernt zu sein und Meinungsumfragen deuten darauf hin, dass eine kritische Sicht in der Bevölkerung weit verbreitet ist. Jedoch sind die genauen Bedenken, Prioritäten und Erwartungen nicht bekannt. Bisherige Studien streifen dieses Thema nur, da ihr Schwerpunkt meistens auf dem Tierwohl-, Qualitäts- oder Sicherheitsaspekt von Lebensmitteln liegt.

Im Kapitel 2.4 werden am Beispiel der modernen Schweinehaltung Präferenzen für landwirtschaftliche Produktionssysteme identifiziert. Dazu werden Einstellungen der Bevölkerung tiefergehend untersucht. Die zugrundeliegende empirische Studie umfasst einen qualitativen Teil, in dem Wahrnehmungen, Meinungen und Erwartungen von etwa 60 Personen aus drei deutschen Städten mittels Gruppendiskussionen erfasst werden. Der darauf aufbauende quantitative Teil der Studie dient dazu, ein annähernd repräsentatives Bild der gesellschaftlichen Einstellungen für Deutschland zu gewinnen. Etwa 1500 Personen werden dazu in einer Online-Befragung befragt. Ergebnisse des qualitativen Teils zeigen, dass vor allem der Platz pro Tier von den Teilnehmern der Diskussionsrunden als unzureichend und nicht tiergerecht eingestuft wird. Auch wird die Häufigkeit der Verabreichung von Medikamenten als zu hoch beurteilt und der prophylaktische Gebrauch von Antibiotika als problematisch gesehen. Obwohl die generell negative Sicht der modernen Schweinehaltung in der quantitativen Studie bestätigt wird, ergibt sich ein differenziertes Bild der Wahrnehmungen, Einstellungen und Erwartungen in der deutschen Bevölkerung. Drei Gruppen mit sehr unterschiedlichen Einstellungen zur modernen Schweinehaltung werden anhand einer Clusteranalyse identifiziert. Die Gruppen sind von vergleichbarer Größe und lassen sich als eine Gruppe der Gegner, der Tolerierenden und der Moderaten beschreiben. Um dem Akzeptanzproblem zu begegnen, wäre es erforderlich, die Einhaltung bestehender Gesetze besser zu kontrollieren und Anreizsysteme für Landwirte zur Verbesserung der Tierhaltung zu schaffen.

Insgesamt zeigen die Ergebnisse der Arbeit, dass durch die Kombination von methodischen Ansätzen detaillierte Erkenntnisse von Verbraucherpräferenzen gewonnen werden können. Bei der Analyse des Entscheidungsverhaltens werden auf Basis von revealed und stated preference-Daten eine Vielzahl an Einflussfaktoren, die das Nachfrageverhalten nach Schulmilch beeinflussen, identifiziert. Zudem werden durch die Kombination von qualitativen mit quantitativen Methoden die in der Gesellschaft vorherrschenden Einstellungen gegenüber der modernen Schweinehaltung de- 


\section{Zusammenfassung}

tailliert erfasst. Letztendlich werden in dieser Dissertation Konsumenten nicht nur in ihrer Rolle als Entscheider oder Käufer betrachtet, sondern auch in ihrer Rolle als Bürger oder als Teil der Gesellschaft. 


\section{Introduction}

\subsection{Research question and objective}

The choices people make in terms of food are highly complex (Furst et al., 1996; Köster, 2009). Consumers are confronted with a multitude of products and their varieties, in range and style, when making food-related choices. Due to the use of modern methods and technologies, a huge range of cost-effective and secure food products are permanently available (Daniel et al., 2014. p. 6). This is further accompanied by the fact that consumers face a high density of information and channels thereof (Pieniak et al., 2007) such as lists of ingredients, nutritional values or labels indicating the type of production and processing. Hence, consumers can choose the ingredients or nutrients which they are going to eat and also the production system in which food is produced.

The huge range of available products in the food market creates transparency and is a response to specific consumer needs. However, it also causes problems: For instance, the abundance of food has often led to over-consumption or to the intake of energy-dense food and, in conjunction with sedentary lifestyles, to serious negative health consequences (WHO, 2014). The magnitude of available information on food products involves the risks of information overload as well as of contributing to a confusion of consumers, which might result in loss of interest (Verbeke, 2005, p. 361), in distrust and in general "tiredness" (Buergelt et al., 2013, p. 44) . Regarding food production systems, the structural change in agriculture and the use of modern methods and technologies has further led to an alienation of consumers and a growing scepticism among parts of society towards modern agriculture (Zander et al., 2013. Salamon et al., 2014). Moreover, consumption habits are considered to be responsible for several negative environmental consequences emerging from food production systems (Reisch et al., 2013). For example, animal production is seen as responsible for ground water pollution or greenhouse gas emission problems. Altogether, the choices people make regarding food relate to several concerns and problems, which not only affect individual well-being but also societal welfare.

Overall, the consumption of food and non-food products has and probably will have a central role in today's society, although, the meaning of consumption might change throughout time. Solomon et al. (2010) describe modern society as a consumer society where people also use their general consumption activities and choices as statements about, for example, personality, values, aspirations, sympathies and antipathies (Solomon et al., 2010, p. 32).

Researchers of various disciplines are engaged in questions concerning the "why" and "how" of consumer behaviour as well as the question of "in which way" individual preferences are reflected in behaviour and activities. Depending on the particular discipline, different facets of consumer behaviour are analysed within the relatively young field of consumer research (Solomon et al., 2010. pp. 22-24). Due to the interdisciplinarity of the field, consumer researchers can make use of a wide range of models and theories explaining consumers' behaviour. Results of these models are not only useful for scientists but also for market researchers, nutrition practitioners, the 
industry or even policy-makers. In order to formulate or to evaluate policies regarding consumerrelated activities governments should, for example, know about people's preferences and about the underlying reasons of consumer behaviour. Appropriate strategies to encourage healthy lifestyles or to improve the acceptance of today's agriculture can only be developed, if the factors underlying unhealthy lifestyles, preferences for sustainable products or the criticism towards modern production systems are known.

In general, research on consumer behaviour focuses on the analysis of people's behaviour in terms of the purchase or consumption of goods (Kroeber-Riel et al., 2009, pp. 3-4). This can include the whole purchasing decision process or only the decision to buy (Kroeber-Riel et al., 2009, p. 410). In this regard, underlying determinants of purchases or consumption can be manifold (Kotler and Bliemel, 1995, p. 280): Besides age, gender, education and income, also psychological factors (e.g., motivation, perception, learning, attitudes), aspects of personal lifestyle and personality are important (e. g., self-confidence, dominance, adaptability). Further, preferences and decisions are influenced by the social and physical environment. For example, opinions and behaviour of friends, available product information, recommendations to eat or avoid particular food items are picked up via the media, public discussions or in conversations with others. As people are part of society, certain cultural values or beliefs affect consumption behaviour, too. Finally, a huge network with determinants exists and over time, this network can grow or become smaller, new connections can be created and even existing ones can be dissolved.

Relating to the analysis of food choices, from an economic point of view it is assumed that consumers are faced with possible consumption bundles and that a "rational consumer will always choose the most preferred bundle" (Varian, 1984, p. 115). This means that consumer preferences manifest themselves on markets in terms of one's willingness to pay. Thus, the selection of a specific food item over another indicates a greater liking or a greater utility among given alternatives (Hensher et al., 2005; Louviere et al., 2000). In economic consumer theory, this is known as preference-maximization behaviour where a consumer maximizes utility given specific constraints, e. g., income (Varian, 1984). In general, preferences are represented within choices and, in turn, preferences influence markets and market conditions through demand behaviour. Overall, preferences for food products, product attributes and production systems can be analysed within the area of choice analysis. In this context, the analysis of preferences can also be referred to as demand analysis.

So far, the analysis of food choice behaviour allows the capture of preferences. However, observed choices do not always indicate the most preferred alternatives. For example, Grunert (2011) takes this into account by describing several barriers for sustainable food choices. Accordingly, consumers' intentions are not always reflected in their buying behaviour due to time restrictions, insufficient or incorrect information, conflicts of interest or a lack of awareness and credibility. The importance of price as a barrier is often emphasized in the context of consumers' decision to buy organic food (e.g., Padel and Foster, 2005, p. 622). Further, the access to and availability of product alternatives are often discussed as barriers in regard to the consumption of sustainable food in general (Thøgersen, 2005, Vermeir and Verbeke, 2006, p. 171) or, for example in the case of "animal friendly" produced meat in particular (Christoph-Schulz et al., 2012a. Krystallis et al., 2009). In respect to the above-mentioned topics, literature often describes and addresses the gap between actual behaviour and behavioural intentions under different terms such as "attitudebehavioural intention gap" (Vermeir and Verbeke, 2006), "value-action gap" (Young et al., 2010), a 
gap between intention and behaviour (GFK-EU3C, 2012) or between attitude and behaviour (Padel and Foster, 2005; Verbeke et al., 2007). Furthermore, Christoph-Schulz et al. (2012a, pp. 2-3) assume that part of the gap becomes coherent when it is seen as the difference between stated and revealed willingness to pay. With respect to preferences for animal husbandry systems, they distinguish between consumers, society, citizens, producers, other interest groups and others. Due to the different roles, consumers' preferences expressed within revealed choices might not correspond to people's stated choices or to their expressed preferences as, e. g., citizens. Hence, the gap can be understood as a gap emerging from different perspectives. Christoph-Schulz et al. (2012a) also emphasise that no clear distinction can be established between these groups. In a similar way, Moisander et al. (2010, p. 77) note in a discussion about the idea of green consumers as a powerful market force, that people are not only consumers but also workers and family members, and that their social context can result in conflicting expectations and contents. Moreover, Solomon et al. (2010, p. 6) differentiate between different roles of consumers in another way. Besides the role as choosers, they describe that consumers can also act as communicators, identity-seekers, pleasure-seekers, victims, activists, etc. Consequently, behaviour and preferences can vary depending on the "role" that consumers may engage in. Overall, to explain and overcome the aforementioned barriers, consumers' preferences should be analysed from different perspectives.

In the following, two areas in which food preferences are of particular interest or relevant to society are identified. One addresses a specific product, the other a production system. Empirical research, that is presented in the articles included in this dissertation, lays the thematic focus on these two areas.

As a specific group of consumers, the first area covers children and young people, i. e., a group that receives high attention in scientific research (Mau et al., 2014) and public health policies (EC, 2014b). Childhood is seen as being of high importance as healthy lifestyles are adopted early-on in life (Kelder et al., 1994, Kemm, 1987, Köster, 2009. Lien et al., 2001). Nutrition and eating behaviour of children and teenagers is seen as a key issue in the fight against obesity since the number of overweight and obese people is increasing among all age cohorts (WHO, 2003). Thus, the prevention of obesity and the intervention on obesity - especially in childhood - is a challenge for society. But, which factors influence children's preferences? One way to analyse children's eating behaviour is through food consumption at school. In addition to family mealtimes, more and more children take one or more meals at school. Emphasising the importance of the school setting in creating an environment for an optimal ability to concentrate and for learning, the "Deutsche Gesellschaft für Ernährung" (German Nutrition Society, DGE) published recommendations on the intake of grain and cereal products, vegetables and salad, fruits, milk and milk products as components of a balanced diet (DGE, 2013). Thus, snacks and meals offered at schools are a good opportunity to influence food choices of children and possibly also to encourage healthy eating patterns. Milk and milk products are spread widely at schools and therefore easy to analyse. However, until now, little is known about children's preferences for school milk as well as the effects of individual and contextual influences on school milk consumption.

The other area covers animal husbandry systems. Here, preferences are important with regard to the societal concern over animal husbandry. Due to structural changes in agriculture towards strongly specialised and large-scale production systems, it seems that particularly animal husbandry developed in a way that no longer matches society's expectations and needs. Recurring food 
scandals and the portrayal of modern agriculture and food production in public discussions and the media, has led to an overall increasing criticism of contemporary animal husbandry. Several aspects and trends can be observed in this regard. First, in public opinion surveys, pig production is seen as a system with considerable room for improvement (Eurobarometer, 2005). Second, people are more and more concerned about how animals are treated on farms and in livestock facilities, and at the same time, it becomes more and more evident that consumer preferences regarding animal production systems are not reflected in their actual buying behaviour - a gap between attitude and behaviour is apparent (Andersen, 2011; GfK-EU3C, 2012. Verbeke et al., 2010). Third, the European Commission has adopted a new strategy to improve welfare conditions for animals kept on farms (EC, 2012). This strategy emphasises that the European agricultural sector is a highly regulated market. Hence, the $\mathrm{EU}$ has to ensure that its rules achieve the right balance between the need to protect the welfare of animals and support for the competitiveness of the EU farming and food processing industry. Finally, while concerns over the sector itself are represented through their representative organisations, societal concerns, priorities and expectations regarding modern animal husbandry are rarely known in detail. In sum, contemporary animal husbandry, the welfare of animals and also the question of who is responsible for the welfare of animals is a major topic in political, public and scientific debates, especially in discussions about sustainable production and consumption of meat.

This dissertation pursues the research objective to increase the knowledge and understanding of consumer preferences for food. It aims at analysing preferences for food products and product attributes as well as for food production systems. Exemplified by school milk and animal husbandry, these three dimensions are covered. Preferences for products and product attributes are studied within the area of school milk. Data on product choices of children is used to explain preferences on an individual basis. The dissertation aims at identifying those influencing factors that drive children's behaviour regarding school milk products. Determinants considered in these analyses cover socio-economics and psycho-metrics as well as factors of the context school milk is bought and consumed in. Different methodological approaches of choice analysis are applied to get a detailed understanding of these determining factors. Preferences for production systems are analysed within the area of animal husbandry. The dissertation intends to identify attitudes towards modern pig production from a societal point of view and obtain a deep understanding of current preferences. Perceptions, opinions and expectations in society are explored in a qualitative way and the gained results are quantified using methods of multivariate analysis.

Overall, determinants of children's choice behaviour and society's attitudes towards animal husbandry are of interest for several concerned parties. These comprise, for instance, policy-makers, government, industry and researchers. Hence, the knowledge and understanding of consumer preferences, achieved in the empirical studies, are used to provide implications and recommendations for these parties.

\subsection{Structure and differentiation}

The cumulative dissertation consists of four contributions. Table 1 provides an overview of the included articles, the co-authors and the journals in which the articles are published. Due to the objectives of the dissertation, the contributions are categorised in accordance with the analysed 
Table 1: Overview of the contributions

\begin{tabular}{clll} 
Article & Author(s) & Title & published in \\
\hline (1) & $\begin{array}{l}\text { D. Weible } \\
\text { P. Salamon } \\
\text { I. B. Christoph-Schulz } \\
\text { G. Peter }\end{array}$ & $\begin{array}{l}\text { How do political, individual and contextual } \\
\text { factors affect school milk demand? Empirical } \\
\text { evidence from primary schools in Germany }\end{array}$ & Food Policy (2013) 43, 148-158 \\
\hline (2) & D. Weible & $\begin{array}{l}\text { Gender-driven food choice: Explaining school } \\
\text { milk consumption of boys and girls }\end{array}$ & Journal of Consumer Policy (2013) \\
& 36 (4), 403-423
\end{tabular}

preference dimension into two core areas. Figure 1 illustrates how the contributions can be assigned to this structure, how they can be distinguished from each other and where the contributions have their priorities.

The first core area is entitled Preferences for food products and covers three articles, all focusing on pupils and their preferences for milk and milk products offered at school. Articles (1) and (2) provide empirical models that explain food choices of children taking individual factors, the family and school environment and particularly political factors into account. While in article (1) the depiction of the methodological approach and model specification is a priority, article (2) concentrates on the appropriate theoretical framework for the description of choice behaviour of children. Moreover, the empirical analysis of article (2) explains food choices separately for boys and girls. Article (3) examines whether the milk products offered at schools still meet children's preferences or if modifications could prove to be useful. In contrast to the first articles, which both focus on children's preferences for milk products, article (3) deals with preferences of youths for several milk product attributes. The contributions of the first section are closely connected to each other and build upon one another. Articles (1) and (2) were both published in 2013 with different time lengths in the revision process. The work on the third article began in 2013 and it currently has the status "submitted".

The second core area, entitled Preferences for food production systems, is represented by article (4) focusing on society's preferences regarding modern pig production. This section provides a methodological approach, which explores society's perception, opinions and expectations and which draws a picture of currently prevalent attitudes in the German population. This contribution is developed separately from the other three.

The cumulative dissertation is limited to the above mentioned four contributions. Further reviewed as well as unreviewed publications and reports are listed in Annex A. These are either very similar to the included articles or go beyond the scope of this dissertation. Many of them consider questions relating to the areas school milk and animal husbandry. For example, with respect to animal husbandry two papers discuss how divergent expectations of consumers, producers, citizens, etc. can be captured. But also the area of sustainable consumption is addressed. Exemplified by wild fish 


\begin{tabular}{|c|c|c|}
\hline \multicolumn{2}{|c|}{ Preferences for food products } & \multirow{2}{*}{$\begin{array}{l}\text { Preferences for food production } \\
\text { systems }\end{array}$} \\
\hline at product level & at product attribute level & \\
\hline (1) Food Policy (2013) 43 & (3) Appetite (submitted) & $\begin{array}{l}\text { EurSafe Conference } \\
\text { (4) Proceedings } 2013\end{array}$ \\
\hline $\begin{array}{l}\text { - Analysis of revealed preferences } \\
\text { for school milk of children in } \\
\text { grades } 2 \text { to } 4 \text { (aged 6-12) in } \\
\text { North Rhine-Westphalia } \\
\text { - Development of a demand } \\
\text { model is based on multilevel } \\
\text { logistic analysis } \\
\text { - Pooled data of } 7336 \text { children and } \\
\text { their parents, } 552 \text { class teachers, } \\
101 \text { school milk managers and } \\
\text { school principles }\end{array}$ & $\begin{array}{l}\text { - Choice experiment to } \\
\text { analyse preferences for } \\
\text { product attributes of milk } \\
\text { products at school } \\
\text { - Survey data of } 500 \text { youths in } \\
\text { Germany aged } 15-18\end{array}$ & $\begin{array}{l}\text { - Mixed-method approach in } \\
\text { order to analyse preferences } \\
\text { of society for modern pig } \\
\text { production in Germany } \\
\text { - Data of } 6 \text { focus group } \\
\text { discussions in } 3 \text { cities (Leipzig, } \\
\text { Mainz, Rheine) } \\
\text { - Survey data of } 1519 \text { adults in } \\
\text { Germany } \\
\text { - Factor and cluster analysis }\end{array}$ \\
\hline \begin{tabular}{l|l} 
(2) Journal of Consumer Policy \\
(2013) $36(4)$
\end{tabular} & & \\
\hline $\begin{array}{l}\text { - Analysis of revealed preferences } \\
\text { for school milk of boys and girls } \\
\text { in grades } 2 \text { to } 4 \text { (aged 6-12) of } \\
\text { North Rhine-Westphalia } \\
\text { - Theoretical considerations } \\
\text { regarding determinants in } \\
\text { children's consumption } \\
\text { behaviour } \\
\text { - Literature review of social } \\
\text { environmental determinants in } \\
\text { adolescence } \\
\text { - Pooled data of } 3658 \text { girls and } \\
3676 \text { boys and their parents, } 552 \\
\text { class teachers, } 101 \text { school milk } \\
\text { managers and school principals }\end{array}$ & & \\
\hline
\end{tabular}

Figure 1: Categories of contributions

products, consumers' perceptions, assessment and relevance of sustainability labels are analysed.

\subsection{Summary of the contributions and synthesis of results}

The following summarises the central issues and results of each article and presents their contribution to the research objectives. In addition, this section shows how the findings fit into the existing literature.

The first three contributions deal with the analysis of preferences for food products and several product attributes. Throughout these articles, food choice behaviour of children and youths regarding milk and milk products offered at school is analysed. The underlying data sets stem from a wide-ranging federal research project, called "Schulmilch im Fokus", carried out with several smaller studies in Germany and one large study in North Rhine-Westphalia between 2007 and 2011.

At the beginning of article (1) the latter study is briefly introduced. Hereafter, two principle data sets, which are used for the analysis in articles (1) and (2), are described: Firstly, survey data was collected through written questionnaires distributed to all concerned agents in targeted schools (i. e., pupils, their parents, class teachers, school milk managers and school principals). Secondly, 
panel data compiled on individual school milk orderings in a price experiment and captured in these targeted schools. The written questionnaires were developed, conducted and collected by the Max Rubner-Institut (MRI), whereas the price experiment was handled by the Thünen-Institut ( TI, formerly vTI). In total, for the school year 2008/2009 data of over 12,000 children (2nd- to 4th-grade pupils) in 125 primary schools was captured. In order to gain detailed insights into the drivers of children's preferences, all relevant information was pooled (the resulting dataset covers 7336 pupils) and a demand model for school milk was specified. It considers individual, context (social and physical environment) and in particular political factors that influence pupils' decisions to order milk at school. Individual factors comprised characteristics, such as socio-economics and psychometrics, of the children and their parents; context factors comprised characteristics of the class teacher, school milk manager and school principal as well as school characteristics and political factors such as the price subsidy 1 .

The depiction of the methodological approach and model specification is prioritised in article (1). Accordingly, a demand model is developed based on the theory of multilevel analysis, which takes the hierarchical structure of the data set into account (as pupils are nested in classes within schools). A random-intercept model with an ordinary logistic model is chosen accounting for four levels: price, individual, class and school level. Such a comprehensive empirical model, illustrating children's preferences on the basis of several levels with a huge range of assumed determinants, has not yet been described in literature. Thus, findings in regard to school milk demand can serve as an example and provide the basis for other programmes related to school food or nutrition programmes.

The findings of article (1) highlight that a price effect exists. However, the effect is limited. Individual as well as social behaviour and attitudes (e. g., pupils' milk image and pupils' consumption habits at home, the role modelling of parents and teachers) are seen as further important triggers in the planning of interventions. Hence, results show that policy-making has to go beyond price politics and adjust school food policies, for instance, to more tailored programmes integrated into an overall concept like school meals. It also has to target on specific groups such as girls, who are generally at risk of suffering from an insufficient calcium supply. In view of teachers' position as role models, programmes should also target them. Finally, policies might also target behaviour and decisions of the dairy industry and schools, namely by extending the product range towards more dairy products in order to address a diversity of preferences.

Similar to prior empirical studies (e.g., Christoph-Schulz et al., 2012b, DGE, 2008, Mensink et al., 2007, Robinson, 1978; Weindlmaier and Fallscheer, 1997), the results of the analysis in article (1) indicate that in the case of milk and school milk, girls consume significantly less than boys. Moreover, for example, Nu et al. (1996) and Jensen and Holm (1999) already emphasised that food preferences generally differ between boys and girls. Thus, over the last few years several researchers (Koehler and Leonhaeuser, 2008: Larson et al., 2009, Sweeting, 2008) came to the conclusion that a clear focus on gender differences is required to gain insights into the role of the issue of gender in food preferences or in food-related behaviour. In addition, governments emphasise that policy strategies should take the gender dimension of health policy into account because women and

\footnotetext{
${ }^{1}$ According to the provisions of the EU School Milk Scheme (EC, 2008), all children attending an educational establishment are allowed to benefit from the so-called Community aid for supplying milk and certain milk products. Hence, pupils are entitled to receive up to $250 \mathrm{ml}$ of subsidised school milk (or school milk equivalents) per school day. Currently, the subsidy is set at 18.15 Euros per $100 \mathrm{~kg}$ of milk equivalent. In Germany (BMELF, 1985), subsidised prices follow a maximum price policy, with maximum prices being fixed at federal level.
} 
men have different health risks and different access to health services (EC, 2014b). Acquiring knowledge on gender differences will consequently help to design more appropriate programmes for groups with special needs - such as girls (Mensink et al., 2007, DGE, 2008; MRI, 2008).

Article (2) attempts to close this "gap" by separately looking for determining factors in school milk consumption 2 for boys and girls, respectively. The empirical model used for this analysis relies on the demand model for school milk in (1) and hence, neither the methodological background nor the model specification is described in detail. Instead, the underlying theoretical framework with its integrative approach is introduced, combining the idea of social cognitive theory with an ecological model for describing choice behaviour of children. Also, the role of the social environment in children's behaviour is portrayed within a literature review comprising parents, peers, teachers and the school context in general.

The results show limitations of an exclusive price policy. While for boys the school milk price affects choice behaviour, for girls other factors seem to be more important. The missing significant price impact for girls could be related to the fact that they are rather driven by healthiness and their parents' and teachers' behaviour. Moreover, results also highlight that with an increasing number of available milk flavours, more girls decide to choose a school milk product. Modifications or the extension of the current product range can be recommended as an option for policy-makers. However, are modifications useful? If yes, which novel products are preferred? These questions are not answered in articles (1) and (2) because no distinction is made between different types of milk products and nutritional aspects were also neglected.

Overall, both contributions indicate that in case of milk products, food preferences are similar to those at home which means that those children who like to consume milk and milk products at home will also do this at school. Moreover, it seems that children's preferences change with increasing age as school milk consumption decreases. But the question of how preferences of older children can further be met is also not addressed by these first two contributions.

Article (3) takes up these open questions and studies whether milk products offered at school still meet older children's preferences and expectations or if modifications could prove to be useful to reach more consumers. In particular, the question of whether the children already care about nutritional aspects is addressed. The core intention of article (3) is to consider attributes of milk products that are generally not yet available at schools, with the attribute-levels of currently available school milk products serving as reference.

A choice experiment was carried out through an online-survey of about 500 youths aged 15-18 to study preferences for different prices $(30,35,40$ cents), fat contents $(0.3,1.5,3.5 \%)$ and sweetening agents (sugar, artificial sweetener). In general, respondents had to choose between three different products: Conventional school milk already available at school, novel school milk and novel yoghurt. Novel products were partly reduced in their calorie content due to artificial sweetener and/or reduced fat content. A nested Logit model is applied to compare the children who always choose the already existing milk products to those who also choose novel products. This type of model explains why some respondents are more likely to choose the novel school milk product with reduced fat content or artificial sweetener. Socio-economics, socio-demographics as well as psychometrics are used to explain differences in preferences.

The findings highlight that on average both, novel school milk and novel yoghurt, generate

${ }^{2}$ Throughout article (2), the term consumption is used in terms of the decision to consume. It corresponds to pupils purchase decisions. There is no information whether the ordered school milk products are really consumed. 
positive benefits, whereas most respondents explicitly prefer novel milk over novel yoghurt. A minor group of youths $(n=159)$ also exclusively prefers the conventional school milk. Although the price has an effect on choices, youths are only slightly price-sensitive, which is in line with the findings in articles (1) and (2). Considering the group of youths that at least once chose a novel milk product, the importance of psychometrics in the explanation of preferences are shown in these two articles. For instance, respondents who assessed themselves as overweight have a higher probability to choose one of the novel products. This group also stated to pay attention to a low fat and sugar content. Article (3) concludes that youths who perceived themselves as being overweight seem to have different attitudes and different preferences. In the light of the debate about childhood obesity, this may be a central result for policy-making and supports previous findings emphasising the relevance of body weight and the (perceived) "healthiness" of food products in choices.

All first three contributions rely on different empirical models to receive a more detailed picture of the complexity of determinants in food choices. Different approaches and perspectives are used to illuminate the determinants of food preferences, of individual and contextual factors, or of sociodemographics, socio-economics and psychometrics, respectively. Further, it gives an indication of how to design appropriate and effective interventional measures for the group of children and youths. It also states that this involves addressing the immediate social environment (the family and school), too. Finally, findings suggest that a relationship exist between food preferences and health behaviour, but these are only touched upon and could not be analysed in detail.

Article (4) deals with preferences for food production systems. The primary objective pursued in this contribution is the analysis of society's preferences for animal production systems. There are several reasons for why the core intention is to investigate society's and not consumers' needs: First, due to the generally growing interest of people in more animal welfare friendly production systems and a deficit of available product alternatives on the market, the analysis of food choice behaviour is not appropriate to gain detailed insights into preferences for current animal production systems. Second, individual preferences and consumption behaviour regarding production systems strongly relate to societal welfare as production systems have social and environmental consequences. Finally, over the last few years, previous studies only touched upon society's perceptions and expectations. So far, the focus of most studies lay elsewhere, either on animal welfare (e. g., Eurobarometer, 2005: Eurobarometer, 2007. Eurobarometer, 2010; Evans and Miele, 2008; Harper and Henson, 2001) or on food and food quality (e.g., Lassen et al., 2006 Alvensleben, 2002). Hence, the intention is to concentrate on people in their role as citizens or as part of society. Consequently, article (4) analyses societal views concerning modern animal husbandry using the example of modern pig production practices in Germany. In addition, the question of "who is responsible for modern pig production?" is also answered from society's point of view.

To discover the unknown structures in preferences, a mixed method approach is applied, which allows one to gain detailed insights in an exploratory way. By combining qualitative focus group discussions with a quantitative survey, society's perception, attitudes and expectations are analysed in detail and in a way that preferences are discovered exploratively and that subsequently interdependencies are analysed within an exploratory factor and cluster analysis. The used dataset stems from the project "Erwartungen der Gesellschaft an die Landwirtschaft" funded by the Stiftung Westfälische Landschaft (SWL), in which - among other things - six focus groups (about 60 participants in total) were conducted in three German cities during September 2012, followed by an online-survey of about 1500 adults in Germany, carried out in the spring of 2013. 
The findings highlight that many people consider modern pig production as problematic and that they trace this back to a high degree of "industrialisation" of animal production. According to their opinions, the animal is almost no-longer seen as a creature in this process. Lack of space and missing outdoor-access are reasons for the high use of medications, for the need of surgical treatments and for behavioural disorders. Often a trade-off between low consumer prices for pork and animal welfare is seen. Citizens expect stronger regulations for farmers and the monitoring of their compliance. Overall, a very diverse picture of attitudes, perception and expectation exists in Germany, whereas a generally negative or critical attitude is present. This is confirmed by results of quantitative analysis. Three groups of people of comparable size are identified with enormous differences in regard to their attitudes towards modern pig production, the groups of opponents, tolerating and moderates.

Article (4) provides empirical evidence that a lack of a socially accepted form of the keeping of pigs exists and hence, that there is a need to improve the image of animal husbandry in society. Several possible ways are mentioned to abate the gap between society's perception of animal husbandry and society's needs: The first possibility is communication strategies to overcome the nostalgic view of pig production based on a very limited knowledge or caused by prejudices, e. g., through opening farm gates to the public. Based on identified population groups with almost homogeneous preferences, specific strategies can be developed that provide appropriate information. Further, policy-makers and the agricultural sector can take societal concerns into account through policies that provide animal welfare promoting incentives or introduce stronger regulations without compensation for farmers at the EU level. This could be supported by a better compliance to regulations and the monitoring thereof. Finally, policy-makers can provide the opportunity to consumers to differentiate between animal-friendly produced meat from other types, for instance, through labelling. In sum, article (4) indicates that, while the relevance of animal welfare in consumption behaviour is limited, an upward tendency can be expected, which may also be driven by the on-going strong criticism in public discussions.

In conclusion, the dissertation consists of four articles. All increase the knowledge and understanding of consumer preferences on the basis of specific topics. Two contributions concentrate on children's preferences for school milk products, another one on youth's preferences for several school milk attributes, and the fourth one on society's preferences for modern pig production.

Based on revealed preference data a demand model for school milk is developed, which allows one to distinguish between different levels of influences. In addition to individual factors, the classroom setting and school context of pupils, as well as policy-driven factors are considered. To gain more insights into gender-specific behaviour, school milk choices are also analysed separately for boys and girls. Stated preference data derived by a choice experiment among youths, allows for explaining preferences for novel school milk products and product attributes not yet available at schools. Finally, an exploratory approach is used to analyse preferences for food production systems. Current perceptions, opinions and expectations towards modern pig production in society are identified in focus groups and attitudes are quantified in an online-survey to receive a picture for society.

Overall, empirical findings show that children's choice behaviour is complex and influencing factors cover market-related, socio-demographic, psychological and sociological aspects. Indications for socialisation ans role modelling effects of parents and teachers are particularly found. Nutritional and health aspects are also relevant for children's choices. Furthermore, results provide a deeper 
understanding of people's attitudes and preferences for pig production. Empirical findings indicate that the main point of criticism is the available space per pig. Although a basic negative or critical attitude is present, a very diverse picture of perceptions, attitudes and expectations exists. Three population groups with differing attitudes regarding pig production are identified.

To summarize, the dissertation studies consumers from different perspectives, as decision-makers or purchasers and as members of society. Different methods of empirical social research are used to analyse consumer preferences. Implications and recommendations address in particular researchers, governments and policy-makers. 


\section{Articles included as part of the dissertation}

2.1 How do political, individual and contextual factors affect school milk demand? Empirical evidence from primary schools in Germany

Daniela Weible, Petra Salamon, Inken B. Christoph-Schulz, Guenter Peter Food Policy (2013) 43, 148-158

(Elsevier Ltd.)

This article was presented in a similar form as a "contributed paper" at the XIIIth Congress of the European Association of Agricultural Economists (EAAE) "Change and Uncertainty; Challenges for Agriculture, Food and National Resources" from 30.08.02.09.2011 in Zurich, Switzerland. 


\title{
How do political, individual and contextual factors affect school milk demand? Empirical evidence from primary schools in Germany
}

\author{
Daniela Weible*, Petra Salamon, Inken B. Christoph-Schulz, Guenter Peter \\ Johann Heinrich von Thünen Institut, Federal Research Institute for Rural Areas, Forestry and Fisheries, Institute for Market Analysis, Bundesallee 50, D-38116 Braunschweig, Germany
}

\section{A R T I C L E I N F O}

\section{Article history:}

Received 13 June 2012

Received in revised form 22 August 2013

Accepted 24 August 2013

\section{Keywords:}

School milk

Demand model

Multilevel analysis

Context effects

Price experiment

Policy impact

\begin{abstract}
A B S T R A C T
Despite the subsidies provided for school milk within the European School Milk Scheme, consumption has declined steadily in Germany. Thus, a federal research project was established to analyze factors that influence the demand for school milk. The results should form a basis to improve future school milk policy. To identify the factors affecting the decisions by individual pupils to order school milk and to quantify the impact of each factor, politically induced factors, individual and context factors were considered. Price effects and the associated policy issues were derived via a price experiment in selected German primary schools, while information on weekly orders for school milk was collected at the individual level. Detailed information on the eating habits, preferences and tastes, attitudes, socio-economic circumstances and characteristics of the persons involved was obtained by administering various surveys. The respondents examined in the study included pupils, the pupils' parents, class teachers, school milk managers (primarily janitors) and school principals.

To properly account for the hierarchical structure of the dataset (pupils within classes and schools along the different price steps of the experiment), a logistic multilevel analysis was applied based on 7336 pupils from 101 schools. The free-of-charge distribution of school milk had a high positive impact in the demand decision, confirming the importance of the policy setting (e.g., availability of subsidies). Although the price had an expected negative effect, its impact is limited. In addition to socio-economic factors (e.g., age, gender, immigration background and income of households), the behavior and attitudes of pupils and parents, as well as the context or environment surrounding the school milk offering (e.g., number of school milk products, whether teachers drink milk with the pupils during the break) had an impact.
\end{abstract}

(c) 2013 Elsevier Ltd. All rights reserved.

\section{Introduction}

As part of a balanced diet school milk like other milk products can help meet children's basic daily nutrition requirements. Often the importance of sufficient calcium in the diet during childhood for bone development and general health is emphasized (Promar International, 2002; Jacobson, 1961). In Germany, the average calcium supply for children up to 18 years old is considered insufficient, and it is particularly low for girls (DGE, 2008; Mensink et al., 2007a). The German Nutrition Society (DGE) recommends daily consumption of milk and dairy products to ensure the recommended daily intake of calcium, which is $900 \mathrm{mg}$ of calcium for children aged 7-10 and $1100 \mathrm{mg}$ of calcium for children aged 10-12 (DGE, 2008). ${ }^{1}$ Actually, real intake of calcium is $749 \mathrm{mg}$ for children aged 7-9 and $855 \mathrm{mg}$ for children aged 10-12 (Kersting

\footnotetext{
* Corresponding author. Tel.: +49 531596 5316; fax: +49 5315965399.

E-mail address: daniela.weible@vti.bund.de (D. Weible).

1 For comparison: Recommended Dietary Allowances of calcium in the USA are $1000 \mathrm{mg}$ for children aged 4-8 and $1300 \mathrm{mg}$ for children aged 9-13 (IOM, 2011).
}

and Bergmann, 2008). According to Alexy et al. (2008), the recommended daily amount of calcium is equivalent to $400-420 \mathrm{ml}$ of dairy products for children aged 7-10. For teens, these recommendations rise to $450-500 \mathrm{ml}$ per day for boys and $425-450 \mathrm{ml}$ per day for girls (Alexy et al., 2008). Dairy products also contain high-quality protein and many vitamins and minerals (Heine, 1999). The former are essential for children's growing muscles as well as for their organs. Vitamins and minerals are essential for many metabolic processes. With the exception of vitamin $\mathrm{D}$, the human body is not able to synthesize them (Biesalski, 1999; Fürst, 1999).

In the European Union for more than 30 years, pupils have, in principle, had access to what is known as "school milk" products in educational establishments. "School milk" products are subsidized dairy products provided in schools and other educational institutions encompassing a range of dairy products, including plain milk, flavored milk ${ }^{2}$, yogurt and cheese. As part of the CAP, the EU School Milk Scheme with its consumption aid belongs to

\footnotetext{
${ }^{2}$ Milk flavored with chocolate or fruit juice or aromatized with $90 \%$ milk and an additive of max. 7\% sugar and/or honey (EC, 2008).
} 
the area of market provisions (market price support) and was originally established in 1977 . However, the objective was subsequently broadened to address nutritional and educational concerns as well. Today the EU Commission intends to improve the nutrition of children and to educate children about food (EC, 2008, 2007; EEC, 1977; Jacobson, 1961; Griffin, 1999; CEAS, 1999).

According to the provisions of the EU School Milk Scheme, all children attending an educational establishment are entitled to receive up to $250 \mathrm{ml}$ of subsidized school milk (or school milk equivalents) per school day (EEC, 1977). Compared to the original program set-up, several adjustments were introduced like gradual cuts in the level of the subsidy. Currently, the subsidy is set at 18.15 Euros per $100 \mathrm{~kg}$ of milk equivalent, which corresponds to 4.4 cents per $250 \mathrm{ml}$ package. Compared to its level in 1993 , the subsidy has been reduced by $47 \%$ (VTI, 2012). Among other amendments, also the range of eligible product was extended and equal subsidies were introduced for all fat content levels so as not to encourage marketing of products with higher fat content (for a detailed development see VTI, 2012). In Germany, subsidized prices follow a maximum price policy, with the maximum prices fixed at the federal level. Distributing firms, in turn, are granted the subsidy in compliance with existing regulations (BMELF, 1985). Another specific aspect deals with the fact that in Germany, subsidized school milk is, in general, not part of school meals.

Besides the EU School Milk Scheme, an EU School Fruit Scheme was established in 2009. The key objective is to address children's low consumption of fruit and vegetables, whereas it is meant as a quite flexible approach to achieve target and tailored programs for the different member states (EC, 2007, 2009).

Despite the existence of the school milk program, school milk consumption has declined steadily in Germany. In 1993, approximately 130,000 tons of school milk equivalents were consumed by German pupils under the EU school milk program. The level dropped to only 36,000 tons for the $2009 / 10$ school year, which represents a reduction of $72 \%$ over the past 16 years. The number of children entitled to participate has declined, and the level of participation among those who are eligible for the EU program has also dropped dramatically (Initiative Milch, 2011). Different reasons have been suggested for the decline in participation, but only a few studies have attempted to analyze the factors that have contributed to the decline (Wietbrauk, 1976; Weindlmaier and Fallscheer, 1997), and no quantitative studies have been conducted.

Factors discussed so far (cut in subsidy, inadequate packaging, high operational and handling efforts in schools, small quantities and low profitability, limited product range) relate either to the supply chain for school milk or to the institutional setting rather than to the consumers themselves. However, individual factors like attitudes of parents and children toward milk and milk products, including individual preferences and tastes; attitudes regarding a healthy diet; and changing eating habits and preferences, may have also contributed to changes in school milk demand.

To identify and quantify the factors that influence the demand for school milk including individual factors, the German Federal Ministry of Food, Agriculture and Consumer Protection (BMELV), in cooperation with the Ministry of Environment and Conservation, Agriculture and Consumer Protection of North Rhine Westphalia, initiated a project called "Focus on school milk." The project is divided into a main project, conducted in North Rhine Westphalia, and several satellite projects that include other German federal states or the whole country of Germany. The primary objectives of the project were to evaluate factors such as price and policy issues, organizational factors (e.g., the product range and the form of distribution) and individual factors (e.g., attitudes, habits and social background). In addition to identifying the driving forces, the project will quantitatively analyze the impact of specific factors.
The results should provide a basis for recommendations to improve future school milk policies.

In this article the focus is on identification of institutional, socio-economic and individual factors affecting the individual decisions by pupils to order school milk or not and to quantify the impact of each factor. The factors that are considered include both individual-level and group-level factors.

The following section describes the theoretical model and subsequently, Sections three and four present the design of the survey and the data. Section five describes the methodology of the underlying analysis, and subsequently, Sections six and seven, the model specification and the results of the analysis. Section eight presents a discussion and the final section gives a short conclusion.

\section{Theoretical model}

Primarily, the individual decision of pupils to order school milk is analyzed. Hence nutritional aspects (type of milk, fat and sugar content) are neglected. Moreover, the underlying idea of the conception focuses on factors which are assumed to affect individual decision and go beyond these individual factors also to reach context factors. Both individual and context aspects are described successively in the following and it is viewed how the determinants leading to consumption decisions.

Individual aspects include socio-economic factors and preferences of the pupil, whereas their preferences may be determined based on their attitudes, knowledge and habits (especially consumption habits). In this particular case, pupils and their parents are assumed to be a single decision-making unit. In principle, the parents make the decision to order school milk in primary schools because they pay for the school milk, but the parents must still rely on their children to carry out their intentions by actually drinking school milk. Thus, parent's attitudes, knowledge and habits can also be seen as a determinant in individual decisions of pupils.

Although the individual decision to order school milk is predominantly determined by pupils and parents, other environmental or context factors may also affect their decisions. As school milk is normally consumed at school, the school environment and the school staff play an important role and need to be considered in analyzing pupils' decisions. In this regard, the teachers, school principals and school-milk managers (mainly janitors) may intentionally or unintentionally influence pupils' decisions. More broadly, the dairy industry and policy instruments such as the EU School Milk Scheme should also be considered because they set the prices and affect other factors such as product availability and product range within the Scheme. So, the school milk context consists of the environment or groups in which the consumption takes place and includes also political and institutional factors. For example, the price for school milk can also be seen as such a context-level aspect.

In contrast to individual-level factors which consist of influences whose effects vary only across individuals, context factors affect all individuals who belong to the same group. In the case of school milk, a group of pupils belong to a particular class, and a certain number of classes belong to a particular school. Therefore, the classes and schools represent group-level or context factors, respectively. Until now, the impacts of these context effects have rarely been demonstrated, and quantitative information regarding their influence on decisions is rare. Therefore, this large-sample study will contribute to a better understanding of these effects. Fig. 1 presents groups of factors assumed to influence school milk demand by pupils and differ between the individual and the various levels of context factors.

Our underlying assumptions are as follows: regarding individual aspects, there are socioeconomic factors (e.g., gender, age, 


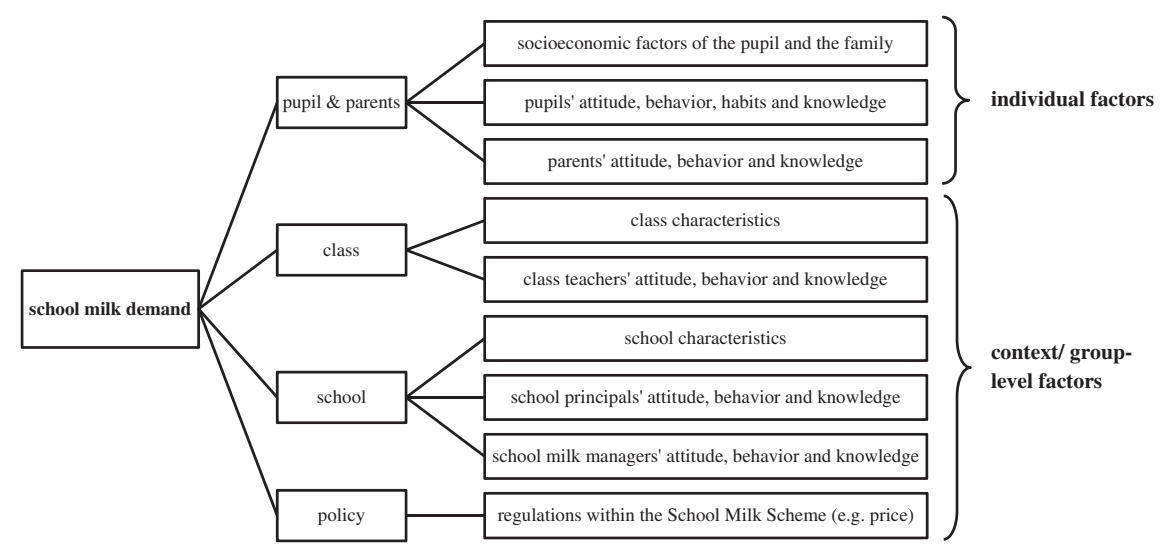

Fig. 1. Demand model for school milk.

immigration background and household income), pupils' breakfast behavior and eating habits (breakfast at home and/or at school, food from home, milk and milk products at home), pupils' and parents' attitudes toward milk and school milk, and their knowledge about milk products and healthy nutrition. We expect that the probability of school milk orders would be higher for boys than for girls (Mensink et al., 2007c; MRI, 2008) and that it would be higher for pupils without an immigration background than for pupils with an immigration background (Mensink et al., 2007b). The lower the income of the household and the higher the pupil's age (Mensink et al., 2007b), the lower we expect the probability of orders to be. As we know from consumer theory, a consumer will maximize his utility under the precondition that he has only a finite amount of money. Compared to milk from the supermarket, school milk is quite expensive in Germany (35 cents for $250 \mathrm{ml}$ compared to 54 cents for one liter). From this point of view we assume that school milk is less likely to be consumed in low-income families (Varian, 1984). The influence of gender and age had already been addressed in the literature. With respect to milk, yogurt, buttermilk and similar products, a study by Mensink et al. (2007c) indicates that consumption is higher among boys than among girls of the same age. Weindlmaier and Fallscheer (1997) also describe gender-specific differences in the breakfast behavior of German pupils. Girls often take no beverage to school, and they rarely drink milk at school (Weindlmaier and Fallscheer, 1997). Pudel and Westenhöfer (1998) emphasize that children who drink milk and consume dairy products regularly will continue to do so as adults because they are used to do so. Thus, we also expect the probability of school milk orders to be higher for pupils drinking and eating milk and milk products at home, especially for breakfast, because children are used to drink milk. In addition, a positive attitude among pupils and their parents toward milk and school milk is expected to increase the probability of orders.

Continuing with the context factors, we assume that the class teachers' attitudes, knowledge and behavior relating to milk (such as drinking milk during breaks with the children) are expected to have a significant influence on school-milk demand. Furthermore, class characteristics such as class size are considered as further class characteristics. Additionally, certain characteristics of the school are expected to be relevant, including the school size, the number of available school milk products, the type of packaging, and the number of people living in the county where the school is located. The expectation in this regard is that the probability of school milk orders would decrease with a larger class and school size because handling school milk requires more efforts the more pupils are involved. The variable county size is included to capture possible demand differences between rural and urban areas, since a lower demand can be expected in rural areas (Landesvereinigung der Bayerischen Milchwirtschaft). In addition, educational programs by the school relating to nutrition and milk are expected to have a positive impact on school milk demand. Finally, the attitude, knowledge and behavior of the school principal and the school milk manager are expected to have a great influence on school milk demand. More broadly, we assume that the school milk price, the free of charge distribution (fully subsidized milk), and the prices for substitutes or complementary goods all have an impact on school milk demand. In accordance with economic theory it is hypothesized that the probability of school milk orders will increase with a decrease in the school milk price, with an increase in prices of substitutes, and with a decrease in the prices of complementary goods (Varian, 1984).

\section{Survey design}

Several related surveys were conducted in the wide-ranging project. In one of these surveys, which is the focus of this article, data relating to orders for school milk by pupils were collected at the individual level. To collect this data, primary schools were selected to participate in a price experiment as well as to answer questionnaires. The primary schools were the principle sampling units, but the data were collected primarily at the individual or class level. From a total population of 3392 primary schools (737,455 pupils) in North Rhine Westphalia, a target sample of 125 schools was selected through a random multi-stage sampling procedure taking different strata into account. The strata formation was based on the socioeconomic status (social index) of the regional district, which was determined on the basis of welfare aid expenditures at the county level and the share of pupils per school with an immigrant background. Details relating to the sampling can be found in VTI (2012) and details relating to other samples and segments of the overall project can be found in MRI (2011), Salamon et al. (2010) and VTI (2012).

The objectives of this article are on identification of political, individual and context factors affecting the individual decisions by pupils to order school milk. As prices for school milk are fixed within the regulations of the EU School Milk Scheme the price-related effects for school milk orders could not simply observed from the market. Therefore an experimental study design was required recording individual school milk orders at changing prices. In addition to this price experiment, detailed information on the habits, attitudes, socio-economic circumstances and characteristics of the people involved was obtained by administering various written questionnaires. The persons examined in the questionnaires include pupils, the pupils' parents, and several people associated with the schools, such as class teachers, and other school personnel (e.g., principals and janitors). 


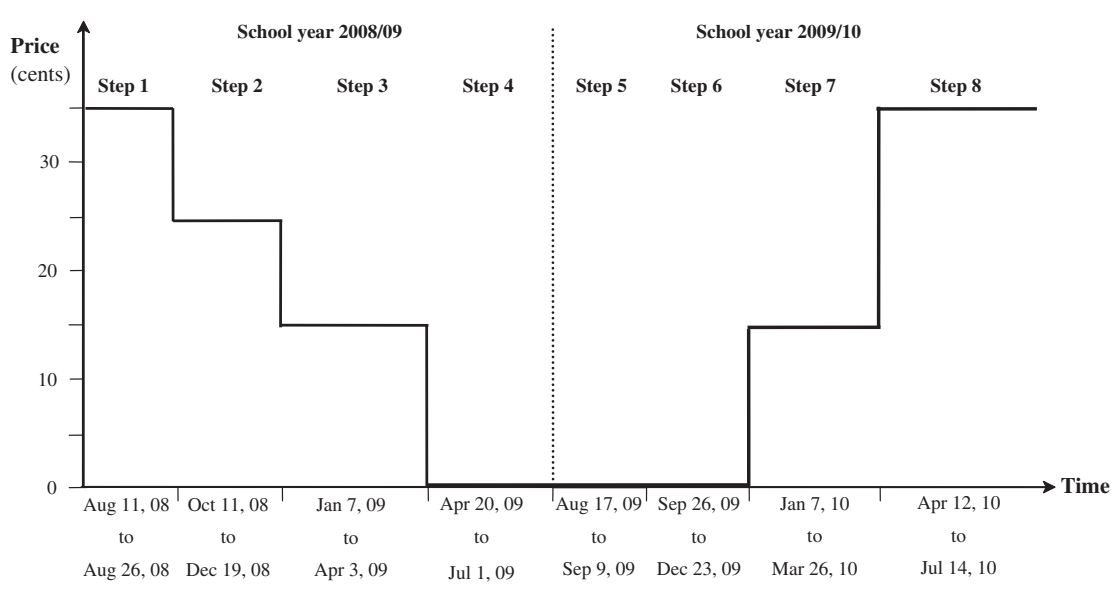

Fig. 2. Prices of school milk during the price experiment.

\section{Price experiment}

A price experiment was conducted in the participating schools to document the number of orders under different price settings to allow for the estimation of the impact of prices on the level of demand. The initial school prices of 30 cents for non-flavored milk and 35 cents for flavored milk were reduced in a price experiment that involved a stepwise reduction of prices during the 2008/09 school year. Starting with a price of 35 cents per school milk package $^{3}$ in step 1 , the price was reduced step-by-step until it reached 0 cents per package by the end of the school year (see Fig. 2). In the next phase of the price experiment, school milk prices increased again by steps to 35 cents during the following 2009/10 school year. Over the course of the data collection process, the number of schools in the sample decreased from initially 125 to 105 . In the schools that remained in the sample, the number of individual orders for school milk for pupils in second, third and fourth grades were registered and recorded at designated intervals. The quantities ordered were reported by the primary schools only during the 2008/09 school year. In the following school year, the quantities ordered were not reported by the schools in the sample.

Every pupil in the sample had his or her own identification number (ID) for the duration of the study. Furthermore, each pupil's class and school were identified by a class- and school-specific identification code. By using the individual, class and school identification codes, it was possible to make all the information for every pupil completely anonymous. In primary schools, children can order either one school milk package per school day or no milk packages for every day in a specific time period (usually a two-week period). The data for the price experiment indicate whether a pupil did or did not order a school milk package for each school day in a particular order period. In addition, the flavor of the school milk was recorded in each instance in which school milk was ordered. The term "school milk" can encompass a variety of products from which pupils can make their choice, but the product range that is actually available in different schools may vary depending on the decisions of the school authorities. School milk products at primary schools normally include plain (non-flavored) and flavored milk drinks in 250-ml packages. Other dairy products are also eligible for the program, but in practice, they are seldom offered. The firms that deliver school milk must provide plain (unflavored) milk, but schools are not required to take this option. The varieties of

\footnotetext{
${ }^{3}$ The price of non-flavored school milk was 30 cents per package. From the second to the seventh price step, the price that was charged for plain milk and flavored milk was the same.
}

flavored milk drinks that are generally offered may include chocolate, vanilla, strawberry, banana or caramel. Our econometric analysis does not take the flavor that was chosen into account, but in the descriptive analyses, it is interesting to note the choices among flavored and non-flavored milk packages.

\section{Written questionnaires}

In addition to the information on school milk orders, other information was collected by written questionnaires that were given to all pupils and their parents and to class teachers, school principals and school milk managers ${ }^{4}$. For this information as well, all data were coded with the same ID numbers for the specific individual, class and school that were already being used for coding the information relating to school milk orders. The questionnaires consisted primarily of questions relating to nutritional behavior, consumption preferences, attitudes toward healthy nutrition, milk and school milk, and ideas about the School Milk Program (facilitating and inhibiting factors), as well as suggestions for improvement, questions about the respondent's knowledge about nutrition and milk, and questions relating to socioeconomic indicators. The questionnaires for teachers, school principals and school milk managers also included questions about the food, meals and, especially, milk that was offered at the schools. There were also questions about the organization of school milk distribution, decisions on the product range, attitudes toward milk and school milk, and educational materials provided by the schools on nutrition and milk. To examine attitudes, all respondents except children were asked to rank statements from "totally disagree" to "totally agree" using a fivepoint Likert scale. All the questionnaires underwent pretesting. Before the pupils were surveyed, the parents' written consent was obtained.

The written questionnaires contain a rich assortment of variables, but for this analysis, only those variables that could have an effect on individual school milk demand have been selected. These variables are in line with the above mentioned influencing determinants for school milk demand (see Section 2). All surveyed variables are listed in detail in the final report of the project (VTI, 2012). In total 102 variables are considered: 12 variables relating to socioeconomics of pupils; 9 variables relating to pupils' attitudes, behavior, habits and knowledge; 13 variables relating to parents' attitude, behavior and knowledge; 2 variables relating to class characteristics and 14 relating to school characteristics; 12

\footnotetext{
${ }^{4}$ These questionnaires were developed by Max Rubner-Institut (MRI), Federal Research Institute of Nutrition and Food, Karlsruhe, Germany.
} 
variables relating to class teachers' attitude, behavior and knowledge; 14 variables relating to school principals' attitude, behavior and knowledge; 23 variables relating to school milk managers attitude, behavior and knowledge; and 3 variables relating to political/ institutional factors.

\section{Data}

Based on general distribution of school milk orders, it is clear that for most pupils, there is very limited variation in school milk orders within each price step. Pupils who decide to order school milk in an order period at a certain price level will usually continue to order school milk in the remaining order periods at the same price step. Only $26 \%$ of the pupils ordered school milk for at least one period at a certain price step but did not order milk for every school day at that price step. Thus, the distribution of orders within one price step is u-shaped (i.e., either a pupil orders in every period or the pupil does not order at all). Furthermore, in analyzing price effects, the differentiation between price steps is important. For this reason, the average level of ordering by each pupil at each price step was calculated. At the initial price of 35 cents for flavored and 30 cents for non-flavored school milk, every pupil ordered an average of 0.43 packages per school day. However, each pupil can receive a maximum of one package per school day; thus, the average figure actually indicates the average number of pupils ordering school milk at this price step. In other words, this figure represents the average probability that a pupil will order school milk. When the prices were lowered to 25 cents, the pupils ordered an average of 0.45 packages per school day, and when the price was 15 cents, the pupils ordered an average of 0.46 packages per school day. Furthermore, when the school milk was offered free of charge, an average of 0.81 packages were ordered by each pupil per school day. It is typically the case that when products are offered at a price of zero, almost all people tend to demand the product. A price that is set at zero can be regarded as a special price because most people do not choose the alternative with the highest cost-benefit difference (Shampan'er and Ariely, 2006). This is contrary to the assumption of neo-classical demand theory. Therefore, the level of consumption in price step four can be considered the maximum possible demand potential. The average consumption of 0.81 packages per day indicates that the average share of pupils ordering school milk was $81 \%$. This result shows that some pupils will never consume school milk even if it is offered for free. A similar situation was reported from a Scottish study where school meals were offered to pupils for free and $71 \%$ of the pupils only took a free meal (The Scottish Government, 2003).

In the subsequent analysis, the determination of whether milk was ordered was based on the average consumption per pupil in a particular period. In accordance with the objectives of our analysis, the appropriate analytical approach was to consider the average decision of pupils to order school milk as a binary decision. Pupils who changed their mind within the period when a certain price step was in effect were treated as zero (no order) if they ordered milk for less for than half of the possible days at that price or as one (order) if they ordered milk for more than half of the possible days. Therefore, a score of "0" represents pupils who were less likely to order school milk at a particular time and at the designated price step, and " 1 " represents pupils who were more likely to order school milk at the designated price step.

Data relating to school milk orders and all the data obtained from the questionnaires were merged into a common dataset. In this way, pupils who did not order school milk were also captured. Individual-level data on school milk orders during the four price steps were used to determine the effects of price and policy. The results of the questionnaires were used to identify individual and context factors relating to pupils who consume school milk in comparison with pupils who do not consume school milk.

Because of missing data or missing questionnaires, not all pupils, classes and schools are completely covered. In total, the sample for which complete data were available included 7336 pupils from 101 primary schools and 552 classes (see Table 1). The proportions of boys and girls were $50.1 \%$ and $49.9 \%$, respectively. Pupils with an immigration background constituted $27.4 \%$ of the whole sample. The distribution of pupils across the second, third and fourth grades is relatively balanced.

The hierarchical structure of the resulting dataset examined in this study requires a special specification of the model. The hierarchical structure of the data indicates that pupils were nested within classes and within schools. First, the basic model is formed by the pooled structure resulting from the repeated measurements (i.e., the measurements at each of the four price steps) of school milk orders at the individual level. Second, the model considers explanatory variables that were measured at the individual level (i.e., characteristics of the individual pupils and parents) or that were measured at a higher level before being applied at the individual level. Thus, context variables are based on an artificially high number of observations. The characteristics of the teachers, for example, are multiplied when they are applied to all the pupils of each teacher. Moreover, the group-level observations are not independent from each other because all the members in a group of pupils belong to the same class and the same school. This type of model specification leads to a multilevel analysis. The multilevel analysis is based on a special form of ordinary least squares (OLS) regression also known as hierarchical linear modeling (HLM).

\section{Methodology - multilevel analysis}

Multilevel analysis is usually applied in social science research areas such as sociology, education, and psychology, but it is also used in bio-medical sciences (Goldstein, 2011; Snijders and Bosker, 2003). According to Bickel (2007), multilevel modeling can be considered "a better way of doing regression analysis under specific circumstances." Such circumstances are present when observations are nested or grouped in identifiable contexts (e.g., pupils in classes, employees in firms, repeated longitudinal measures of the same subjects, etc.). In contrast to OLS regression, multilevel regressions have an inherently hierarchical structure that is designed to deal with nested data. Therefore, the nesting of observations within groups is fundamental to multilevel models. In fact, nesting is the primary reason for conducting multilevel analysis (Bickel, 2007). Due to clustering, observations of members of the same group are usually more similar to each other than they are to observations of members in different groups. This pattern violates the OLS assumption of independence of all observations. Moreover, the number of observations at the context level is artificially increased. In terms of the conventional statistical significance tests that are used in OLS regression, the estimates of the t-values for coefficients at the context level would be over-estimated, causing the standard errors to be far too small. This effect may result in many spuriously "significant" results (Hox, 2002).

In principle, the concept of multilevel analysis reflects the fact that individuals interact with others within the social context to which they belong. The individuals are influenced by the common environmental conditions and by the social groups, but the groups, in turn, are affected by the individuals who make up the group. The individuals and the social groups can therefore be seen as a hierarchical system in which different levels can be defined (Goldstein, 2011; Hox, 2002; Snijders and Bosker, 2003). In analyzing the determinants of individual demand, the multilevel approach assumes that individual decision making is dependent on individual 
Table 1

Sample characteristics.

\begin{tabular}{|c|c|c|}
\hline Number of pupils & Total number & Percentage (\%) \\
\hline Boys & 3676 & 50.1 \\
\hline Girls & 3658 & 49.9 \\
\hline Pupils with an immigration background & 1917 & 27.4 \\
\hline Pupils without an immigration background ${ }^{a}$ & 5089 & 69.4 \\
\hline 2nd-Grade pupils & 2522 & 34.4 \\
\hline 3rd-Grade pupils & 2443 & 33.3 \\
\hline 4th-Grade pupils & 2371 & 32.3 \\
\hline Pupils in schools with a social index score of 1 & 2121 & 28.9 \\
\hline Pupils in schools with a social index score of 2 & 2358 & 32.1 \\
\hline Pupils in schools with a social index score of 3 & 675 & 9.2 \\
\hline Pupils in schools with a social index score of 4 & 904 & 12.3 \\
\hline Pupils in schools with a social index score of 5 & 795 & 10.9 \\
\hline Pupils in schools with a social index score of 6 & 483 & 6.6 \\
\hline Former participation in the EU School Milk Scheme & 6988 & 95.3 \\
\hline No former participation in the EU School Milk Scheme & 348 & 4.7 \\
\hline Total & 7336 & 100.00 \\
\hline
\end{tabular}

${ }^{\text {a }}$ For 330 pupils ( $3.2 \%$ of the total), there is no information about the existence or non-existence of an immigration background.

properties as well as on context factors. For example, pupils in the same school tend to be similar because of the selection process and their common social background. Thus, in such a sample, individual observations cannot be regarded as completely independent.

A main difference between OLS regression and multilevel models is that the equation defining the hierarchical linear model contains more than one error term, one (or more) for each level (Snijders and Bosker, 2003). In the current literature regarding multilevel approaches, the proper treatment of the error structure for these models has received special attention (Hox, 2002; Snijders and Bosker, 2003; Raudenbush and Bryk, 2002).

The term "multilevel" is used for a variety of models that are designed to examine multilevel theories with multilevel data techniques (DiPrete and Forristal, 1994). Two general specifications of multilevel regression models are commonly used, the randomintercept model and the random-slope model (Hox, 2002; Snijders and Bosker, 2003; Raudenbush and Bryk, 2002). A simple example of a two-level multilevel regression model will be considered to clarify the differences. In general, multilevel models can be expressed either in a single equation or in a set of equations in which the coefficients of the micro unit (level 1) are expressed as functions of the macro unit (level 2). Based on the latter approach, the following equation presents a fixed-effects multilevel regression model:

Level 1 model : $Y_{i j}=\beta_{0 j}+\beta_{1 j} X_{i, j}+r_{i j}$

Level 2 model : $\beta_{0 j}=\gamma_{00}+u_{0 j}$

$\beta_{1 j}=\gamma_{10}$

Whereas the level 1 intercept $\beta_{0 j}$ is random at level 2 , the level 1 coefficient $\beta_{1 j}$ is expressed in level 2 as an exact function. In other words, $\beta_{1 j}$ provides an estimate of the effect of $X_{i j}$ and is the same for all level 1 units. In contrast, in random-effects multilevel models, the coefficient $\beta_{1 j}$ is random. Therefore, the level 2 equations now become

$$
\text { Level } 2 \text { model : } \begin{aligned}
\beta_{0 j} & =\gamma_{00}+u_{0 j} \\
\beta_{1 j} & =\gamma_{10}+u_{1 j}
\end{aligned}
$$

Each level 1 unit has its own coefficient so the effect of $X_{i j}$ is not the same for all level 1 units. The specification of random effects leads to a more complex error structure in the model equation and makes it possible to decompose the variance in the dependent variable into the within-group variance and the between-group variance. Thus, the estimation of the coefficients is not trivial and is limited by possible optimization techniques (DiPrete and Forristal, 1994).

\section{Model specification}

The multilevel approach of the ordinary logistic model chosen for this analysis is a random-intercept model that includes random intercepts and fixed slopes at the specified levels. $Y_{i j k}$ is the outcome (i.e., the response of the $i$ th pupil of the $j$ th class in the $k$ th school, which is either 0 [if the pupil does not order school milk] or 1 [if the pupil orders school milk]). For this reason, the logistic approach was used.

It is assumed that the given random effects $u_{j k}$ and $u_{k}$ represent unobserved class and school characteristics, respectively. Further, for pupil $i$ of class $j$ in school $k$, it is assumed that

$\pi_{i j k}=\operatorname{probability}\left(Y_{i j k}=1\right)$

and the logit of this probability is described by

$\operatorname{logit}\left(\pi_{i j k}\right)=\beta_{0}+\beta_{1} X_{i j k}+\beta_{2} X_{j k}+\beta_{3} X_{k}+u_{j k}+u_{k}$,

where $X_{i j k}, X_{j k}$ and $X_{k}$ represent observed characteristics at individual, class and school levels, with corresponding fixed effects $\beta_{1}, \beta_{2}$ and $\beta_{3}$. Further, it is assumed that the random effects $u_{j k}$ and $u_{k}$ are independent and normally distributed, with zero mean and variances $\sigma_{2}^{2}$ and $\sigma_{3}^{2}$ respectively.

$u_{j k} \sim N\left(0, \sigma_{2}^{2}\right)$,

$u_{j k} \sim N\left(0, \sigma_{3}^{2}\right)$.

So, the random effects are not directly estimated as model parameters, but are instead summarized by the only variances. Thus, $\sigma_{2}^{2}$ contains the summarized class (level-2) and $\sigma_{3}^{2}$ the summarized school level (level-3) variance components. The linearized form of the logistic multilevel model is described in the following equation:

$Y=\pi+\epsilon$ with $\pi=f(X \beta+Z U)$,

whereas the conditional distribution of the response given the random effects is assumed to be Bernoulli, with success probability determined by logistic cumulative distribution function (c.d.f.). Thus, outcome variable $Y$ is expressed as the sum of the probability plus an individual-level error term. $f$ is the inverse logit transformation, whereas $X$ is the model matrix for the fixed effects, analogous to the covariates which can be found in a standard logistic regression model, with the regression coefficients $\beta$. Further, $Z$ is a block diagonal matrix and is used as model matrix for the random effects. The individual-level error term $\varepsilon$ has a mean of zero and a (conditional) variance given by a diagonal matrix with entries 
$\pi(1-\pi)$ whereas $\pi$ represents the probability that $Y=1$. This is a unique property for these dichotomous variables. As a consequence, the logistic multilevel model does not include a separate parameter for the level-one variance. The level-one residual variance of the dichotomous outcome variable follows directly from the standard logistic distribution with a variance of $\pi^{2} / 3(=3.28988)$ (note that $\pi$ here represents the famous mathematical constant 'pi') (Stata Corp., 2009; Snijders and Bosker, 2003; Rodriguez and Goldman, 2001; Hox, 2002).

Following Rodriguez and Goldman (2001), the model written above can be illustrated as a graph (see Fig. 3 ) in which the nested structure (pupils of classes in schools) is shown by using stacked sheets. Boxes symbolize known quantities, and ovals symbolize unknown quantities. Full arrows describe probabilistic dependences, and broken arrows represent deterministic relationships (Rodriguez and Goldman, 2001).

An additional level is included to quantify the effect of the subsidy of the school milk and the prices of other goods. Because there are four measurements for each pupil with one measurement for each price step (as explained in the previous section), the pooled data structure of the dataset results in a four-level model. Repeated measures on individuals are entered at the first level, individual variables are entered at the second level, and context variables are entered at the third and fourth levels (Heck and Thomas, 2009; Snijders and Bosker, 2003). Thus, the demand for school milk by a single pupil is determined by the price as well as by individual, class and school characteristics, which are quantified in the multilevel approach.

\section{Analysis and results}

Data handling and estimation were performed with the STATA Version 11 statistical program using the 'xtmelogit' procedure for a logistic linear random intercept model. As a preliminary step, a correlation matrix was generated depicting the correlations across all the available explanatory variables to guard against the risk of multicollinearity. At the first stage of the analysis, the interceptonly model (referred to as the 'empty model') was estimated. The empty model contains no explanatory variables and shows the decomposition of the variance across the levels. In the next step, all available explanatory variables were entered as fixed effects. Variables that led to insignificant results or that caused the regres-

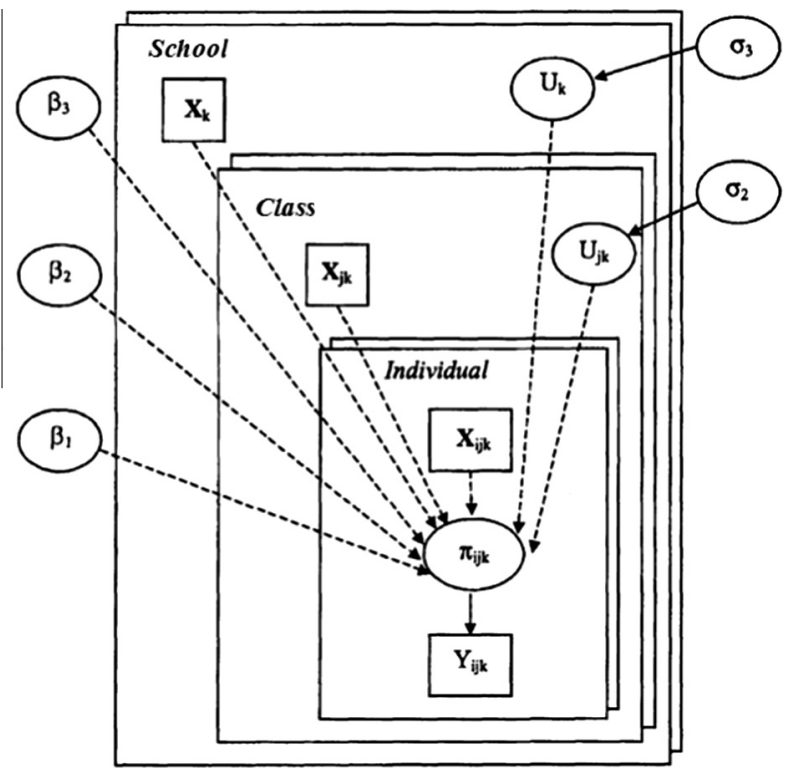

Fig. 3. A three-level logit model with class and school effects on an individual-level binary outcome. Source: Modified from Rodriguez and Goldman, 2001, p. 341. sion not to converge were excluded. For the applied model, the first level was identified by the price step variable, the second level was defined by each pupil's ID variable, the third level was defined by the class-ID variable, and the fourth level was defined by the school-ID variable. ${ }^{5}$ The dependent variable was the probability of a school milk order for each pupil.

The random-effects part of the intercept-only model shows the decomposition of the variances for the individual level, class level and school level (see Table 2). As noted above, the logistic multilevel model does not include a parameter for level-one variance. The variance at the individual level (level 2) represents the largest portion of the unexplained variation (3.09) followed by the variance at the level of classes (where the value was 0.51) and the variance at the level of schools (where the value was 0.33). Since the logistic distribution for the level-one error implies a variance of $\pi^{2}$ / $3=3.28988$, this implies that following Snijders and Bosker (2003) for a four-level logistic random intercept model the intraclass correlation, e.g. at level 2, that is the expected correlation between two level-2 units in the same group, is defined by

$$
\rho_{2}=\frac{\sigma_{2}^{2}}{\sigma_{2}^{2}+\sigma_{3}^{2}+\sigma_{4}^{2}+\pi^{2} / 3} .
$$

The intraclass correlation for the other levels is calculated similarly. So, at the individual level (level 2) this leads to the intraclass correlation coefficient $\rho_{2}=0.4284$ followed by $\rho_{3}=0.0704$ at the level of classes and $\rho_{4}=0.0457$ at the level of schools. This coefficient shows the proportion of variance of total variance that is accounted for by the group level. The high value of unexplained variation at level 2, however, requires further explanation. Based on this first step, it is appropriate to verify the significance of the variation at each level in the random-effects part of the model. The likelihood ratio test is performed to see whether the estimated variances are significant. In particular, the model is fitted with and without the level 2 random effect $u_{j}$ testing the significance of the variance at level 2. The null hypothesis is $\sigma_{2}^{2}=0$ that means that the random effect $u_{i}$ is not needed in the model specification. For each incorporated level, the variances at all levels are significantly different from zero.

Turning to the random-intercept model, the random portions in the estimated models declines for most of the levels (see Table 3). Thus, the explanatory variables that were included in the fixed-effects part of the random-intercept model reduced the unexplained variance of the group-level effects at the school and class level (i.e., at school level from 0.33 to 0.22 and at the class level from 0.51 to 0.37 ). The variance at the level of individual pupils increased from 3.09 to 5.31 , which is typical for multilevel analyses involving a panel structure. This increase occurs because the data collection procedure was designed in such a way that the repeated measurements were evenly spaced, and the individual-level data were collected at the same time for the entire sample. As a result, the variability among pupils in relation to the time series variable is usually much higher than what is assumed in a hierarchical sampling model. Consequently, the intercept-only model over-estimates the variances at the level with the repeated measurements and under-estimates the variance at the individual level (in this case, level 2) (Hox, 2002).

The fixed-effects part of the estimated model contains the explanatory variables that contribute significantly to the likelihood that pupils will order school milk. Two significant variables that were measured at level 1 are the price of school milk and the

\footnotetext{
${ }^{5}$ In accordance with the common terminology, we call our model a four-level model. In contrast to the common terminology, the xtmixed documentation of STATA calls the type of model that we examined a three-level model because the lowest level (i.e., the repeated measurements in our study) is not considered to be a separate level (Rabe-Hesketh and Skrondal, 2007).
} 
Table 2

The intercept-only model. Source: Own calculations with STATA.

\begin{tabular}{lll}
\hline Fixed part & Coefficient & Standard error \\
\hline Constant & $0.430^{\mathrm{a}}$ & 0.072 \\
Random part & Variance & Standard error \\
\hline$\sigma_{4}^{2}:$ school & 0.330 & 0.080 \\
$\sigma_{3}^{2}:$ class & 0.508 & 0.064 \\
$\sigma_{2}^{2}:$ pupil & 3.094 & 0.012 \\
Number of schools & & 101 \\
Number of classes & & 552 \\
Number of pupils & & 7336 \\
Log-restricted likelihood & & -17468.96 \\
\hline
\end{tabular}

a Significant at the .01 level.

free-of-charge distribution of school milk. Both of these variables have a significant influence on the decision to order school milk. As expected according to economic theory, and under the condi- tion that nothing else changes, the negative sign for the 'school milk price' variable indicates that a reduction in school milk prices is associated with an increasing probability that pupils will order school milk. Furthermore, also as expected, the free-of-charge distribution of school milk variable is found to be associated with a strong and highly significant effect on school milk demand. In addition to the regression coefficients, odds ratios were calculated. Odds ratios are the results that are typically used in the context of logistic analysis. The word "odds" refers to what may also be called "chance" or "likelihood," and the odds ratio is an indicator of the ratio of two odds. The odds of an event occurring is the probability of the event divided by the probability of the event not occurring (Tutz, 2000). The odds ratio of the variable 'school milk free of charge,' which has a value of 27.5 , is the highest odds ratio in this entire study. The likelihood that pupils will order school milk when there is a free-of-charge distribution is much higher than the likelihood of an order when the milk is not free.

Table 3

The random-intercept model. Source: Own calculations using STATA.

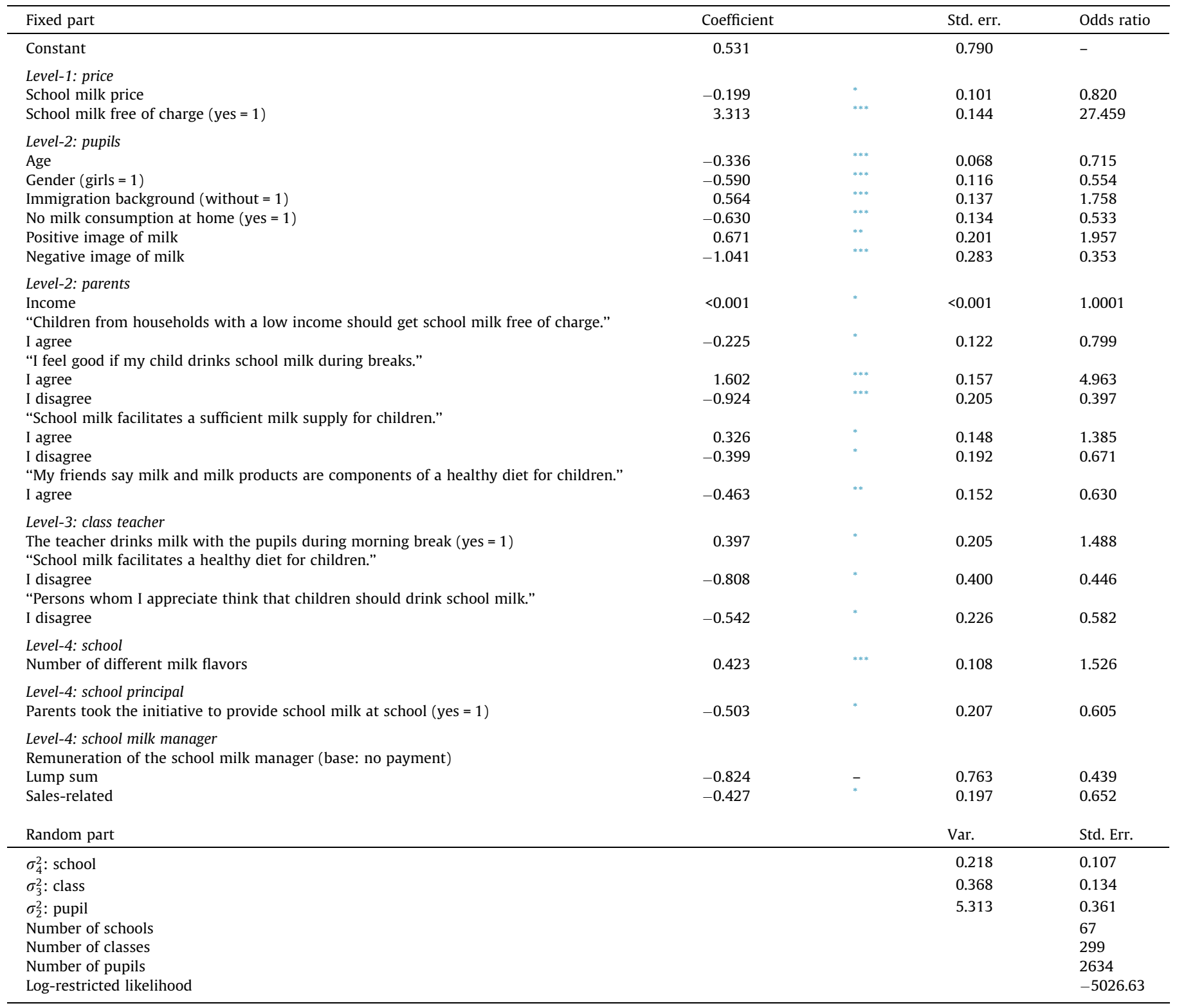

* Significant at the 10 level.

** Significant at the .05 level.

*** Significant at the .01 level. 
An additional set of 13 variables apply at level 2 . These variables represent the impact of the characteristics of individual pupils and parents on the decision to order school milk. In this set, psychographic and economic factors, as well as gender, are the most significant drivers. These factors include pupils' age, gender, immigration background, habits relating to milk consumption at home, and positive or negative attitudes about milk. The variables at this level also include the family net income, the parents' attitude toward milk and school milk, and attitudes regarding healthy nutrition. The variables that relate to pupils at the individual level are all highly significant. The coefficients for the variables 'age', 'gender' and 'migration background' show that the chance that a pupil will demand school milk is higher for younger pupils than for older pupils, it is higher for boys than for girls, and it is higher for pupils without an immigration background than for pupils with an immigration background. Furthermore, the probability that pupils will order school milk is lower for pupils who do not drink milk and milk products at home. The image of school milk is also highly significant. This image variable is created from several statements ${ }^{6}$ that were included in the pupils' questionnaires, and it indicates whether the pupil's image of milk is positive, negative or not clear. The probability of ordering school milk is higher for pupils who have a positive attitude toward milk, and it is lower for pupils whose attitude is negative. However, the results also indicate that the odds ratio for the variable that represents pupils' negative perception of milk has a stronger effect on demand than the variable that represents a positive perception.

The net income of households is also a significant variable because the probability that pupils will order milk increases when the income is higher. As noted above, parents were asked to rank several statements using a five-point Likert-scale. For every statement listed in Table 3 in quotation marks, respondents had five choices ranging from completely agree to completely disagree. The results show that the probability that a pupil will order school milk is lower if parents agree with the statement, "Children from households with a low income should get school milk free of charge." Pupils whose parents agree with the statement, "I feel good if my child drinks school milk during breaks" have a higher probability of ordering school milk. Thus, pupils whose parents rejected the statement show a lower probability of ordering school milk. The probability that a pupil will order school milk increases if parents agree with the statement, "School milk facilitates a sufficient milk supply for children," and vice versa. The level of agreement with the statement, "My friends say that milk and milk products are components of a healthy diet for children" is associated with a lower probability of ordering school milk.

At the next levels (levels 3 and 4), context variables were considered. At level 3, which includes variables that apply to classes, there are three significant variables relating to class teachers. The probability that a pupil will order school milk is higher if the class teacher drinks milk with the pupils during breaks. Furthermore, the attitudes that teachers express in relation to two statements in the questionnaires have a significant impact on pupils' decisions to order school milk. The probability that a pupil will order school milk is lower if the class teacher disagrees with the following statements: "School milk facilitates a healthy diet for children" and "Persons whom I appreciate think that children should drink school milk."

The context variables at level 4 represent characteristics of school principals, school milk managers and the school environment. For each of the groups, one variable proved to be significant.

\footnotetext{
${ }^{6}$ The variable that was developed to represent the 'image of milk' was based on the pupil's agreement with the following five statements: "Milk is cool," "Milk makes me fit," "Milk is healthy," "Milk is something for babies," "Milk is unhealthy." If pupils agreed with one or more statements, they were asked to mark it.
}

Regarding school characteristics in general, the coefficient for the number of different school milk products that are available at each school is positive and highly significant. As the number of available products increases, the chance that an individual pupil will demand school milk becomes higher. Furthermore, in the questionnaires, school principals were asked, "Who decided to offer school milk at your school?" If the principal's response to that question indicated that parents originally initiated the arrangements to supply school milk at their school, that response was associated with a lower chance that pupils would order school milk. Finally, if the school milk managers' remuneration for handling school milk was linked to the number of school milk packages that were sold, there was a significant negative effect on demand. The base for this categorical variable is 'no payment.' Sales-related remuneration means that the payment for handling school milk is variable and depends on the sales volume. Another payment possibility would be a fixed lump-sum payment, but this variable is not significant.

\section{Discussion}

As expected, the price of school milk, which indicates the institutional impact, has an influence on the decisions of individual pupils to order milk. This finding confirms the proposition that the policy setting (e.g., the availability and the size of subsidies) plays a role in the demand for school milk. The variable that had the highest positive impact on the probability that pupils would order milk was the free-of-charge distribution of school milk. Not all pupils order school milk even when it is free of charge, however. This outcome is driven by a certain share of pupils with lactose intolerance as well as pupils who simply dislike milk and pupils who forget to order. In all, the proportion of pupils who order milk under the free-of-charge condition reflects the overall potential in demand.

The significant effect of the presence of an immigration background can be explained in two ways. First, pupils with an immigration background may not accustom to consuming such milk. Instead, they may be more familiar with other dairy products (e.g., kefir or ayran), which are not part of the available product range. Second, there might be greater price sensitivity among pupils with an immigration background, such as children from lowincome households, for whom ordering school milk is primarily a matter of price (BPB, 2008).

There is a significant effect of parents' agreement with the statement, "Children from households with a low income should get school milk free of charge." In this instance, the negative sign of the coefficient seems counterintuitive. One possible explanation may be that parents who regard themselves as poor order less school milk because they would like to receive the school milk free of charge. Parents' agreement with the statement, "My friends say that milk and milk products are components of a healthy diet for children" is also associated with a significant negative effect. A possible explanation may be that the statement has no real reference to school milk and the fact that in families in which parents agrees with the statement, the level of milk consumption may already be high.

The chance that pupils will order school milk is higher if the class teacher drinks milk with the pupils during break. This finding indicates that teachers serve as a role model for their pupils. In addition, the attitude of teachers toward milk, and especially toward school milk, has an effect on their pupils. This finding is reflected in a lower chance that pupils will order school milk if their class teachers disagree with the statements, "School milk facilitates a healthy diet for children" and "Persons whom I appreciate think that children should drink school milk." 
With regard to the school-level effects, as the number of available products increases, the chance that an individual pupil will demand school milk also increases. From this finding, it is easy to conclude that pupils prefer a wider range of products from which they can choose. The decision made by the school's principals and teachers to introduce school milk and to participate in the school milk program seems to be an important component for the success of the school milk program. When parents are the ones who originally initiated the introduction of school milk at their school, the impact on the probability that a pupil will demand school milk is negative.

Finally, the school milk managers' remuneration for handling school milk has a significant negative influence on demand when it is based on the number of milk packages that are sold. An interpretation of this finding might be that the motivation of school milk managers to organize the school milk scheme at their schools is independent of the payment system.

Before drawing conclusions from this study, several limitations need to be discussed. First, the data may be vulnerable to a selfselection bias because pupils who ordered school milk were slightly over-represented among the pupils who completed the individual questionnaires compared to pupils who did not order school milk. This outcome led to a positive selection bias of pupils who order school milk for this detailed analysis. Several options have been discussed to overcome the problem, including a twostep Heckman estimation for sample selection problems. Such estimations require a censored, or truncated, sample, however, and that would not have been applicable in this case. Therefore, that approach was not pursued in this study. Another limitation is that it was not possible to include all relevant levels and explanatory variables in the model to explain school milk orders because some potentially relevant variables had been found not to be significant, and some would have made it impossible for the model to be solved. For example, the model was not able to take into account regional information about the schools involved, information on school milk suppliers, or the seasonality of consumption. Finally, the focus on the federal state of North Rhine Westphalia may limit the generalizability of the results as the consumption patterns of dairy products vary considerably across the different German regions. The analysis has, so far, not yet covered individual decisions concerning the product type chosen as the number of products and the product range is decided on by the school and varies. However, descriptive analysis indicates that only very few children (about $4 \%$ on average) buy plain milk. In the analysis, two schools provided plain milk as the only choice, but during the project one of the two chose to extend its product range. In schools providing only plain milk, the average consumption is lower than in others and could not be increased by lower prices and only to a lower extent by free-of-charge distribution (details see VTI, 2012).

\section{Conclusions}

Several levels of determining factors explain school milk orders. First, as expected, the policy-driven school milk price has an influence on the order decisions of individual pupils. Policy influences school milk through subsidies, price ceilings, certification procedures and controls. The free-of-charge distribution of school milk shows the highest positive impact on the probability that school milk will be ordered.

The characteristics of pupils and parents comprise more than half of the factors that influence demand and exhibit the highest levels of significance. Of crucial importance is pupils' age and gender, the presence of an immigration background, household income and, in addition to socioeconomic factors, the behavior and attitudes of various agents have an impact on the probability that pupils will order school milk. Finally, the context factors relating to the wider environment are not negligible. They demonstrate the importance of various influential group-level effects on individual decision making.

By including all the relevant agents in the pupil's environment in the analysis, the special data structure, which is characterized by different aggregated explanatory variables, needs to be taken into account. In this regard, it is important to note that group-level variables, such as the number of milk products that are available at school and the class size, are equal for all pupils within the same school or class, but they differ only between pupils of different schools or classes. In addition, pupils in the same school or class tend to behave more similarly compared to members of their own group than to pupils of different classes and schools. Therefore, the nesting of pupils within classes and schools must to be taken into account in analyzing the factors that influence school milk demand. The variability that stems from the inherently hierarchical data structure is considered in multilevel analysis and is expressed in the random portion of the analysis. This random-effects analysis shows the variance that is attributable to each incorporated level, which can be considered the group-level effect.

Further extensions of the models examined in this study are possible, but because the research question for this study was aimed at the identification of the main effects, the random-intercept model was chosen. Based on existing information associated with different influential groups, the multilevel approach seems to be an appropriate strategy for selecting the key factors that influence school milk demand. Furthermore, this study made it possible to quantify the price effects gained through a price experiment and to combine those panel data with individual-level and higher-level information in a single model.

Several recommendations for policy makers can be derived within the study from its results with respect to the targeted objectives. In principle, there are different types of amendments possible: one type comprises changes of the EU regulations, another one adjustments to the German implementation and a third group deals with behavior and decisions of the dairy industry and schools. In the following some examples are given, hence, nutritional aspects are not covered here.

An amendment which could possibly be achieved by changing regulations is the free-of-charge distribution as a very important driver in the analysis. However, a free-of-charge distribution within the EU is not really considered as an option because significant groups of parents and school personnel (e.g., teachers) see this as a devaluation of food items. Instead, the development of more tailored EU programs for special groups (e.g., girls or pupils with an immigration background) would seem to be reasonable. Girls, for example, are obviously at risk of an insufficient calcium supply.

Further, as teachers serve as role models and pupils imitate their behavior, the example of school milk drinking by teachers has a positive effect on the ordering decisions of pupils. Therefore the program could be opened-up for teachers.

Finally, the integration of school milk into an overall concept may help to increase the attention to the School Milk Scheme and may reduce handling costs. As in Germany, school milk is integrated as victuals during breaks and is, in general, not provided during school lunches. So, for example, the integration of school milk into school meals or exiting similar programs could be a possible option. Additionally the scheme may be tailored to better serve different school types by, e.g., distributing school milk to older students via a vendor.

Concerning other agents it is recommended that the dairy industry and the schools should extend the product range toward more dairy products (e.g., drinking yogurt, buttermilk, kefir, ayran, curd and cheese). In this way, more diverse preferences can be addressed. 


\section{Acknowledgements}

The project on school milk in Germany "Schulmilch im Fokus" was financially supported by funds from the German Federal Ministry of Food, Agriculture and Consumer Protection and from the Ministry for Climate Protection, Environment, Agriculture, Nature Conservation and Consumer Protection of the German State of North Rhine-Westphalia. The authors wish to thank the colleagues from the Max Rubner-Institut, Department for Nutrional Behaviour, for successful research cooperation as well as the anonymous reviewers of this journal for their recommendations and constructive comments.

\section{References}

Alexy, U., Clausen, K., Kersting, M., 2008. Die Ernährung gesunder Kinder und Jugendlicher nach dem Konzept der optimierten Mischkost. ErnährungsUmschau 3, 168-177.

Bickel, R., 2007. Multilevel Analysis for Applied Research: It's Just Regression! Guilford Press.

Biesalski, H.K., 1999. Vitamine. In: Biesalski, H.K., Fürst, P., Kasper, H., Kluthe, R. Pölert, W., Puchstein, C., Stähelin, H.B. (Eds.), Ernährungsmedizin, Nach dem Curriculum Ernährungsmedizin der Bundesärztekammer, second ed. Georg Thieme Verlag, Stuttgart, New York, pp. 111-158.

BMELF, 1985. Schulmilch-Beihilfen-Verordnung vom 8. November 1985 (BGBl. I S 2099), die zuletzt durch Artikel 25 der Verordnung vom 13. Dezember 2011 (BGBl. I S. 2720) geändert worden ist, pp. <http://www.gesetze-im-internet.de/ bundesrecht/schulmbhv_1985/gesamt.pdf> (accessed 04.04.12).

BPB, 2008. Armutsgefährdungsquoten von Migranten. <http://www.bpb.de/ nachschlagen/zahlen-und-fakten/soziale-situation-in-deutschland/61788/ armut-von-migranten> (accessed 18.2.13).

CEAS, 1999. Evaluation of the School Milk Measure: Final Report. For DGIV European Commission Submitted by CEAS Consultants (Wye) Ltd., Centre for European Agricultural Studies and Institute for the Management of Dairy Companies, Technische Universität München. <http://ec.europa.eu/agriculture/ eval/reports/schoolmilk/sum_en.pdf> (accessed 04.04.12).

EC, 2009. Council Regulation (EC) No 13/2009 of 18 December 2008 amending Regulations (EC) No 1290/2005 on the financing of the common agricultura policy and (EC) No 1234/2007 establishing a common organisation of agricultural markets and on specific provisions for certain agricultura products (Single CMO Regulation) in order to set up a School Fruit Scheme. Official J. Eur. Union L 5/1, pp. 1-4. <http://eur-lex.europa.eu/LexUriServ/ LexUriServ.do? uri=OJ:L:2009:005:0001:0004:EN:PDF> (accessed 12.02.13).

EC, 2008. Commission Regulation (EC) No 657/2008 of 10 July 2008 laying down detailed rules for applying Council Regulation (EC) No $1234 / 2007$ as regards Community aid for supplying milk and certain milk products to pupils in educational establishments. Off. J. Eur. Union L 183/17, pp. 1-10. <http://eurlex.europa.eu/LexUriServ/

LexUriServ.do?uri=OJ:L:2008:183:0017:0026:EN:PDF> (accessed 04.04.12).

EC, 2007. Council Regulation (EC) No 1234/2007 of 22 October 2007 establishing a common organisation of agricultural markets and on specific provisions fo certain agricultural products (Single CMO Regulation). Off. J. Eur. Union L 299/1, pp. 1-149. <http://eur-lex.europa.eu/LexUriServ/ LexUriServ.do?uri=OJ:L:2007:299:0001:0001:EN:PDF> (accessed 15.02.13).

EEC, 1977. Council Regulation (EEC) No 1080/77 of 17 May 1977 on the supply of milk and certain milk products at reduced prices to schoolchildren. Off. J. Eur. Commun. L131/8, pp. 1-2. <http://eur-lex.europa.eu/LexUriServ/ LexUriServ.do?uri=OJ:L:1977:131:0008:0009:EN:PDF> (accessed 04.04.12).

DGE, 2008. Ernährungsbericht. Deutsche Gesellschaft für Ernährung, Bonn.

DiPrete, T., Forristal, J., 1994. Multilevel models: methods and substance. Annu. Rev. Sociol. 20, 331-357.

Fürst, P., 1999. Proteine. In: Biesalski, H.K., Fürst, P., Kasper, H., Kluthe, R., Pölert, W., Puchstein, C., Stähelin, H.B. (Eds.), Ernährungsmedizin, Nach dem Curriculum Ernährungsmedizin der Bundesärztekammer, second ed. Georg Thieme Verlag Stuttgart, New York, pp. 91-110.

Griffin, M., 1999. FAO's international survey of milk in schools: summary, conclusions and future directions. Bull. Int. Dairy Fed. 341, 24-64.

Goldstein, H., 2011. Multilevel Statistical Models, Internet Version April 1999. <http://www.ats.ucla.edu/stat/examples/msm_goldstein/goldstein.pdf> (accessed 20.08.13).

Heck, R.H., Thomas, S.L., 2009. An Introduction to Multilevel Modeling Techniques, second ed. Routledge, New York, NY.

Heine, W., 1999. Ernährung vom Säuglings- bis zum Jugendalter. In: Biesalski, H.K., Fürst, P., Kasper, H., Kluthe, R., Pölert, W., Puchstein, C., Stähelin, H.B. (Eds.), Ernährungsmedizin, Nach dem Curriculum Ernährungsmedizin de Bundesärztekammer, second ed. Georg Thieme Verlag, Stuttgart, New York, pp. 201-211.
Hox, J., 2002. Multilevel Analysis: Techniques and Applications. Lawrence Erlbaum, Mahwah, New Jersey.

Initiative Milch, 2011. Statistik zur Schulmilch für das Schuljahr 2010/11. <http:// www.initiative-milch.de/images/schulmilch-statistik-2010_2011.jpg> (accessed 20.08.13).

IOM, 2011. Dietary Reference Intakes (DRIs): Recommended Dietary Allowances and Adequate Intakes, Elements. <http://iom.edu/Activities/Nutrition/ SummaryDRIs/ /media/Files/Activity Files/Nutrition/DRIs/RDA and Als_VitaminandElements.pdf> (accessed 26.02.13).

Jacobson, R.E., 1961. The School Milk Program in Illinois, Circular 831, Urbana, Illinois.

Kersting, M., Bergmann, K., 2008. Die Calcium- und Vitamin-D-Zufuhr von Kindern. Ernährungs-Umschau 9, 523-527.

Landesvereinigung der Bayerischen Milchwirtschaft, 2013. Das tatsächliche Angebot an Milchprodukten in bayerischen Schulen. <http://www.milchlandbayern.de/3782.php> (accessed 26.02.13).

Mensink, G.B., Heseker, H., Richter, A., Stahl, A., Vohmann, C., 2007a. Forschungsbericht: Ernährungsstudie als KIGGS Modul (EsKiMo). <http:// www.bmelv.de/SharedDocs/Downloads/Ernaehrung/ EsKiMoStudie.pdf?_blob=publicationFile> (accessed 18.02.13).

Mensink, G.B., Kleiser, C., Richter, A., 2007b. Lebensmittelverzehr bei Kindern und Jugendlichen in Deutschland. Bundesgesundheitsbl. - Gesundheitsforsch. Gesundheitsschutz 50, 609-623.

Mensink, G.B., Richter, A., Vohmann, C., Stahl, A., Six, J., Kohler, S., Fischer, J. Heseker, H., 2007c. EsKiMo - Das Ernährungsmodul des Kinder- und Jugendgesundheitssurveys (KiGGS). Springer Gesundheits- und Pharmazieverlag, Neu-Isenburg.

MRI, 2008. Ergebnisbericht, Teil 2: Nationale Verzehrsstudie II. <http:/| www.bmelv.de/SharedDocs/Downloads/Ernaehrung/ NVS ErgebnisberichtTeil2.pdf? blob=publicationFile> (accessed 18.02.13).

MRI, 2011. Ergebnisbericht: Einflussfaktoren auf die Nachfrage nach Schulmilch in Grundschulen in Nordrhein-Westfalen. Begleitforschung zum Modellvorhaben "Schulmilch im Fokus" des BMELV, Max Rubner-Institut, Karlsruhe. <http:// www.mri.bund.de/fileadmin/Institute/EV/Schulmilch/ Schulmilch_NRW 020212.pdf> (accessed 19.02.13).

Promar International, 2002. School Milk Pilot Test: Estimating the Effects of National Implementation. Report prepared for National Dairy Council and American School Food Service Association. <http:/l www.nationaldairycouncil.org/SiteCollectionDocuments/child_nutrition/ milkinschools/pilotTest.pdf> (accessed 04.04.12)

Pudel, V., Westenhöfer, J., 1998. Ernährungspsychologie. Hogrefe, Göttingen.

Rabe-Hesketh, S., Skrondal, A., 2007. Multilevel and Longitudinal Modeling Using Stata, second ed. Stata Press, College Station.

Raudenbush, S.W., Bryk, A.S., 2002. Hierarchial Linear Models: Applications and Data Analysis Methods, second ed. Sage Publications, Thousand Oaks, California.

Rodriguez, G., Goldman, N., 2001. Improved estimation procedures for multilevel models with binary response: a case-study. J. Roy. Stat. Soc. Ser. A 164 (2), 339355.

Salamon, P., Pfau, C., Grillenberger, M., Christoph, I.B., Straßburg, A., Weber, S.A. Peter, G., Gonzalez, A., Bonfig, J., Weible, D., 2010. School milk demand: Design and first results of the German federal research project "Focus on school milk". vTI Agric. For. Res. 60 (1), 1-10.

Shampan'er, K., Ariely, D., 2006. How Small is Zero Price? The True Value of Free Products. Working Paper 06-16, Federal Reserve Bank of Boston. <http:// www.bos.frb.org/economic/wp/wp2006/wp0616.pdf> (accessed 04.04.12).

Snijders, T.A.B., Bosker, R.J., 2003. Multilevel Analysis: An Introduction to Basic and Advanced Multilevel Modeling. Sage, London.

Stata Corp., 2009. Stata Release 11. Statistical Software. StataCorp LP, College Station, TX.

The Scottish Government, 2003. Hungry for Success - A Whole School Approach to School Meals in Scotland. Final Report of the Expert Panel on School Meals. <http://www.scotland.gov.uk/Resource/Doc/47032/0023961.pdf> (accessed 18.01.13).

Tutz, G., 2000. Die Analyse kategorialer Variablen. Oldenbourg Wissenschaftsverlag, München.

Varian, H.R., 1984. Microeconomic Analysis, second ed. W.W. Norton \& Company, New York.

VTI, 2012. Endbericht: Ökonomische Begleitforschung zum Bundesmodellvorhaben "Schulmilch im Fokus". Projekt des BMELV, Johann Heinrich von ThünenInstitut, Braunschweig. <http://www.ti.bund.de/fileadmin/dam_uploads/ Institute/MA/Aktuelles_und_Service/Endbericht-

ÖkonomischeBegleitforschungzumBundesmodellvorhaben-

SchulmilchimFokus.pdf> (accessed 17.07.13).

Weindlmaier, H., Fallscheer, T., 1997. Schulmilchversorgung in Deutschland: Situation, Problembereiche, Ansatzpunkte für eine Erhöhung des Distributionsgrades. Sonderveröffentlichung Technische Universität München.

Wietbrauk, H., 1976. Vorschläge zur Verbesserung des Schulmilchabsatzes und der Distribution von Schulmilch. Abschlussbericht eines Forschungsauftrages des Bundesministeriums für Ernährung, Landwirtschaft und Forsten, Bundesanstalt für Milchforschung, Kiel. 


\subsection{Gender-driven food choice: Explaining school milk consumption of boys and girls}

Daniela Weible

Journal of Consumer Policy (2013) 36 (4), 403-423

(With kind permissions of Springer Science+Business Media, New York)

This article was presented in a similar form as a "contributed paper" at the Joint Conference of the AAEA and EAAE "Food Environment: The Effect of Context on Food Choice" at Tufts University in Boston, MA from 30-31.05.2012. 
J Consum Policy (2013) 36:403-423

DOI 10.1007/s10603-013-9225-1

\title{
Gender-Driven Food Choice: Explaining School Milk Consumption of Boys and Girls
}

\author{
Daniela Weible
}

Received: 17 December 2012 / Accepted: 6 May 2013 /

Published online: 28 June 2013

(C) Springer Science+Business Media New York 2013

\begin{abstract}
The literature on the factors influencing children's consumption behaviour is vast; however, gender-specific consumption behaviour and the determinants driving these discriminative decisions are largely unknown. This article contributes insights to the role of gender in food preferences using the example of school milk consumption by German primary school children. Study subjects included pupils, their parents, teachers, and other school personnel. The results of the multilevel model reveal that there are various factors influencing the probability that a child will decide to order school milk. In addition to individual factors such as socio-economics, eating habits, and preferences, consumption behaviour is also affected by social environmental factors. These factors include the preferences of parents, the consumption behaviour of teachers, teachers' attitudes, and the attitude of the school principal. Additionally, policy-driven aspects (e.g., school milk price, product range) were included in the analysis and proved to have an impact on a child's decision to order school milk. Although the results are limited to consumption behaviour for school milk, they can be used in the development of new or the revision of existing school food programmes. The example of school milk may shed light on how specific measures affect boys' and girls' consumption, e.g., how they react to price reductions or specific school settings.
\end{abstract}

Keywords Consumption behaviour - Children - Gender differences · School environment . Multilevel analysis $\cdot$ School milk

\section{Introduction}

Children's food consumption is a prevalent topic in the literature, and studies have shown that nutrition behaviour and eating habits are formed during childhood and are resistant to changes in later years (Kelder et al. 1994, p. 1121; Kemm 1987, p. 210; Lien et al. 2001, p. 217).

\footnotetext{
D. Weible $(\bowtie)$

Thünen Institute of Market Analysis, Federal Research Institute for Rural Areas, Forestry and Fisheries, Bundesallee 50, 38116 Braunschweig, Germany

e-mail: daniela.weible@vti.bund.de
} 
Of all life stages, childhood is known to be of crucial importance for later food choices (Koehler and Leonhaeuser 2008, p. 17) and is seen as the appropriate time to modify food preferences (e.g., through food exposure) or to implement dietary interventions (Birch 1979, p. 191; Kelder et al. 1994, p. 1125; Kemm 1987, p. 210). Food habits are learned through experience and education; thus, establishing healthy eating habits with a set of knowledge, beliefs, and attitudes during childhood encourages healthy eating patterns throughout life. Today, the development of healthy eating patterns is of great importance as childhood obesity has become one of the most serious public health challenges of the twenty-first century (WHO 2012a). Preliminary results from the European Childhood Obesity Surveillance Initiative indicate that there is a trend towards overweightness and obesity in primary school children (aged 6-9 years) (WHO 2012b).

A variety of factors influencing eating behaviour and the behaviour itself can be explained by a dynamic and reciprocal interaction among these factors. This article proceeds from the assumption that an integrated theoretical framework based on social cognitive theory and Bronfenbrenner's ecological model is appropriate for describing factors that influence the consumption patterns of children and adolescents (Reisch and Gwozdz 2010; Story et al. 2002). According to the above mentioned framework, influences are categorised into four broad groups: individual (intrapersonal), social environmental (interpersonal), physical environmental, and macrosystem factors. Individual factors that affect consumption patterns include psycho-social, biological, behavioural, and lifestyle factors. Further, the consumption habits of children are affected by their social environment, which comprises family, friends, and peers. The physical environment concerns the community settings, including schools, restaurants, stores, and vending machines, and influences the accessibility and availability of food. In a broader sense, the macrosystem plays a role in determining consumption patterns relating to societal influences like mass media, advertising, and social and cultural norms (Reisch and Gwozdz 2010, p. 726; Story et al. 2002, p. 41).

In the present article, different levels of influencing factors on children's eating behaviour are analysed using the example of school milk consumption by German primary school children. The primary objective was to look for determining factors in school milk consumption for boys and girls. The determinants evaluated comprise individual factors and social and physical environmental factors considered together in an original analysis. Beyond the individual factors of each pupil, characteristics of their parents, their class teacher, and the school environment with additional personnel and institutional settings were taken into account. This comprehensive approach for analysing consumption behaviour should lead to a better understanding of the driving forces in school milk consumption as food choice is a complex human behaviour.

Furthermore, it was considered reasonable to differentiate consumption between girls and boys as prior studies emphasize that food preferences generally differ for boys and girls $(\mathrm{Nu}$ et al. 1996, p. 258) and in the case of milk/school milk girls consume less than boys (Christoph-Schulz et al. 2012; DGE 2008; Mensink et al. 2007; Robinson 1978; Weindlmaier and Fallscheer 1997). Sweeting (2008) concludes in a review that gender differences in food choice and dietary concerns of children and adolescents are the results of culture-bounded conventions and roles. In addition, societal expectations and stereotypes for males and females are highly transmitted through parental, peer, and media influences (Sweeting 2008, pp. 10-11). The role of socio-cultural aspects of gender-specific consumption was also reported by Jensen and Holm (1999). Specific foods and types of food meals are markers of femininity or masculinity in Western food culture, resulting in a gendered character of dietary habits (Jensen and Holm 1999, pp. 351, 356). Finally, 
previous findings of the study reveal significant gender-specific consumption behaviours (vTI 2011; Weible et al. 2011).

The purpose of the present article arose from the fact that the existence of a genderspecific "gap" is known, but the determinants driving these discriminative decisions are widely unknown. Several researchers have come to the conclusion that a clear focus on gender differences is required for gaining more insights into the topic (Koehler and Leonhaeuser 2008, p. 19; Larson et al. 2009, p. 259; Sweeting 2008, p. 11). The hypothesis is that influencing factors on eating patterns are different for boys and girls. Knowing these factors may help to design and to target an appropriate and effective intervention programme for groups with special needs, such as girls.

\section{Background}

Below, the role of parents, peers, teachers, and the school environment in children's consumption behaviour is described briefly within a literature review. The gender aspect has not been analysed in this context and will therefore only be described if such aspects arise. After the review, the underlying concept of aspects that are assumed to be driving forces in school milk consumption is explained and grouped according to the theoretical model introduced previously. General background information about school milk is also given as it is not an ordinary product that can be sold in food stores and therefore requires a brief description.

\section{Literature Review}

As part of children's social environment, parents are the most influential factor in the development of children's eating habits (Crockett and Sims 1995, pp. 235, 241; Nicklas et al. 2001, p. 226), and they have a key role in shaping their children's dietary intake (Birch and Davison 2001, pp. 903-904; Reinaerts et al. 2007, p. 256). There are different types of parental influence. Parents' food selection is perceived as a primary environmental influence on children's food choices. Parents are in the position to decide what kinds of food and to what extent foods are available and accessible at home (Holsten et al. 2012, p. 71; Roos et al. 2012, p. 86). Meal structure, feeding practices, and home eating patterns can impact children's food consumption (Golan and Crow 2004, p. 41; Nicklas et al. 2001, p. 226).

The eating behaviour of parents shapes children's eating behaviour directly as a result of social role modelling. Parents serve as role models, and parental consumption can be a predictor of their children's dietary intake (Reinaerts et al. 2007, p. 256; Weber Cullen et al. 2001, p. 188; Wind et al. 2006, p. 216). As a result of these influences, parents make a contribution to the child's food-related attitudes, preferences, beliefs, and consumption patterns.

In general, parents own food preferences and food choices are determined by the cultural and economic context, including the costs, convenience, taste, and availability of food (Birch and Davison 2001, p. 896). Parenting style is also a factor in the effectiveness of parents' behavioural methods to maintain, modify, or control children's behaviour (Golan and Crow 2004, p. 41; Nicklas et al. 2001, p. 226). Interestingly, Sweeting (2008) demonstrated that parents treat boys and girls differently concerning nutritional behaviour (Sweeting 2008, p. 8).

With the start of schooling as children get older, the behaviour and opinions of peers, friends, teachers, and other people at school gain more importance (Crockett and Sims 1995, 
p. 243). In addition to the family, peer environments are a primary social context contributing to youth's eating behaviour (Salvy et al. 2012, p. 370; Salvy and Pliner 2010, p. 621). The familiarity with peers is an important social influence. Children are more likely to eat novel foods or disliked food items when familiar peers are doing so. The familiarity of others moderates social facilitation of eating for both girls and boys (Salvy et al. 2008, p. 516). Peers can influence children's food selection (Salvy and Pliner 2010, p. 624), food acceptance (Hendy 2002, p. 222), and food intake (Salvy et al. 2008, pp. 516-517). Weber Cullen et al. (2001) and Vereecken et al. (2005) analysed both children's fruit and vegetable consumption considering peer influences among other things (e.g., attitudes, beliefs, preferences, self-efficacy, parental influences). Weber Cullen et al. (2001) only reported a correlation between children's fruit and vegetable consumption and what the children believe their friends think about eating the foods (normative beliefs). Instead, Weber Cullen et al. found no relation between children's consumption and their perceived norms ("what fruit, juice and vegetable children think their [family and] friends are eating," p. 190) or normative expectations ("a child's beliefs about whether [parents or] friends think the child should or should not eat fruit, juice and vegetable," p. 191) for eating fruits and vegetables (Weber Cullen et al. 2001, pp. 187, 197). In contrast, a more recent study by Vereecken et al. showed a highly significant correlation between perceived peers' behaviour and fruit and vegetable consumption (Vereecken et al. 2005, p. 260). Another study of Crockett and Sims (1995) differentiated between peer influence towards behaviour and peer influence towards attitude. During the preteen years, peer influence has a considerable effect on behaviour, whereas during the teen years, peer influences are more directed towards attitude (Crockett and Sims 1995, p. 243). Altogether, peer modelling and perceived peer behaviour are important factors explaining children's consumption behaviour.

In contrast to the literature on the influences of parents and peers, there are only a few inconsistent studies on the effects of teachers and the school context on children's eating behaviour. Teachers are a source of nutrition information and education, and they may influence children's eating habits through their food-related attitudes, preferences, beliefs, and consumption patterns. In principle, teachers serve as role models for their pupils and may contribute to the development of eating habits and the achievement of their nutritional needs (Crockett and Sims 1995, pp. 242-243). Addessi et al. (2005) described a greater acceptance and intake of novel food in a familiar school environment when an adult consumed the same novel food in front of the children. Thus, teacher modelling and repeated exposure may serve as powerful influences promoting children's acceptance of food (Addessi et al. 2005, pp. 269-270). However, Hendy and Raudenbush (2000) reported that there is an effect of teacher modelling only if teachers are enthusiastic and only if they are not in direct competition with peers (Hendy and Raudenbush 2000, pp. 62, 74-75). A similar outcome was described by Hendy (1999); children's acceptance of novel food will be greater if teachers offer a reward ("special dessert" or "candy"), insist that the children try one bite of the new food, or offer the choice to try the new food. The acceptance of novel food, however, will be ineffective if teachers are role models only by eating the new food in front of the children (Hendy 1999, pp. 22-24).

The school context is also important, as schooling is compulsory, and many of the drinks and food items children consume at school are provided by the school. Poor information exists about which components of the school environment influence the nutrition behaviour of pupils (Maes and Lievens 2003, p. 518). Although schools are at a more distal level and have a more indirect role, their school policy may influence issues such as the availability of drinks and foods during breaks, food rules, diet-related activities, and pricing (Story et al. 2002, p. 42). In Germany, such aspects are strongly driven by regional characteristics or 
school settings. Differences among schools in children's consumption of food and beverages may be explained by differences among schools or regions or by differences in food policy. Vereecken et al. (2008) analysed whether potential differences among schools in children's consumption of snacks and drinks could be explained by differences in school food policy. The results revealed that controlling for pupil variables, no differences among schools were observed for the consumption of milk, water, sugared soft drinks, and snacks; however, the variation was significant for the consumption of flavoured milk drinks, fruit juice, and fruits. These results indicate that the availability of sweetened milk drinks may lower the consumption of unsweetened milk (Vereecken et al. 2008, pp. 724-726). Food availability and food regulations may cause variation among schools; thus, schools should provide a context where healthy food choices and healthy eating habits are available.

This brief literature review has made clear that social-environmental influences of parents and peers dominate children's eating behaviours and that there may be influences of teachers and the physical school environment as well, although the latter has not been well studied.

\section{Applied Theoretical Model of School Milk Consumption}

On the basis of this review and according to the initially presented theories, the determinants of school milk consumption can be mapped to the different levels of influence. Environmental influences are primarily characterized by the school setting as children purchase and consume school milk only at school. In German primary schools, school milk is consumed typically as part of the second breakfast, which usually takes place with the class teacher in the classroom. Thus, important factors of the social environment include classmates and the class teacher, who influence the child's decision to drink school milk. Parents are also important as they are the key persons in the food socialisation process of their children (Nicklas et al. 2001, p. 227; Salvy and Pliner 2010, p. 622) and are responsible for paying for their children's school milk; thus, the buying decision is a decision of both parents and children together. Thus, children's and parents' food preferences, eating habits, and attitudes towards milk, milk products, and school milk, as well as their knowledge about a healthy diet, are important factors when explaining school milk consumption. In addition, the entire school, with its specific physical environment and characteristics (e.g., geographical location, school size, availability of food and beverages/school lunch) and its policies (programmes for nutrition education; subsidies for food at the European, state or federal level; local co-financing of food) and its broader social environment (e.g., the school principal and school milk manager) influence the consumption of school milk. Each factor is assigned to its respective level, as mapped in Figure 1.

\section{School Milk}

As a matter of principle, school milk in Germany can be a part of the school food policy but is not obligatory. Rather, it depends on the individual school to offer school milk or not. The implementation of school milk is regulated at the European level by Council Regulation (EC) No. 657/2008 and should therefore have a nutritional and educational character (EC 2010). The specific objective of the scheme is to stimulate the consumption of milk by young people by providing them with healthy dairy products (EC 2007, Recital 43) and, therefore, to contribute to the global objective to fight against obesity (EC 2008, Recital 2). Milk consumption is promoted through a community aid that is provided for supplying certain processed milk products to pupils at educational establishments. 


\begin{tabular}{|c|c|c|}
\hline Individual level & Child (boy or girl) & $\begin{array}{l}\text { - Demographics } \\
\text { - Socio-economics } \\
\text { - Cultural aspects } \\
\text { - Household structure/family characteristics } \\
\text { - Food preferences } \\
\text { - Eating habits } \\
\text { - Attitude towards nutrition, milk and school milk } \\
\text { - Knowledge about nutrition and health }\end{array}$ \\
\hline & Parents & $\begin{array}{l}\text { - Food preferences } \\
\text { - Eating habits } \\
\text { - Attitude towards nutrition, milk and school milk } \\
\text { - Knowledge about nutrition and health } \\
\text { - Parents' modelling behaviour }\end{array}$ \\
\hline Class level & $\begin{array}{l}\text { Class teacher } \\
\text { Other class-specific factors }\end{array}$ & $\begin{array}{l}\text { - Attitude towards nutrition, milk and school milk } \\
\text { - Food preferences } \\
\text { - Eating habits } \\
\text { - Knowledge about nutrition and health } \\
\text { - Learning units about nutrition and health } \\
\text { behaviour } \\
\text { - Teachers' modelling behaviour } \\
\text { - Class size } \\
\text { - Food rules }\end{array}$ \\
\hline School level & $\begin{array}{l}\text { School principle } \\
\text { School milk manager } \\
\text { Intervention policy } \\
\text { Other school-specific factors }\end{array}$ & $\begin{array}{l}\text { - Implementation of the school milk offer at } \\
\text { - school } \\
\text { - Pricing/amount of subsidy } \\
\text { - Availability of other beverages and food } \\
\text { - Educhool-specific food policy } \\
\text { - Attitude towards material } \\
\text { - Food preferences } \\
\text { - Knowledge about nutrition and health } \\
\text { - School size } \\
\text { - Urban/rural region }\end{array}$ \\
\hline
\end{tabular}

Fig. 1 Levels of influence on pupils' school milk consumption

The term "school milk" can encompass a variety of products from which pupils can choose. In Germany, school milk products at primary schools typically include plain (nonflavoured) and flavoured milk drinks, and the varieties of flavoured milk typically offered include chocolate, vanilla, strawberry, banana, and caramel. Other dairy products (e.g., yoghurt) are seldom offered.

According to the provisions of the scheme, all children are entitled to receive up to $250 \mathrm{ml}$ of subsidised school milk (or school milk equivalents) per school day (EC 2008). Because of this restriction in quantity, school milk products are offered in packages of $250 \mathrm{ml}$. In general, prices are equal for all primary schools as subsidised prices follow a maximum price policy (BMELF 1985).

As stated by the German Nutrition Society (DGE), milk and milk products are seen as part of a healthy diet because of their high protein, vitamin, and mineral content contained in an optimal combination. According to the DGE, milk and milk products are important as a calcium source to fulfil dietetic requirements, especially for adolescents. In the case of girls, who have a high need for calcium, these requirements are often insufficiently met (Biesalski et al. 1999, pp. 162-170, 571; DGE 2008, pp. 63, 66, 79). 


\section{Analytical Approach}

This article is based on a large federal research project, "Schulmilch im Fokus" (School Milk in Focus), set up by the German Ministry of Food, Agriculture, and Consumer Protection and conducted by the Max Rubner-Insitut, Karslruhe and Thünen-Institut, Braunschweig in Germany. Its objective was to identify and quantify factors that influence demand for school milk. Data were collected in 125 targeted primary schools in North Rhine-Westphalia (MRI 2011; Salamon et al. 2010; vTI 2011), which were selected through a random multi-stage sampling procedure. ${ }^{1}$

Data

Two principle data sets were used: survey data that were collected by questionnaires distributed to all concerned agents in the targeted schools and panel data generated by a price experiment conducted in those schools.

Survey data were collected among primary school children in grades $2-4^{2}$ and their respective parents, class teachers, school principals, and school milk managers in September 2008 at school. The questionnaire focused on nutritional behaviour; consumption preferences; and attitudes towards healthy nutrition, milk and school milk and included questions related to the respondents' knowledge about nutrition and milk and socio-economic indicators. The questionnaires for teachers, school principals, and school milk managers also included questions about the food, meals, and especially the milk offered at school. There were also questions about the organization of school milk distribution, decisions about the product range, attitudes towards milk and school milk, and educational materials provided by the schools on nutrition and milk.

Additionally, a price experiment was conducted during the school year 2008/2009 to document the number of orders under different price settings and to capture the buying behaviour of the surveyed children at each of the 125 schools (for more details regarding the price experiment, see Salamon et al. 2010, pp. 3-4; vTI 2011, pp. 38-41). In the selected schools, current maximum prices ( 35 cents for flavoured milk and 30 cents for plain milk) were reduced stepwise to 25,15 , and 0 cents for all offered school milk products.

Because of missing data or missing questionnaires, not all pupils, classes, and schools were completely covered. In total, the sample for which complete data were available included 7,336 pupils (3,676 boys and 3,658 girls) from 101 primary schools and 552 classes. Pupils with an immigration background constituted $27.4 \%$ of the sample, and the distribution of pupils across the grades was relatively balanced, with $34.4 \%$ second-grade pupils (normally aged 7-8), $33.3 \%$ third-grade pupils (normally aged $8-9$ ), and $32.3 \%$ fourth-grade pupils (normally aged 9-10).

\section{Binary Dependent Variable}

Based on documented numbers of orders during the school year, a binary dependent variable for each price setting was created. The calculation was performed as follows: primary school

\footnotetext{
${ }^{1}$ The strata formation was based on the socio-economic status (social index) of the regional district, which was determined on the basis of welfare aid expenditures at the county level and the share of pupils per school with an immigrant background. Former participation, or non-participation, in the EU School Milk Scheme was also considered.

${ }^{2}$ In these grades children are generally aged between 7 and 10.
} 
pupils decide for a specific time period (usually a 2-week period) to order one school milk package per school day or no school milk package per school day. Based on a general distribution of school milk orders, it is clear that for most pupils, there was very limited variation in school milk orders within each price setting. Pupils who decided to order school milk in an ordering period at a given price usually continued to order school milk for the remaining periods. Only $26 \%$ of the pupils ordered school milk for at least one period at a given price but did not order milk for every school day at that price. Thus, the distribution of orders within one specific price was u-shaped (i.e., either a pupil ordered in every period or the pupil did not order at all). For this reason, the average level of ordering by each pupil at each price setting was calculated.

Pupils were treated as zero (no order) if they ordered milk for less than half of the possible days at a specific price or as one (order) if they ordered milk for more than half of the possible days. Therefore, a score of " 0 " represents pupils who were less likely to order school milk at a particular time and at the designated price, and "1" represents pupils who were more likely to order school milk at the designated price.

Explanatory Variables

Tables 1, 2 and 3 provide an overview of the individual-level variables used. Variables stem from the children's or parents' questionnaire. Factors regarding demographics, socioeconomics, and household characteristics are components of Table 1; factors regarding food preferences, eating habits, and knowledge are listed in Table 2; attitudes of children towards milk and parents' attitudes towards nutrition, milk, and school milk are presented in Table 3.

Explanatory variables at the class level, which stem from the class teachers' questionnaire, are listed in Table 4. Finally, explanatory variables at the school level are presented in Table 5. These variables were gathered from the school principals' questionnaire, the school milk managers' questionnaire, and general school information from further surveys or sources.

\section{Statistical Methods and Analyses}

Multilevel modelling was used to examine the factors influencing girls' and boys' school milk consumption in consideration of explanatory variables that were measured at different levels of aggregation. As pupils are nested within classes and within schools, this is a typical case of a hierarchical data structure, which requires the specification of such a model (Bickel 2007; Heck and Thomas 2009; Hox 2002; Raudenbush and Bryk 2002; Snijders and Bosker 2003).

In addition to the "individual level," "class level," and "school level," the "price level" was included to take the pooled data structure (different price settings) into account (Heck and Thomas 2009, p. 44; Snijders and Bosker 2003, p. 9).

For the analysis, a random-intercept model was chosen with an ordinary logistic model that included random intercepts and fixed slopes at the specified levels. Analyses were conducted with STATA statistics version 11 using the procedure "xtmelogit," which produced separate estimations for girls and boys to enable a comparison of estimated coefficients between the groups.

\section{Results}

Results from the random intercept model are presented with "price" at level 1, "individual" at level 2, "class" at level 3, and "school" at level 4. The binary dependent variable is the choice to order school milk by each pupil. 
Table 1 Overview of the explanatory variables at the individual level (part 1)

\begin{tabular}{|c|c|}
\hline \multicolumn{2}{|c|}{ Demographics, socio-economics, and household characteristics } \\
\hline Childs' age & Between 6 and 12 years old \\
\hline Immigration background & Yes $(0)$ or no $(1)$ \\
\hline Household income & $\begin{array}{l}\text { Average monthly net income category: }<500 ; 500-<1,000 ; 1,000-<1,500 \\
\qquad 1,500-<2,000 ; 2,000-<2,500 ; 2,500-<3,000,3,000-<3,500 ; 3,500-<4,000 \\
4,000-<4,500 ; 4,500-<5,000 ; 5,000-<7,500 ; 7,500-<10,000 ;>10,000\end{array}$ \\
\hline $\begin{array}{l}\text { School education of the } \\
\text { mother }\end{array}$ & $\begin{array}{l}\text { Highest general school education level: no degree (1), still at school (2), } \\
\text { primary education level (3), intermediate education level (4), qualification to } \\
\text { study at technical college (5), qualification to study at university/high school } \\
\text { level (6) }\end{array}$ \\
\hline $\begin{array}{l}\text { School education of the } \\
\text { father }\end{array}$ & $\begin{array}{l}\text { Highest general school education level: no degree (1), still at school (2), } \\
\text { primary education level (3), intermediate education level (4), qualification to } \\
\text { study at technical college (5), qualification to study at university/high school } \\
\text { level (6) }\end{array}$ \\
\hline $\begin{array}{l}\text { Professional degree of } \\
\text { he mother }\end{array}$ & $\begin{array}{l}\text { No professional degree (1); still in professional training (2); apprenticeship or } \\
\text { dual professional training (3); training at technical academy, master classes, } \\
\text { technical school, professional academy (4); graduate from technical col- } \\
\text { lege (5); graduate from university (6) }\end{array}$ \\
\hline $\begin{array}{l}\text { Professional degree of } \\
\text { the father }\end{array}$ & $\begin{array}{l}\text { No professional degree (1); still in professional training (2); apprenticeship or } \\
\text { dual professional training (3); training at technical academy, master classes, } \\
\text { technical school, professional academy (4); graduate from technical col- } \\
\text { lege (5); graduate from university (6) }\end{array}$ \\
\hline $\begin{array}{l}\text { Employment of the } \\
\text { mother }\end{array}$ & $\begin{array}{l}\text { Present employment: parental leave, other sabbatical, housewife, unemployed } \\
\text { (0); other (1); minor employment, mini job, employed from time to time or } \\
\text { irregular (2); part-time employment, old age part-time, other part-time em- } \\
\text { ployment (3); fully employed, "one-euro-job," professional training/appren- } \\
\text { ticeship/requalification (4) }\end{array}$ \\
\hline $\begin{array}{l}\text { Employment of the } \\
\text { father }\end{array}$ & $\begin{array}{l}\text { Present employment: parental leave, other sabbatical, housemen, unemployed } \\
\text { (0); other (1); minor employment, mini job, employed from time to time or } \\
\text { irregular (2); part-time employment, old age part-time, other part-time em- } \\
\text { ployment (3); fully employed, "one-euro-job," professional training/appren- } \\
\text { ticeship/requalification (4) }\end{array}$ \\
\hline Children per household & Between 1 and 10 children (under 18 years) living in the household \\
\hline
\end{tabular}

Results of the empty model (Table 6) and the final model (Table 7) containing all explanatory variables at each level are presented and discussed. In both tables, the boys are on the left side and the girls are on the right side. As intended in multilevel modelling, the final model includes only the significant variables. In this case, a total of 23 explanatory variables were identified.

\section{Empty Model}

Table 6 presents the random part of the empty model without independent variables and with the decomposition of the variance across identified levels. A likelihood ratio test was performed, and the results indicate that the variance at all levels is significantly different from zero. For boys and girls, the share of variance explained by the pupils' structure is the primary component of the unexplained variation (boys, 3.22 and girls, 2.63), followed by the class structure and the school structure with a considerably lower share. Differences in the variances between girls and boys were identified; the individual variance was higher for boys than for girls, whereas the context variances were higher for girls than for boys. However, these differences were very small. 
Table 2 Overview of the explanatory variables at the individual level (part 2)

Childs' food preferences and eating habits

Taste is a reason for (not) drinking school milk

Parents are a reason for (not) drinking school milk

Health or diet are a reason for (not) drinking school milk

Mainly drinks milk (products) at home

Breakfast at home before school

Child consumes no milk or dairy products at home

Child consumes soy milk (almost) every day at home

Child consumes lactose-free milk (almost) every day at home

Child consumes only milk or dairy products at home

Child takes something to eat to school

Child takes only milk (products) to school for drinking

Child takes no milk (products) to school for drinking

Child takes soy milk to school for drinking

Child takes lactose free milk to school for drinking

Parents stated that their child consumes soy milk and/or or other milk substitutes

Parents stated that their child consumes lactose-free milk

Parents like to drink milk and/or milk products

Knowledge about nutrition and health

Childs' knowledge about the importance of milk for bone development

Knowledge of parents about nutrition

Knowledge of parents about milk
Taste is not a reason (0), milk tastes good (1), milk does not taste good (2)

Parents are not a reason (0), my parents want that I drink school milk (1), my parents do not want that I drink school milk (2)

Health or diet is not a reason (0), milk is healthy (1), milk is not part of my diet (2)

No (0), sometimes (1), (almost) every day (2)

Yes (0) or no (1)

No (0) or yes (1)

No $(0)$ or yes (1)

No (0) or yes (1)

No (0) or yes (1)

Yes (0) or no (1)

No $(0)$ or yes (1)

No $(0)$ or yes (1)

No $(0)$ or yes (1)

No $(0)$ or yes (1)

No $(0)$ or yes (1)

No (0) or yes (1)

No (0) or yes (1)

No (0) or yes (1)

Between 0 and 2; number of correctly answered questions about milk

Between 0 and 3; number of correctly answered questions about milk

Table 6 presents the numbers of considered schools, classes, and pupils. Boys and girls were nearly equally distributed, with approximately 3,650 pupils each.

\section{Final Model: Explanatory Variables Significant for Both Genders}

The explanatory variables from Table 7 , which were significant for both genders, are described below.

Independent of gender, distributing "school milk free of charge" was associated with a strong and highly significant effect on school milk demand. This variable had the greatest positive impact on the probability that pupils would order school milk. The coefficient for the variable "child's age" indicated that the probability that a pupil will demand school milk is greater for younger pupils than for older pupils. The negative effect was greater for girls than for boys. Children's food preferences also played an important role in school milk demand. For girls and boys, the good or bad taste of milk was associated with a strong and 
Table 3 Overview of the explanatory variables at the individual level (part 3)

Childs' attitude towards milk

Childs' image of milk

Indifferent (0), positive (1), negative (2)

Developed categorical variable based on the pupil's agreement with the following statements: "milk is cool," "milk is healthy," "milk makes me fit," "milk is something for babies," "milk is unhealthy"

Parents' attitude towards nutrition, milk, and school milk

"It is important to me that my child drinks milk and/or eats milk products."

"If the school offers milk and/or milk products, I can assume this is healthy."

"Parents whom I respect think that children should drink school milk."

"Children from households with a low income should get school milk free of charge."

"I feel good if my child drinks school milk during breaks."

"School milk facilitates a sufficient milk supply for children."

"I feel good if my child drinks milk and/or eats milk products."

"My friends say that milk and milk products are components of a healthy diet for children."

"School milk facilitates a healthy diet for children."

"Nutrition must not cost much."

"It is important to me that my child has breakfast before school."

"I would spend more money for food if the household income was higher.

"A balanced diet does not have to be more expensive than an unbalanced diet."
(Dis)agreement with several statements Indifferent (0), agree (1), disagree (2)

Indifferent (0), agree (1), disagree (2)

Indifferent (0), agree (1), disagree (2)

Indifferent (0), agree (1), disagree (2)

Indifferent (0), agree (1), disagree (2)

Indifferent (0), agree (1), disagree (2)

Indifferent (0), agree (1), disagree (2)

Indifferent (0), agree (1), disagree (2)

Indifferent (0), agree (1), disagree (2)

Indifferent (0), agree (1), disagree (2)

Indifferent (0), agree (1), disagree (2)

Indifferent (0), agree (1), disagree (2)

Indifferent (0), agree (1), disagree (2)

highly significant effect. Independent of gender, the probability of ordering school milk was greater for pupils who reported in the questionnaire that they ordered because "milk tastes good," and the probability was lower for pupils who reported that they did not order milk because "milk does not taste good." In both cases, boys reacted more strongly than girls. Nevertheless, if pupils ordered school milk for health reasons, the demand was positively influenced. In contrast to the taste variable, the variable "milk is healthy" had a stronger and more highly significant effect for girls than for boys. Girls and boys who "mainly drink milk and milk products at home" had a significantly greater probability of ordering school milk; however, the effect was greater for boys.

The probability that a pupil would order school milk was greater if parents agreed with the statement "I feel good if my child drinks school milk during breaks." Pupils whose teacher disagreed with the statement "School milk facilitates a healthy diet for children" had a lower probability of ordering school milk; however, the probability increased significantly if the teacher agreed with the statement "Offering school milk is still a problem, as some children do not tolerate milk." At first glance, the latter result is counter-intuitive, but agreement to this statement could be interpreted as a high involvement of teachers with the school milk issue and the underlying difficulties. Thus, an intensive examination with the topic has a positive impact on both girls' and boys' demand.

The probability that a pupil would order school milk was reduced by whether the school milk manager agreed or disagreed with the statement "Every school should provide school 
Table 4 Overview of the explanatory variables at the class level

Teachers' preferences and behaviour

Teacher likes to drink milk and/or milk products

Teacher drinks milk with the pupils during morning break

Teachers' attitude towards the school milk offer at school

Personal opinion about the school milk offer at school

Teacher is satisfied with the school milk offer at school

Teachers' attitude towards nutrition, milk, and school milk

"School milk facilitates a healthy diet for children."

"Offering school milk is still a problem, as some children do not tolerate milk."

"School milk facilitates a sufficient milk supply for children."

"School milk is unnecessary as children can drink milk at home."

"I feel good if the children drink school milk during breaks."

"Every school should provide school milk."

"Persons whom I respect think that children should drink school milk."

"Milk and milk products are components of a healthy diet for children."

"Persons whom I respect think that milk is unhealthy for children."

Other class specific factors

School milk is bottled in glass

Class participated in campaigns on diet and/or visited an operation No (0) or yes (1) of food production in the past school year.
Yes (0) or no (1)

$$
\begin{aligned}
& \text { No (0) or yes (1) } \\
& \text { No (0) or yes (1) }
\end{aligned}
$$

Indifferent (0), agree (1), disagree (2)

No $(0)$ or yes (1)

(Dis)agreement with several statements Indifferent (0), agree (1), disagree (2) Indifferent (0), agree (1), disagree (2)

Indifferent (0), agree (1), disagree (2)

Indifferent (0), agree (1), disagree (2)

Indifferent (0), agree (1), disagree (2)

Indifferent (0), agree (1), disagree (2)

Indifferent (0), agree (1), disagree (2)

Indifferent (0), agree (1), disagree (2)

Indifferent (0), agree (1), disagree (2)

milk." These findings may also be counter-intuitive, but it might be that the engagement of the school milk manager declines when he feels forced in his support.

Finally, the probability of ordering school milk was lower for pupils whose school principal reported that "parents initiated to provide school milk at school." As the parents - instead of the school principal - took the initiative to provide school milk at school, in general, the school principal might have a rather low involvement which is reflected in the lower probability of orderings. If, upon reverse, the school principal or teachers had been proactive in providing school milk, this would have rather increased than decreased the probability that pupils order school milk at school. However, for this case no significant effect was found. It could also be the case that parents' initiative psychologically impeded the involvement of the school.

Final Model: Gender-Specific Significant Explanatory Variables

The explanatory variables from Table 7, which are only significant for boys or for girls, are described below.

The negative sign for the variable "school milk price" indicates that a reduction in school milk prices was associated with an increasing probability that pupils would order school milk. Interestingly, this variable was only found to be significant for boys, not for girls. Boys 
Table 5 Overview of the explanatory variables at the school level

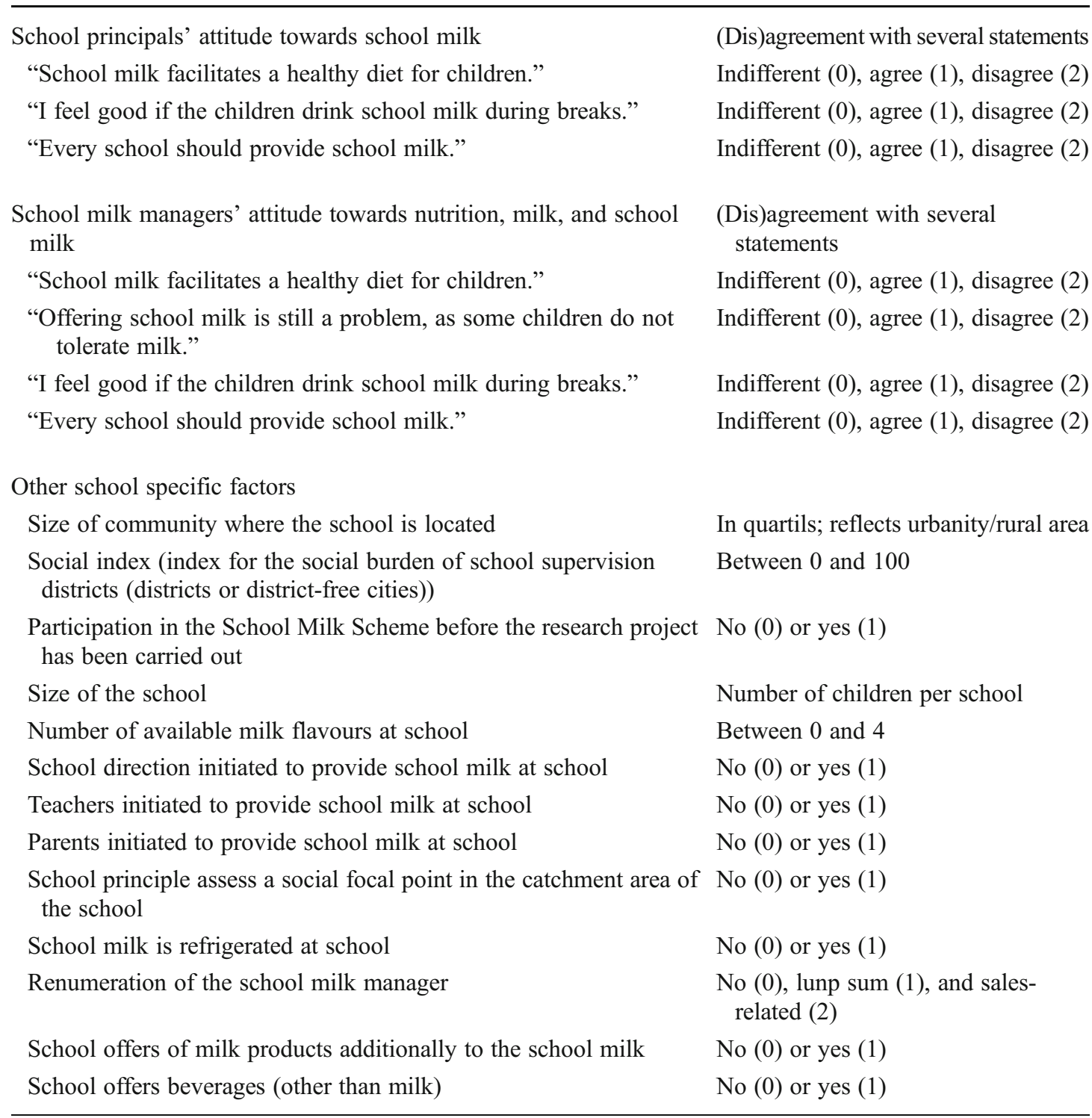

were influenced significantly by changing school milk prices, whereas girls were not. This in itself is an unexpected and surprising outcome. One explanation could have been that the effect of the free-of-charge distribution concerning girls might mask the price impact; however, there are no considerable differences in the coefficients of the parameter between boys and girls. Yet, another reason could be that for girls other factors are much more important in the decision-making process. In contrast, the variable "immigration background" was found to be associated with a significantly negative effect on girls' demand. The probability of ordering school milk was greater for girls without an immigration background. For boys, an immigration background had no significant impact on school milk orders. The variable "child's image of milk" was also significant. Results indicate that the probability of ordering school milk was greater for boys who had a positive attitude towards milk and lower for girls whose attitude was negative; however, significant results were not observed for girls' positive or boys' negative image of milk. No common explanation was found to illuminate this outcome. However, one could speculate that boys are often more active or better more adventurous in their behaviour while 
Table 6 Individual, class, and school level variance (empty model)

\begin{tabular}{lll}
\hline & Boys & Girls \\
\hline Constant & $0.66-^{\mathrm{b}}$ & $0.19-^{\mathrm{a}}$ \\
School level variance & 0.29 (SD 0.09) & 0.31 (SD 0.09) \\
Class level variance & 0.61 (SD 0.10) & 0.68 (SD 0.09) \\
Pupil level variance & 3.22 (SD 0.18) & 2.63 (SD 0.15) \\
Number of schools & 101 & 101 \\
Number of classes & 550 & 548 \\
Number of pupils & 3,676 & 3,658 \\
Log restricted likelihood & $-8,604$ & $-8,842$ \\
\hline
\end{tabular}

${ }^{\text {a }}$ Significant at the $10 \%$ level

${ }^{\mathrm{b}}$ Significant at the $1 \%$ level

girls try to avoid risks which would fit to the result that boys with a positive image of milk react with a significant positive response and girls with a negative image react with a significant negative response.

The food preferences of parents also played a role in children's school milk demand. The probability that a girl would order school milk was greater if her parents liked to drink milk and/or eat milk products. Interestingly, only girls seemed to imitate their parents' eating and drinking habits in this way and had a significantly positive influence on school milk ordering. The variable "parents like to drink milk and/or eat milk products" had no significant influence on boys' demand. Instead, boys were more driven by their parents' wishes than by their parents' habits. Boys whose parents agreed with the statement, "It is important to me that my child drinks milk and/or eats milk products" had a greater probability of ordering school milk. In addition, the probability was reduced if parents disagreed with the statement, "I feel good if my child drinks school milk during breaks." Girls' decisions were not significantly influenced by either statement. In principal, it appears that girls imitate the behavioural practise of their parents, while boys capture more verbal or non-verbal expectations. Supported is this result at the class level where the modelling behaviour of an adult only influenced girls' school milk demand. This finding was confirmed by the significant variable "the teacher drinks milk with the pupils during morning break." Girls whose teachers drank milk with their pupils had a greater probability of ordering school milk. The variable was not significant for boys. Further, the boys demonstrated a significantly lower probability of ordering school milk if their teacher disagreed with the statement, "Persons whom I respect think that children should drink school milk" or if their school principal agreed with the statement, "Every school should provide school milk."

Finally, the variable "number of available school milk flavours" was significant for the girls. As the number of available products increased, the chance that an individual pupil would demand school milk became greater. For girls, it is quite important to have a broad variety of choices.

Final Model: Explanatory Variables Not Significant for Either Gender

There were several explanatory variables that were not significant for boys or for girls. Variables regarding the household structure (e.g., number of children per household) or 
Table 7 Parameters estimated in the final model for school milk consumption

\begin{tabular}{|c|c|c|}
\hline & Boys & Girls \\
\hline Constant & 0.58 & $-2.14^{\mathrm{a}}$ \\
\hline \multicolumn{3}{|l|}{ Price level (LEVEL 1) } \\
\hline School milk price & $-0.47^{\mathrm{b}}$ & -0.06 \\
\hline School milk free of charge & $3.59^{\mathrm{c}}$ & $3.42^{\mathrm{c}}$ \\
\hline \multicolumn{3}{|l|}{ Individual level (LEVEL 2) } \\
\hline Child's age & $-0.17^{\mathrm{a}}$ & $-0.24^{b}$ \\
\hline Immigration background & 0.24 & $0.31^{\mathrm{a}}$ \\
\hline \multicolumn{3}{|l|}{ Reason for (not) drinking school milk } \\
\hline Milk tastes good & $2.5^{\mathrm{c}}$ & $2.26^{\mathrm{c}}$ \\
\hline Milk does not taste good & $-0.94^{\mathrm{c}}$ & $-0.49^{\mathrm{a}}$ \\
\hline Milk is healthy & $0.52^{\mathrm{b}}$ & $0.66^{\mathrm{c}}$ \\
\hline Mainly drink milk and milk products at home & $1.25^{\mathrm{b}}$ & $0.79^{\mathrm{a}}$ \\
\hline \multicolumn{3}{|l|}{ Childs' image of milk } \\
\hline Positive image of milk & $0.46^{\mathrm{a}}$ & -0.03 \\
\hline Negative image of milk & -0.07 & $-0.78^{\mathrm{a}}$ \\
\hline Parents like to drink milk and/or eat milk products & -0.04 & $1.19^{\mathrm{a}}$ \\
\hline \multicolumn{3}{|c|}{ "It is important to me that my child drinks milk and/or eats milk products." (P) } \\
\hline I agree & $1.11^{\mathrm{b}}$ & 0.3 \\
\hline \multicolumn{3}{|l|}{ "I feel good if my child drinks school milk during breaks." (P) } \\
\hline I agree & $0.86^{\mathrm{c}}$ & $0.94^{\mathrm{c}}$ \\
\hline I disagree & $-0.62^{\mathrm{a}}$ & -0.2 \\
\hline \multicolumn{3}{|l|}{ Class level (LEVEL 3) } \\
\hline Teacher drinks milk with the pupils during morning break & 0.00 & $0.51^{\mathrm{a}}$ \\
\hline \multicolumn{3}{|l|}{ "School milk facilitates a healthy diet for children." $(\mathrm{T})$} \\
\hline I disagree & $-1.01^{\mathrm{a}}$ & $-0.89^{\mathrm{a}}$ \\
\hline \multicolumn{3}{|c|}{ "Offering school milk is still a problem, as some children do not tolerate milk." (T) } \\
\hline I agree & $0.82^{\mathrm{a}}$ & $0.69^{\mathrm{a}}$ \\
\hline \multicolumn{3}{|c|}{ "Persons whom I respect think that children should drink school milk." (T) } \\
\hline I disagree & $-0.58^{\mathrm{a}}$ & -0.32 \\
\hline \multicolumn{3}{|l|}{ School level (LEVEL 4) } \\
\hline \multicolumn{3}{|l|}{ "Every school should provide school milk." (SM) } \\
\hline I agree & $-1.55^{\mathrm{c}}$ & $-1.1^{\mathrm{a}}$ \\
\hline I disagree & $-2.18^{\mathrm{b}}$ & $-1.96^{\mathrm{a}}$ \\
\hline \multicolumn{3}{|l|}{ "Every school should provide school milk." (SP) } \\
\hline I agree & $-0.8^{\mathrm{b}}$ & 0.14 \\
\hline Parents initiated to provide school milk at school (SM) & $-0.64^{\mathrm{b}}$ & $-0.52^{\mathrm{a}}$ \\
\hline Number of available milk flavours & 0.08 & $0.3^{\mathrm{a}}$ \\
\hline School level variance & $0.01(\mathrm{SD} 0.08)$ & $0.11(\mathrm{SD} 0.09)$ \\
\hline Class level variance & $0.41(\mathrm{SD} 0.19)$ & $0.74(\mathrm{SD} 0.19)$ \\
\hline Pupil level variance & $3.8(\mathrm{SD} 0.41)$ & $2.94(\mathrm{SD} 0.32)$ \\
\hline Number of schools & 67 & 68 \\
\hline Number of classes & 295 & 297 \\
\hline Number of pupils & 1,319 & 1,442 \\
\hline
\end{tabular}

$P$ parents, $T$ teacher, $S P$ school principal, $S M$ school milk manager

${ }^{\text {a }}$ Significant at the $10 \%$ level

${ }^{\mathrm{b}}$ Significant at the $5 \%$ level

${ }^{\mathrm{c}}$ Significant at the $1 \%$ level 
family characteristics (e.g., parents' employment, household net income) appeared to have no effect on pupils' decisions. Further, in this case, the decision to order school milk was not significantly driven by the fact that a child has no breakfast at home before school or that a child takes nothing to eat to school. No significant influences were evident from children's or parents' knowledge about nutrition and health.

At the class level, the personal opinion of the teacher towards school milk and his/her preferences for milk products revealed no significant effects. None of the included classspecific factors revealed an effect on pupils' decisions to order school milk. This finding reflects results at the school level, where several school-specific factors had no influence on pupils' decisions, including community size, social burden, school size, or the availability of other beverages at school.

\section{Discussion}

The price setting or the food policy (e.g., availability of subsidies) is of importance in the demand for school milk. The variable that had the greatest positive impact on the probability that pupils would order milk was the free-of-charge distribution of school milk. However, not all pupils order school milk even when it is free of charge; the proportion is approximately $81 \%$ (vTI 2011; Weible et al. 2011). This outcome is driven by a certain proportion of pupils with lactose intolerance, pupils who simply dislike milk, pupils whose parents dislike milk, and pupils (or rather their parents) who forget to order. The proportion of pupils who order milk under the free-of-charge condition reflects the overall potential demand. Surprisingly, the school milk price was not an influencing factor for girls' demand. As there is nearly no difference in the coefficient of "free-of-charge distribution" between boys and girls, the speculated effect that the free-of-charge distribution might has masked the price impact concerning girls can be rejected. Thus, for girls other factors might be more important in the decision-making process which could be associated with the fact that girls generally consume less milk/school milk than boys and are rather driven by preferences and the behaviour of parents and teachers. In contrast to girls, boys seem to be more pricesensitive. Besides stimulating consumption through the price setting (availability of subsidies), further areas should be focused within the programme such as information and communication activities in the field of nutrition concerning children, parents, teachers, and other school personnel. Also, extensions regarding the product range would reach more preferences and could lead to an increase in demand.

A decrease in milk consumption with increasing age is in accordance with results from the literature, as other dairy products (e.g., cheese) become more and more important for this age group (Mensink et al. 2007). Nu et al. (1996) discussed that food habits and tastes of adolescents are mostly related to age and gender. As children grow older, their food habits change as they come into contact with novel foods and their food repertoire broadens. Gender differences were observed for children's preferences or reasons for consuming school milk. Taste and healthiness of milk were highly significant factors for both genders, whereas boys were more strongly influenced by good or bad taste and girls by health. Previous studies on the driving factors of food selection for girls and boys reported similar results. Girls' food choices are more influenced by healthiness, and boys' food choices are more influenced by taste and the nourishing aspect (Larson et al. 2009, p. 257; $\mathrm{Nu}$ et al. 1996, p. 256).

Children of either gender who primarily drink milk and eat milk products at home had a significantly greater probability of ordering school milk. Eating patterns appear to be formed 
at home as a result of availability, meal structure, feeding practices and home eating patterns, role modelling, and related factors and continue to exist away from home. This idea is supported by the results of the present study, which show that consumption behaviour is stable away from home in the case of milk products. However, what is learned and practised during childhood may not survive adolescence or rebound during young adulthood. A tracking analysis by Lien et al. (2001) reported that there is some stability of eating behaviour into young adulthood (Lien et al. 2001, pp. 225-226).

In Germany, the following trend is observable: pupils go to school without having breakfast at home or bringing something to eat to school. From theoretical considerations, school milk could contribute to balancing out this potential deficit and could help to improve the nutritional status especially for children who go to school hungry. However, the results indicate the contrary. If children had no breakfast at home before school, this did not result in a significantly greater probability of ordering school milk; also, no significantly greater probability was observed when children took nothing to eat to school. These results are interesting and potentially demonstrate that the decision to order school milk is independent of children's breakfast behaviour. Here, the importance of information and communication activities regarding nutrition and health is apparent again to encourage healthy eating patterns throughout life.

Regarding the parents, the probability of ordering school milk was not significantly influenced by their employment, education, income, or knowledge about health and nutrition. Instead, parents' opinions and preferences for milk products primarily determine their child's consumption. Thus, the attitudes of parents, teachers, and other school personnel have an effect on school milk demand, a result that has not been emphasized in previous studies. The results indicate that in addition to the attitudes of parents, which have often been emphasized, the opinions of other adolescents are important for children's milk consumption at school. However, especially for results at a higher level, the interpretation should be carefully arrived at, as further research is necessary for validation. The result of decreasing the probability of demand if parents initiated to provide school milk at school may be associated with the level of engagement of the school itself. Since parents are the driving forces in introducing school milk at school, the school principle and teachers are less interested. Support from the responsible person at the schools may be necessary for the success of the school milk programme; such a programme cannot be realized by parental engagement alone. One of the persons responsible for the success of the programme is the school milk manager, who organizes the distribution of milk at school. In order to increase the schools' acceptance, it is of particular importance to share the organizational work in handling school milk between different persons or groups of persons and thus, reducing individual efforts. Ideally, the decision to provide school milk at certain school is a joint one (school principal, teacher, pupils, school milk manager). A group decision and the engagement of all actors promote acceptance of the school milk. In Germany, people with an immigration background are very heterogeneous in composition, and thus, food cultures differ considerably within this group. To give an idea, the German health survey among children and young people considered four groups: Turkish, ethnic Germans, other migrants, and non-migrants (Mensink et al. 2007). As the data, unfortunately, did not allow to distinguish between them in the analysis, at least, the immigration background in general should be taken into considerations. A negative effect a variable capturing the presence of an immigration background can be explained in two ways: first, pupils with an immigration background are not accustomed to consuming much milk due to culture-bound consumption patterns. Instead, they are more familiar with other dairy products (e.g., kefir or ayran), which are not part of the available product range. Again, broadening the product range 
would also reach culture-bound consumption patterns. Second, there might be greater price sensitivity among pupils with an immigration background, as they are often from lowincome households, for whom ordering school milk is primarily a matter of price. However, both reasons would influence girls as well as boys. This aspect may have only influenced girls in this study as a consequence of the fact that boys pay more attention to the nourishing aspect of food and eat a greater variety of what is presented or available to them ( $\mathrm{Nu}$ et al. 1996, p. 256), regardless of their immigration background. Alternatively, this result may have been due to modelling by peers of the same sex.

Girls whose teacher drinks milk with the pupils had a greater probability of ordering school milk, but the variable was not significant for boys. This result is only partially in line with previous literature concerning teacher modelling, which has presented differing results (Addessi et al. 2005, pp. 269-270; Hendy 1999, pp. 22-24; Hendy and Raudenbush 2000, pp. 62,74-75). Analysing the effect of teacher modelling, these studies are only based on one observation and can therefore be described as the result of a unique modelling action to encourage children's food acceptance. In contrast, the present research integrates the milk consumption of the teacher as a daily routine throughout an entire school year. The results of this research indicate that teacher influence on children's consumption via modelling behaviour is stronger than the influence of personal opinion towards school milk or personal preferences for milk products, as these two aspects were not significant in the analysis.

The number of available school milk flavours was also important, especially for the girls. From this finding, it is easy to conclude that girls especially prefer a broader range of products from which they can choose. The most common flavours, including chocolate, vanilla, and strawberry, do not reach all preferences, and more effort could therefore be made on both the political and the supply sides to provide a greater variety. However, the results of the present study are not only important for the case of the school milk scheme, with its objective to improve the effectiveness or acceptance of the programme by schools and children. Experiences and results from this research may also provide the groundwork for other programmes regarding school food policies or nutritional programmes. This possibility is supported by the fact that school milk comprises less than $1 \%$ of the entire milk market, and this quantity is comparatively negligible in comparison to the EU budget. Thus, school milk may serve as an example for how specific measures affect boys' and girls' consumption, e.g., how they react to price reductions or specific school settings. The development of new programmes or revisions to existing programmes (e.g., the school fruit programme) can draw from and build upon the findings of this research. Moreover, this project indicates the necessity of considering the individual and the social and physical environments the child is embedded within when analysing the determinants of consumption behaviour. Regardless of environmental factors, the explanation of consumption using only the characteristics of the child is fragmentary and leads to limited results. Considering the context of children's consumption is important.

\section{Conclusion}

The gender-specific consumption behaviour of school milk is described in this article, and some determinants driving these discriminative decisions are discussed, including the finding that girls are more likely to consume school milk if their teacher consumes milk. The results of the present study contribute to the aim of gaining more insight into the role of gender in food-related behaviour.

The results indicate that the immediate environment, the family, is an essential influence on school milk consumption patterns. In addition to the parents, further 
influential agents include teachers and school personnel, e.g., the school principal and school milk manager, who are part of the class and school environments. These personnel all play an important role in school milk demand, as they contribute together to a successful school milk programme. The policy-driven aspects (e.g., school milk price and product range) have also demonstrated an impact on the probability that school milk will be ordered.

Results from the present study indicate that the lower participation of girls in the school milk programme requires specific programme adaptations, especially in view of the fact that the calcium supply of girls is often insufficient. Additionally, girls' specific need for a broader range of product choices could be fulfilled by extending the school milk products to include yoghurt drinks, buttermilk, kefir, ayran, curds, and cheese, among other options. In this way, more diverse preferences could be addressed. Further, the current regulation that only children are able to order school milk should be lifted. Because girls imitate the behaviour of their teachers, the example of milk drinking by teachers could have a positive effect on pupils; therefore, the regulation should allow teachers to order school milk.

Finally, the different levels of determining factors of school milk consumption emphasize the importance of incorporating parents, teachers, and other school personnel in the implementation of school food programmes and of providing information to all persons involved.

\section{References}

Addessi, E., Galloway, A. T., Visalberghi, E., \& Birch, L. L. (2005). Specific social influences on the acceptance of novel foods in 2-5-year-old children. Appetite, 45(3), 264-71.

Bickel, R. (2007). Multilevel analysis for applied research: it's just regression. New York: The Guilford Press.

Biesalski, H. K., Fuerst, P., Kasper, H., Kluthe, R., Poelert, W., Puchstein, C., et al. (1999). Ernährungsmedizin. Stuttgart: Thieme.

Birch, L. L. (1979). Preschool children's food preferences and consumption patterns. J Nutr Educ, 11(4), 189-92.

Birch, L. L., \& Davison, K. K. (2001). Family environmental factors influencing the developing behavioral controls of food intake and childhood overweight. Pediatr Clin N Am, 48(4), 893-907.

BMELF. Schulmilch-Beihilfen-Verordnung vom 8. November 1985. Bundesministerium für Ernährung, Landwirtschaft und Forsten; 1985.

Christoph-Schulz I, Buergelt D, Peter G, Salamon P, Weible D. The small difference: How does gender affect preference for school milk? In Gasiorowska A, Zaleskiewicz T, Microcosm of Economic Psychology, Warsaw School of Social Sciences and Humanities, Faculty in Wroclaw, ISBN 978-83-935288-1-3; 2012

Crockett, S. J., \& Sims, L. S. (1995). Environmental influences on children's eating. J Nutr Educ, 27(5), 235-49. DGE. (2008). Ernährungsbericht. Bonn: Deutsche Gesellschaft für Ernährung.

EC. (2007). Establishing a common organisation of agricultural markets and on specific provisions for certain agricultural products (Regulation No. 1234/2007). Brussels: European Commission.

EC. (2008). Regulations laying down detailed rules for applying Council Regulation No. 1234/2007 as regards community aid for supplying milk and certain milk products to pupils in educational establishments (Regulation No. 657/2008). Brussels: European Commission.

EC. (2010). Strategy for Europe on nutrition, overweight and obesity related health issues. Implementation progress report, December 2010. Brussels: European Commission.

Golan, M., \& Crow, S. (2004). Parents are key players in the prevention and treatment of weight-related problems. Nutr Rev, 62(1), 39-50.

Heck, R. H., \& Thomas, S. L. (2009). An introduction to multilevel modeling techniques. New York: Routledge.

Hendy, H. (1999). Comparison of five teacher actions to encourage children's new food acceptance. Ann Behav Med, 21(1), 20-6.

Hendy, H. M. (2002). Effectiveness of trained peer models to encourage food acceptance in preschool children. Appetite, 39(3), 217-25.

Hendy, H. M., \& Raudenbush, B. (2000). Effectiveness of teacher modeling to encourage food acceptance in preschool children. Appetite, 34(1), 61-76. 
Holsten, J. E., Deatrick, J. A., Kumanyika, S., Pinto-Martin, J., \& Compher, C. W. (2012). Children's food choice process in the home environment. A qualitative descriptive study. Appetite, 58(1), 64-73.

Hox, J. (2002). Multilevel analysis: techniques and applications. Mahwah: Lawrence Erlbaum Associate.

Jensen, K. O., \& Holm, L. (1999). Preferences, quantities and concerns: socio-cultural perspectives on the gendered consumption of foods. Eur J Clin Nutr, 53(5), 351-9.

Kelder, S. H., Perry, C. L., Klepp, K. I., \& Lytle, L. L. (1994). Longitudinal tracking of adolescent smoking, physical activity, and food choice behaviors. Am J Publ Health, 84(7), 1121-6.

Kemm, J. R. (1987). Eating patterns in childhood and adult health. Nutr Heal, 4(4), 205-15.

Koehler, J., \& Leonhaeuser, I.-U. (2008). Changes in food preferences during aging. Ann Nutr Metab, 52, 159.

Larson, N. I., Neumark-Sztainer, D., Harnack, L., Wall, M., Story, M., \& Eisenberg, M. E. (2009). Calcium and dairy intake: longitudinal trends during the transition to young adulthood and correlates of calcium intake. J Nutr Educ Behav, 41(4), 254-60.

Lien, N., Lytle, L. A., \& Klepp, K.-I. (2001). Stability in consumption of fruit, vegetables, and sugary foods in a cohort from age 14 to age 21. Prev Med, 33(3), 217-26.

Maes, L., \& Lievens, J. (2003). Can the school make a difference? A multilevel analysis of adolescent risk and health behaviour. Soc Sci Med, 56(3), 517-29.

Mensink, G. B., Richter, A., Vohmann, C., Stahl, A., Six, J., Kohler, S., et al. (2007). EsKiMo-Das Ernährungsmodul des Kinder-und Jugendgesundheitssurveys (KiGGS). Neu-Isenburg: Springer Gesundheits- und Pharmazieverlag.

MRI. (2011). Ergebnisbericht - Einflussfaktoren auf die Nachfrage nach Schulmilch in Grundschulen in Nordrhein-Westfalen. Karlsruhe: Max Rubner-Institut. (http://www.mri.bund.de/fileadmin/Institute/EV/ Schulmilch/Schulmilch NRW 020212.pdf). Accessed 16 May 2013.

Nicklas, T. A., Baranowski, T., Baranowski, J. C., Cullen, K., Rittenberry, L., \& Olvera, N. (2001). Family and child-care provider influences on preschool children's fruit, juice, and vegetable consumption. Nutr Rev, 59(7), 224-35.

$\mathrm{Nu}$, C. T., MacLeod, P., \& Barthelemy, J. (1996). Effects of age and gender on adolescents' food habits and preferences. Food Qual Prefer, 7(3-4), 251-62.

Raudenbush, S. W., \& Bryk, A. S. (2002). Hierarchical linear models: applications and data analysis methods. Thousand Oaks: Sage Publications.

Reinaerts, E., de Nooijer, J., Candel, M., \& de Vries, N. (2007). Explaining school children's fruit and vegetable consumption: the contributions of availability, accessibility, exposure, parental consumption and habit in addition to psychosocial factors. Appetite, 48(2), 248-58.

Reisch, L. A., \& Gwozdz, W. (2010). The impact of consumer behavior on the development of overweight in children. An overview. Bundesgesundheitsblatt Gesundheitsforschung Gesundheitsschutz, 53(7), 725-32.

Robinson, J. S. (1978). Special milk program evaluation and national school lunch program survey. Washington, DC: U.S. Department of Agriculture, Food and Nutrition Service.

Roos, E., Lehto, R., \& Ray, C. (2012). Parental family food choice motives and children's food intake. Food Qual Prefer, 24(1), 85-91.

Salamon, P., Pfau, C., Grillenberger, M., Christoph, I. B., Straßburg, A., Weber, S. A., et al. (2010). School milk demand: design and first results of the German federal research project "Focus on school milk". vTI Agric For Res, 60(1), 1-10.

Salvy, S.-J., de la Haye, K., Bowker, J. C., \& Hermans, R. C. J. (2012). Influence of peers and friends on children's and adolescents' eating and activity behaviors. Physiol Behav, 106(3), 369-78.

Salvy, S.-J., \& Pliner, P. P. (2010). Chapter 50-Social influences on eating in children and adults. In D. Laurette, B. Antoine, D. Alain, D. Adam, L. Jordan, J. Philip, \& Y. Y. Rickey (Eds.), Obesity prevention (pp. 617-27). San Diego: Academic Press.

Salvy, S.-J., Vartanian, L. R., Coelho, J. S., Jarrin, D., \& Pliner, P. P. (2008). The role of familiarity on modeling of eating and food consumption in children. Appetite, 50(2-3), 514-8.

Snijders, T. A. B., \& Bosker, R. J. (2003). Multilevel analysis: an introduction to basic and advanced multilevel modeling. London: Sage.

Story, M., Neumark-Sztainer, D., \& French, S. (2002). Individual and environmental influences on adolescent eating behaviors. J Am Diet Assoc, 102(3, Supplement), 40-51.

Sweeting, H. (2008). Gendered dimensions of obesity in childhood and adolescence. Nutr J, 7(1), 1-14.

Vereecken, C., Huybrechts, I., Maes, L., \& De Henauw, S. (2008). Food consumption among preschoolers. Does the school make a difference? Appetite, 51(3), 723-6.

Vereecken, C. A., Van Damme, W., \& Maes, L. (2005). Measuring attitudes, self-efficacy, and social and environmental influences on fruit and vegetable consumption of 11- and 12-year-old children: reliability and validity. J Am Diet Assoc, 105(2), 257-61. 
vTI. (2011). Endbericht-Ökonomische Begleitforschung zum Bundesmodellvorhaben "Schulmilch im Fokus", Projekt des BMELV. Braunschweig: Johann Heinrich von Thünen-Institut. (http:// www.ti.bund.de/fileadmin/dam_uploads/Institute/MA/Aktuelles_und_Service/Endbericht\%20$\% 20 \%$ C3\%96konomische\%20Begleitforschung\%20 zum $\% 20 \bar{B}$ undesmodellvorhaben $\% 20$ \%20Schulmilch\%20im\%20Fokus.pdf. Accessed 16 May 2013.

Weber Cullen, K., Baranowski, T., Rittenberry, L., Cosart, C., Hebert, D., \& Moor, C. (2001). Child-reported family and peer influences on fruit, juice and vegetable consumption: reliability and validity of measures. Heal Educ Res, 16(2), 187-200.

Weible D., Buergelt D., Christoph I. B., Peter G., Rothe A., Salamon P., Weber S. A. School milk demand in Germany: individual as well as contextual factors play a major role-preliminary results. Selected paper prepared for presentation at the EAAE 2011 Congress "Change and Uncertainty; challenges for agriculture, food and national resources”, Zurich, Switzerland; 2011

Weindlmaier, H., \& Fallscheer, T. (1997). Schulmilchversorgung in Deutschland: Situation, Problembereiche, Ansatzpunkte für eine Erhöhung des Distributionsgrades. Special Publication of the Trade Association for Carton Packaging of Liquid Foodstuffs (FKN). Wiesbaden.

WHO. (2012a). Regional Office for Europe. The double burden of nutritional diseases - a global challenge. Geneva: World Health Organisation.

WHO. (2012b). Regional Office for Europe. European Childhood Obesity Surveillance Initiative (COSI). Geneva: World Health Organisation.

Wind, M., de Bourdeaudhuij, I., te Velde, S. J., Sandvik, C., Due, P., Klepp, K. I., et al. (2006). Correlates of fruit and vegetable consumption among 11-year-old Belgian-Flemish and Dutch schoolchildren. J Nutr Educ Behav, 38(4), 211-21. 


\subsection{Youths' preferences for milk products at school: How product} attributes and perceived body image affect choices

Inken Christoph-Schulz, Daniela Weible, Petra Salamon

Appetite, submitted 2014 


\title{
Youths' preferences for milk products at school: How product attributes and perceived body image affect choices
}

\author{
Inken Christoph-Schulz, Daniela Weible, Petra Salamon \\ Thünen Institute of Market Analysis, Bundesallee 50, 38116 Braunschweig, Germany
}

\begin{abstract}
Snacks and lunches offered at school can decisively influence children's dietary habits.

In the light of discussions to establish prevention and intervention programs to abate current trends of rising childhood obesity, children's preferences for food items with lower calorie content gain on importance. But youths preferences concerning different school milk products are not well-known. Therefore, the objective is to investigate if the milk products offered at school still meet older children's preferences or if modifications could prove to be useful. Based on outcomes of an online survey covering a choice experiment and conducted among juveniles in Germany a nested logit model is used to estimate the probability that youths benefit from different products as well as varying prices, sugar and fat contents. Socio-demographics, psycho-metrics and perceived weight status are employed to explain youths choices preferring novel school milk products yet unavailable in German schools. Results of the choice experiment show that youths aged 15-18 prefer a wider range of different products including drinking yoghurt as an option as well. Also results indicate that nutritional aspects (low sugar/fat content, artificial sweetener) as well as the taste aspect are important for successful modifications.
\end{abstract}

Keywords: school milk, youths, preferences, choice experiment, nested logit model, body image

\section{Introduction}

Childhood is the time when dietary habits are decisively formed or when food preferences can be modified through, for example, the availability of food within families, role modelling or nutrition education. The development of healthy eating patterns during childhood is of particular importance, as childhood obesity has become one of the most serious public health challenges of the $21^{\text {st }}$ century (WHO, 2007). Studies show that eating habits and nutrition behaviour are almost resistant to dietary changes attempted after adolescence (KELDER ET AL., 1994:1121; KEMM, 1987:210; KÖSTER, 2009; LIEN ET AL., 2001:217). Therefore, healthy food items as components of a balanced diet should match children's tastes and preferences. In addition to a healthy diet, lower-calorie foods might be helpful for overweight children and youths. However, the question remains as to which occasions contribute to shaping children's dietary habits.

In addition to family meals, snacks and lunches offered at school can decisively influence children's dietary habits (CRAWFORD ET AL., 2008; STORY ET AL., 2002; VEREECKEN ET AL., 2008:723). These offerings can be regarded as one of the prime vehicles for influencing the development of childhood obesity (CRAWFORD ET AL., 2008). Hence, in Germany, the German Nutrition Society (DGE) emphasises that school catering should focus on creating an environment for optimal concentration and learning as well as on providing a balanced diet. Such measures can assist in forming or modifying children's food preferences, preserve health and prevent chronic disease (DGE, 2013:10). Children are freer to decide what they want to eat at school than they are at home. At home, children's food choices are strongly influenced by what their parents buy or prepare, although children often provide suggestions. Some parents even control whether their children actually eat what they are supposed to eat. At school, children can make their own eating decisions. Children can trade food with friends, decide whether and how much food to buy at school, or even dispose of food that they do not 
want to eat. It is nearly impossible for parents to control what their children eat at school. Thus, it is assumed that children reveal their real food preferences at school as long as peer influence is limited.

One type of product regularly offered at school is milk or milk products. Milk has been provided in schools since the conclusion of the Second World War. Milk is an important part of a child's diet for several reasons: milk contains significant amounts of calcium, milk protein has high biological value, and milk fat is easily digestible (BIESALSKI ET AL., 1999; DGE, 2008). Because of the special nutritional requirements of children and adolescents, milk and milk products are essential dietary staples, as they provide important nutrients in a relatively optimal combination (HEINE, 1999). The importance of dairy consumption during childhood to ensure sufficient calcium intake and, in turn, optimal bone development and general good health has been particularly emphasised (JACOBSON, 1961; Promar InTERNATIONAL, 2002). Although the dairy consumption of younger children tend to be nearly sufficient, consumption often declines with age and often becomes insufficient (MENSINK ET AL., 2007A). Moreover, girls consume less dairy than boys do. With regard to milk, yoghurt and similar products, the so-called "Eskimo study" indicates higher dairy consumption by boys aged 6 to 11 years and 12 to 17 years than girls of the same age (MENSINK ET AL., 2007A). Gender-specific differences in the breakfast behaviour of German pupils were described by WEINDLMAIER AND FALLSCHEER (1997). Approximately 10\% more boys than girls drink milk as part of breakfast. Furthermore, girls seldom consume milk at school (WEIBLE, 2013). On average, the calcium consumption of German children under 18 years of age is insufficient, and it is particularly low for girls (MENSINK ET AL., 2007b; DGE, 2008), with 74\% of girls and 51\% of boys aged 14 and 18 failing to consume the recommended amounts (MRI, 2008: 259). Calcium intake in the US is even worse: $65 \%$ of boys and $87 \%$ of girls aged 12 to 19 do not consume the recommended daily level of $1,300 \mathrm{mg}$ of calcium (WILSON ET AL., 1997).

Based on the above-mentioned figures, this article focuses on milk drinks offered to pupils at school. The paper's objective is to investigate whether the products offered at school meet older children's preferences and expectations and, if they do not, whether modifications to school meals should be made. Therefore, youths aged 15 to 18 are surveyed concerning their preferences for milk products that are currently unavailable within the school milk programme in Germany. Milk products currently available within the German school milk programme are also included, as they serve as a reference for children's preferences. For topical reasons, the paper will examine whether and to which extent fat and sugar content is relevant to children's preferences. In particular, the question of whether overweight youths choose calorie-reduced products more often than normal-weighted youths is examined. Knowing youth's preferences among different school milk products is of interest for several reasons; for example, producers can adapt the products supplied according to children's preferences and expectations. However, this article primarily aims to design and target an appropriate and effective intervention programme for improving children's nutrition and educating children about food. In addition, the paper aims to determine whether milk products offered in German primary schools still meet children's preferences or whether children require other products milk products compared with secondary school youths (LOUIE ET AL., 2011).

This article is structured as follows. Section 2 provides additional information as to why one can question whether the milk products currently offered in schools actually satisfy the needs of pupils. Section 3 discusses the paper's methodological approach. Section 4 presents the results, and Section 5 discusses their implications. The final section provides a brief conclusion. 


\section{Background}

\section{Limited product range within the EU School Milk Programme and within schools}

The provision of subsidised milk and milk products in educational establishments through specific programmes, such as the EU School Milk Scheme and the National School Lunch Program (NSLP) in the US, is one option for increasing adolescent milk consumption. The EU School Milk Scheme has been part of the market price support within the Common Agriculture Policy since 1977. Although the original programme was implemented as a marketing aid, its objective was subsequently broadened. Thus, the EU Commission aims to improve the nutrition of children and to educate them about food (EC, 2007; EC, 2008; EEG, 1977). The EU School Milk Scheme strictly regulates which products can be sold as subsidised school milk (EC 2007; EC 2008). "School milk" comprises a range of subsidised dairy products provided in schools and other educational institutions, including plain milk, flavoured milk $^{1}$, yoghurt and cheese. Some EU member states, such as Germany, restrict the number of permitted milk products ${ }^{2}$. Although artificially sweetened milk products have been allowed in the EU School Milk Scheme since 2008 (EC, 2008), the German School Milk Programme does not permit them. Milk and flavoured milk drinks with fat content of $1.5 \%$ or $3.5 \%$ and various amounts of sugar are currently offered to German schoolchildren (SALAMON ET AL., 2012). In general, schools are supplied by only one dairy company, and only that company's products are offered. Although milk with varying levels of fat can be distributed in schools, children often cannot choose which milk fat levels to buy because the distributor normally does not supply school milk with different fat levels. The same holds true for the sugar content and flavour of milk products. The rationale behind the limited fat, sugar and flavour content of school milk products is high production and distribution costs combined with relatively small profit margins. For further information on other relevant problems concerning school milk supply and demand, please see the works of WEINDLMAIER AND FALLSCHEER (1997), WiETBRAUK (1976) and SALAMON ET AL. (2012).

\section{General nutrition guidelines for German children differing from observed children's preferences}

In Germany, dietary recommendations for school catering are provided by the German Nutrition Society (DGE) and supported by the German Federal Ministry of Food and Agriculture (BMEL). These bodies recommend daily consumption of milk and milk products as part of lunch and snacks. Although milk and milk products are important in children's diets, the DGE notes that they can be high in fat and sugar and consequently recommends the consumption of only half-fat and unsweetened milk products (DGE, 2013). However, sales of plain milk drinks in schools are low. Few schools offer plain milk as the only milk product for purchase. Examining children's preferences and real milk demand, a German study of school milk showed that only $3.8 \%$ of pupils aged 7 to 10 choose plain milk, whereas $26.5 \%$ choose flavoured milk. Moreover, pupils more often choose flavoured and sweetened milk despite the lower cost of plain milk (SALAMON ET AL., 2010).

A similar picture emerges among children in the US: chocolate is the preferred milk flavour, and although plain milk is available, it is typically the least popular choice (JOHNSON ET AL., 2002). Are children who drink sweetened and flavoured milk more unhealthy than those who consume only plain milk? Studies in the US and Australia have produced ambiguous results, finding that children who drink only plain milk do not achieve the daily recommendation for milk consumption, whereas children who drink flavoured milk do achieve the daily recommendation. There was no difference in BMI between children who consumed flavoured milk and children who consumed soft drinks.

\footnotetext{
${ }^{1}$ Milk flavoured with chocolate or fruit juice or aromatised with $90 \%$ milk and an additive of maximum $7 \%$ sugar and/or honey (Commission of the European Union, 2008).

${ }^{2}$ For details on the German programme, see BMELF (1985).
} 
However, children who consumed flavoured milk had a greater supply of micronutrients than children who consumed plain milk or soft drinks (FAYET ET AL., 2013; JOHNSON ET AL., 2002; MURPHY ET AL., 2007; MURPHY ET AL. 2008). In summary, whether a child consumes plain milk, flavoured milk or soft drinks does not affect BMI. However, children who consume flavoured milk are those who achieve the daily recommendations for micronutrients. Another study depicting the positive effects of flavoured milk drinks was conducted by PORUBCAN AND VICKERS (2005), who found that people who do not like to drink milk in general are more tolerant of flavoured milk with added sugar than they are of plain milk.

\section{Changing preferences during adolescence}

There is considerable evidence that children like milk products. The wide variety of milk products, ranging from those with low to high sugar amounts or from skimmed or half fat to full fat and with a range of flavours, provides a good opportunity to reach a high proportion of children as consumers. However, changing preferences during adolescence requires a well-adapted product range. Satisfying the preferences of secondary school children is particularly difficult. Compared with younger children, adolescents are more likely to try new food items, to expand the range of products that they consume and to change their preferences. This observed difference fuels the on-going discussion that school milk no longer satisfies children's preferences and that primary school children require different products than secondary school children (LOUIE ET AL., 2011).

However, it is unclear which products children actually want to consume at school. WEIBLE ET AL. (2013) showed that out of a sample of 7,336 surveyed children visiting primary schools, $43 \%$ consume school milk at regular prices and $81 \%$ consume milk if it is free of charge. Do the remaining $19 \%$ of children dislike milk products? Would they consume other milk products that are currently not offered in schools? Would these children like more sugar or artificially sweetened milk products, or do they prefer fatty or skimmed milk products? Do they want to drink milk, or do they prefer to eat yoghurt? To increase demand for milk and milk products at school, children's preferences must be matched with the products offered because the level of consumption is influenced by individual preferences (BAXTER ET AL. 2000), especially taste and convenience (NOBLE ET AL., 2003).

\section{Method}

This article proceeds from the assumption that preferences for different products and product attributes can be revealed by analysing choice behaviour. When products are affordable, consumers generally choose the product that satisfies them the most. In other words, consumers choose the product that provides the maximum utility. The same holds true for pupils, who are also consumers. To measure this product utility, a choice experiment is applied in this paper. Further, a nested logit model is applied to compare children who always choose conventional school milk with those who choose new products. How can utility analysis be explained according to our example?

\section{Utility analysis}

The starting point for utility analysis is consumer preferences, which are preferences for school milk in this case. A product's attributes are used to determine consumer preference for it. Such preferences include the type of product (drinking milk versus yoghurt), fat and/or sugar content, price, flavouring and the type of sweetener. The characteristics of the attributes and their levels may differ across various products. In Germany, for instance, milk typically has a fat content of 3.5\%, $1.5 \%$ or $0.3 \%$, and milk drinks and yoghurt are sweetened with sugar or artificial sweetener. It is assumed that consumers will compare the different alternatives offered in the decision-making process. Finally, 
consumers choose the product that has the best combination of attributes and attribute levels; in other words, they choose the products that provide the maximum utility. One consumer may prefer low-fat content, another prefers the variety with the lowest price, and a third type cares about the flavour or the brand. For example, out of 20 different types of yoghurt, the strawberry yoghurt from company $\mathrm{X}$ with $1.5 \%$ fat that is sweetened with sugar and that is $250 \mathrm{~g}$ for 65 cents will be chosen.

Lancaster was the first to establish this concept of attributes and levels in the 1960s (LANCASTER, 1966) as a new approach to consumer theory. McFadden extended this approach in the 1970s using his random utility model (MCFADDEN, 1974). Both Lancaster and McFadden described the alternatives chosen by using a number of attributes, $k$. Individual $n$ chooses alternative $i$, resulting in utility $U_{n i}=U$ $\left(X_{k i}\right)$, where $X_{k i}$ is a vector describing the attributes embedded in alternative $i$. Applying random utility models, utility is composed of a deterministic and a random part $U_{n i}=V_{n i}+\varepsilon_{n i}$. Here, $V_{n i}=f\left(X_{n i}\right)$ is deterministic and depends on the product attributes, whereas $\varepsilon_{n i}$ represents the random component. Total product utility is the sum of all single utilities that arise from different attributes:

$U_{n i}=\sum_{k=1}^{K}\left(\beta_{n k} * X_{n k}\right)+\varepsilon_{n i}$

(HENSHER ET AL., 2006:74 PP; LOUVIERE, 2001).

$\beta$ presents a weighting of the regarded attribute. Larger $\beta$ indicates higher attribute utility. Negative $\beta$ indicates an adverse effect. Thus, the regarded attribute will decrease overall product utility.

The attributes selected for this study are listed in Table 1. The content levels were chosen based on widely available products in Germany and other countries. The types of products are milk drinks and yoghurt. Milk drinks are the most prevalent milk products sold in schools, but yoghurt is also available. This paper will evaluate whether there is a need to broaden the milk product range sold in schools. The fat content of the products is $0.3 \%, 1.5 \%$ and $3.5 \%$. These levels are the typical fat content levels for milk and yoghurt in Germany. The sweetening agent was chosen as an attribute, as children may already be accustomed to this attribute.

\begin{tabular}{ll}
\hline Attribute & Levels \\
\hline Products & Novel school milk, yoghurt, conventional school milk \\
Price (in cents) & $30,35,40$ \\
Fat content & $0.3 \%, 1.5 \%, 3.5 \%$ \\
Sweetening agent & Sugar, artificial sweetener \\
\hline
\end{tabular}

Source: Own illustration.

Table 1: Attributes and attribute levels.

Furthermore, sweetening agents are permitted within the EU school milk scheme but not in the German school milk programme. One aim of this study is to evaluate whether there is a need for sweetened products within school catering. Price was included as an attribute to simulate a shopping situation. The average price of school milk in Germany is 35 cents for $250 \mathrm{ml}$. To avoid placing excessive strain on the respondents, no other attributes were chosen. As previously mentioned, schools are typically catered by only one dairy company. Consequently, we did not include attributes such as brand or type of packaging. Overall, novel products represent those products that are not currently sold as school milk.

\section{Choice Experiments}

In addition to determining the willingness to pay, the measurement of product utility is the other major purpose of choice experiments (CEs). LOUVIERE (2001: 17) described CEs as follows: "CE typically 
are designed to elicit preferences such that as wide an array of possible choice model forms can be estimated from the resulting choice data". CEs are a type of stated preference method that arose out of conjoint analysis. In contrast to the latter, the respondents in CE methods do not rank or rate the different alternatives; rather, they must decide on one of several alternatives (ADAMOWICZ ET AL., 1998; LOUVIERE, 2001). After initially being used almost exclusively for transportation problems (BEN-AKIVA and LERMAN, 1974; Ben-AKIVA, 2000; MCFADDEN, 1999; MoreY and Rowe, 1993), CEs are now being applied in other research areas, such as environmental economics (ADAMOWICZ ET AL., 1997; HANLEY ET AL., 1998A) and food consumption (LUSK ET AL., 2003; LUSK AND SCHROEDER, 2004). CEs are not the only method for measuring product utility, but they have several advantages compared with other methods: (i) it is easier for respondents to choose the most preferred product rather than ranking many different alternatives, as in a conjoint analysis (ADAMOWICZ ET AL., 1998; HAIR et al., 1998:394); (ii) CEs are less susceptible to respondents' strategic behaviour, which is a major problem in contingent valuation method applications (BREYER ET AL., 2005:61); and (iii) compared with the alternative methods, it is easier to check for internal consistency, to compute single attribute parameters, to detect substitutive relationships between different attributes and to allow for heterogeneity among respondents using different econometric models (HANLEY ET AL., 1998a). Following HANLEY ET AL. (1998b), choice experiments should be the favoured method to assess particular attributes.

Choice scenarios were constructed using orthogonal main-effects designs (compare HENSHER ET AL., 2006:116), which led to 27 product combinations. To facilitate the decision-making process, the number of choices was limited to three.

In the following example, models for analysing choice experiments are based on the utility analysis presented above. The models analyse the probability that an individual chooses a special product out of the presented products. Additionally, it is assumed that the individual chooses the product that offers the highest degree of utility. The probability of choosing product $\mathrm{i}$ out of $\mathrm{J}$ is

$\operatorname{Pr}(i \mid J)=\operatorname{Pr}\left(\left(V_{i}+\beta_{i}\right) \geq\left(V_{j}+\beta_{j}\right)\right) ; \forall j \in j=1,2, \ldots, J ; i \neq j$

(Hensher ET AL. 2006:82).

Choice experiments can be analysed with different models, such as multinomial, nested or mixed logit models (RYAN AND SKATUM, 2004; CAMPELL ET AL., 2008). One major purpose of our analysis is to explain why some respondents are more likely to choose the novel milk products with reduced fat content or artificial sweeteners. Following VON HAEFEN ET AL. (2005), a nested logit model (NL) is appropriate in this case.

\section{Nested Logit Model}

The utility function $U_{n i}=V_{n i}+\varepsilon_{n i}$ discussed earlier is the starting point for the NL. The underlying idea is graphically shown in Figure 1. The basic assumption in the case of school milk consists of one segment that contains no novel product and another segment that contains both novel and conventional school milk. Thus, the decision tree shows that the purchase of a product is based on two different decisions: the first decision is the general decision to buy or not buy a novel product. If this question is answered positively, then the next question is the selection of the most favoured product based on the product attributes. Thus, the following analysis is based on the assumption that different product alternatives can be divided into different segments. 


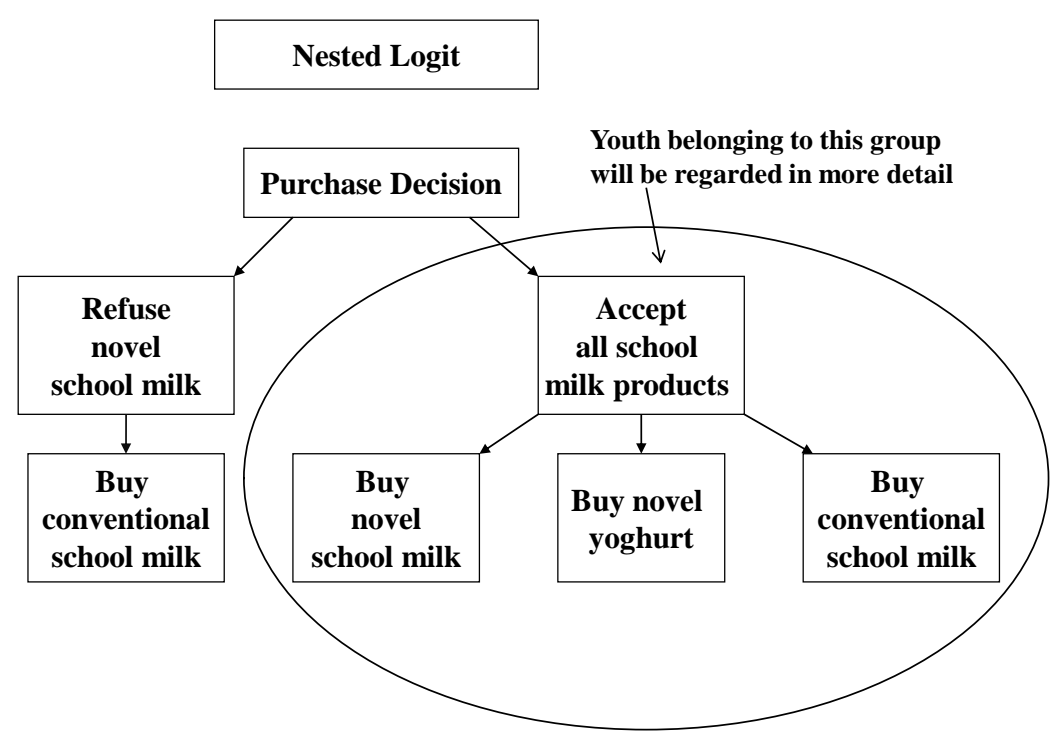

Source: Based on RYAN AND SKÅTUN (2004).

Figure 1: Decision process.

The total utility is $U_{s i}=V_{s i}+\varepsilon_{s i}$, where $s$ describes the different segments $(\mathrm{s}=1, \ldots, \mathrm{S}$, in our case: "refuse novel school milk" versus "accept all school milk products"). The probability $\operatorname{Pr}$ that a particular alternative of a particular segment is chosen results from the arithmetic product of the probability that alterative $i$ from segment $s$ is chosen and the probability that segment $s$ is chosen.

$P r_{s i}=P_{i \mid s} * P_{S}$

Using a logit model, we can write this decision problem as follows:

$\operatorname{Pr}_{i \mid s}=\frac{e^{V_{s i}}}{\sum_{i=1}^{I} e^{V_{s i}}}$

In estimating $\mathrm{Pr}_{\mathrm{S}}$, we must consider two different decision problems. The first is the decision of whether a novel product is accepted in general, and the second is the particular purchase decision. These two decisions can be linked using the concept of expected maximum utility (=EMU), which is also known as inclusive value (IV-Parameter). The IV-Parameter describes the degree of substitution between the offered alternatives. Formally, the IV-Parameter can be noted as follows:

$I V_{S}=\ln \sum_{i=1}^{I} \exp ^{V_{s i}}$

After this parameter is integrated into the mentioned product groups (conventional versus all products), a consumer's probability of choosing segment $s$ is the following:

$P r_{S}=\frac{e^{\left(V_{S}+I V_{S}\right)}}{\sum_{S=1}^{S} e^{e\left(V_{S}+I V_{S}\right)}}$

(HENSHER ET AL., 2006:479PP; LOUVIERE ET AL., 2000:186; TUTZ, 2000:194; URBAN, 1993:141).

An IV-Parameter within the $[0,1]$ boundary is the sufficient condition for NL. Thus, the decision to buy the conventional product or one of the novel products is influenced by the expected product utility. 
Those who refuse to choose one of the presented products are not included in Figure 1. These individuals are also excluded when analysing the NL model.

\section{Results}

\subsection{Data and descriptive results}

The data used in the analysis were collected from an online survey developed in autumn 2010 and completed by 509 German youths aged 15 to 18 years. Because cognitive pretesting showed that children under the age of 15 were overstrained by the CE, these children will not be considered in this analysis ${ }^{3}$. This finding is not surprising considering that Ward and Wackman (1972) and John (1999) published similar outcomes regarding children's competence in making purchasing decisions and judging various product attributes. The participants were equally distributed with regard to age, gender and region. The questionnaire consisted of three parts. The first part included information on regularly consumed milk products, preferred product attributes and general attitudes towards milk products and nutrition. Additionally, the question of whether the youths viewed themselves as overweight or too thin was posed. The second part consisted of a CE in which the respondents had three options in each decision: two novel school milk products (novel school milk and yoghurt) and one conventional milk product (conventional school milk). The conventional milk product was a type of school milk that is widely offered in German schools and was provided as a constant "opt-out" option in all sets. A sample question from the CE is provided in Table 2.

\begin{tabular}{|c|c|c|c|}
\hline \multicolumn{4}{|c|}{ Please check the option $(\mathrm{A}, \mathrm{B}$, or $\mathrm{C})$ that you would most likely purchase. } \\
\hline Product attribute & $\begin{array}{c}\text { Novel school milk } \\
250 \mathrm{ml}\end{array}$ & $\begin{array}{l}\text { Novel yoghurt } \\
150 \mathrm{ml}\end{array}$ & $\begin{array}{c}\text { Conventional school milk } \\
\qquad 250 \mathrm{ml}\end{array}$ \\
\hline Price in cents & 40 & 30 & 35 \\
\hline Fat content & $0.3 \%$ & $1.5 \%$ & $3.5 \%$ \\
\hline Sweetening agent & sweetener & Sugar & sugar \\
\hline I would choose...... & $\square$ & $\square$ & $\square$ \\
\hline
\end{tabular}

Table 2: Sample choice experiment question.

The third part of the questionnaire contains socio-demographic variables, such as age, gender, household size, (im)migration background, school year and type of school.

Table 3 presents some descriptive characteristics of the dataset. Because of space limitations, only the variables that were proven to have a significant influence on choice behaviour or that were regarded as having a significant influence after the literature review are presented. For the respondents in our sample, $50 \%$ are female, the mean age is 16.28 years, the mean household size is 3.64 persons, and the mean number of brothers and sisters is 0.73 . A total of $7 \%$ of the respondents may have had a migration background, as they indicated that a language other than German was spoken at home. Moreover, $60 \%$ of the youths assessed themselves as having a normal weight, $31 \%$ as overweight and $9 \%$ as underweight. Being overweight appeared to be a more important topic then being underweight in the self-assessment. Nevertheless, it cannot be determined whether these youths are actually overweight based on their self-assessment.

${ }^{3}$ Children aged 10 to 14 years completed a pair comparison; the results can be found in Christoph et al. (2012). 


\begin{tabular}{|c|c|}
\hline Variable & Youths \\
\hline Gender ( 1 if male, 0 if female) & $50.0 \%$ \\
\hline Mean age (in years) & 16.28 years \\
\hline Mean household size (in persons) & 3.64 persons \\
\hline Number of brothers and sisters (in persons) & 0.73 persons \\
\hline Immigration background ( 1 if appropriate) & $7.0 \%$ \\
\hline My figure is ok ( 1 if appropriate) & $60.0 \%$ \\
\hline Think I'm too corpulent ( 1 if appropriate) & $31.0 \%$ \\
\hline Think I'm too thin ( 1 if appropriate) & $9.0 \%$ \\
\hline Low fat content is important ( 1 if appropriate) & $47.0 \%$ \\
\hline Low sugar content is important ( 1 if appropriate) & $55.0 \%$ \\
\hline Low calorie content is important ( 1 if appropriate) & $44.0 \%$ \\
\hline Low price is important ( 1 if appropriate) & $73.0 \%$ \\
\hline Product brand is important ( 1 if appropriate) & $23.0 \%$ \\
\hline I like milk products ( 1 if appropriate) & $92.0 \%$ \\
\hline Would like to eat milk products daily ( 1 if appropriate) & $78.0 \%$ \\
\hline I'm interested in a healthy nutrition ( 1 if appropriate) & $67.0 \%$ \\
\hline Care about good nutrition ( 1 if appropriate) & $63.0 \%$ \\
\hline My parents take care that I consume enough milk products ( 1 if appropriate) & $68.0 \%$ \\
\hline Might buy milk products at school ( 1 if appropriate) & $76.0 \%$ \\
\hline Consume milk product at school ( 1 if appropriate) & $56.0 \%$ \\
\hline $\begin{array}{l}\text { Given a range of flavoured and plain milk products, I would choose a plain milk product } \\
\text { (1 if appropriate) }\end{array}$ & $7.3 \%$ \\
\hline
\end{tabular}

Source: Own calculations.

Table 3: Sample characteristics.

We used a 4- or 5-point Likert scale for questions on attitudes towards and preferences for milk products and on relevant aspects regarding nutrition in general and milk products in particular. The participants had the choice of agreeing, disagreeing or being indifferent within the 5-point Likert scale. Approximately half of the youths stated that low fat, low sugar or low calorie content is important regarding milk products. Low sugar content was the highest priority, followed by low fat content, while low calorie content was the lowest priority (44\%). Low product price was important for three-quarters of the respondents, and the product brand was rated as important for approximately onequarter of the respondents. Most of the respondents liked milk products (92\%) and/or would like to consume them daily (78\%). Approximately two-thirds were interested in good nutrition and/or paid attention to nutrition. Most of the respondents also stated that their parents ensured that they consumed sufficient milk products. Of the respondents, $76 \%$ had the opportunity to buy milk products at school, and $56 \%$ stated that they consumed milk products at school (brought from home or purchased at school). Furthermore, $7.3 \%$ of the respondents stated that they would choose a plain milk product (milk, yoghurt or buttermilk) if they could choose only one product (flavoured milk drinks, yoghurt, pudding and curd were also offered).

\subsection{Econometric results}

In the choice experiment, 24 youths (4.7\%) refused to choose any of the three presented products. Their primary reasons were the ingredients (because of the sugar, fat, artificial sweetener or lactose) or a general refusal of (the presented) milk products. Hence, an NL estimation was conducted with 485 
youths (1,419 choices in total). A product with artificial sweetener was chosen 278 times, and a reduced-fat product was chosen 663 times. The results are presented in Table 3.

\begin{tabular}{lccc}
\hline Parameter & Scale & Coefficient & Standard Deviation \\
\hline Utility from school milk & & & \\
Constant of novel school milk utility & Metric & $0.776^{* * *}$ & 0.098 \\
Constant of novel yoghurt utility & Metric & $0.256^{* *}$ & 0.103 \\
Price & Categorical & $-0.086^{* * *}$ & 0.011 \\
Artificial sweetener as sweetening agent & Dummy & $-0.280^{* * *}$ & 0.093 \\
Fat content & Categorical & -0.050 & 0.033 \\
Factors that influence the probability of choosing & novel school milk & & \\
Constant & Metric & $1.191^{* * *}$ & 0.714 \\
Number of brothers and sisters & Metric & $-0.249^{* * *}$ & 0.084 \\
Perceived overweight & Dummy & $0.733^{* * *}$ & 0.216 \\
Low fat content is important & Dummy & $0.561^{* *}$ & 0.222 \\
Low sugar content is important & Dummy & $0.860^{* * *}$ & 0.212 \\
Low price is important & Dummy & $-0.425^{* *}$ & 0.196 \\
Like milk products & Dummy & $0.935^{* * *}$ & 0.344 \\
Would like to eat milk products daily & Dummy & $-0.660^{* *}$ & 0.269 \\
Care about good nutrition & Dummy & $-0.493^{* * *}$ & 0.181 \\
Given a range of flavoured and plain milk & Dummy & $-0.958^{* * *}$ & 0.267 \\
products, I would choose a plain milk product & & & \\
\hline
\end{tabular}

$*$ Significance Level $=0.1 ; *$ Significance Level $=0.05 ; * * *$ Significance Level $=0.01$.

IV-Parameter non-refusers: $-0.007 ; \mathrm{R}^{2}: 0.248$

Source: Own calculations.

Table 4: Results of NL Estimation.

The model explains $25 \%$ of the total variance. The $\mathrm{R}^{2}$ derived from choice models cannot be directly be compared to the $\mathrm{R}^{2}$-statistic of linear regression models. Following Hensher et al. (2006:338), $\mathrm{R}^{2}$ can be translated into an $\mathrm{R}^{2}$ of a linear regression model of between 0.55 and 0.60 .

The IV-Parameter remains within the $[0,1]$ bound but is not significant. Following Hensher et al. (2006:547), the Wald test, a one-sample t-test, must be subsequently performed in this case. This method tests the hypothesis of whether the IV-Parameter is statistically equal to zero by dividing the IV-Parameter by the standard deviation. The critical value is \pm 1.96 for the $95 \%$ confidence interval.

$\frac{\text { IV - Parameter }}{\text { Standard deviation }}=\frac{-0.007}{0.383}=-0.018$

With a value of -0.018 , the statistic is below the critical value of 1.96 . This result implies that the null hypothesis that the IV-Parameter is equal to zero cannot be rejected. The IV-Parameter remains within the $[0,1]$ bound, and two different choice models can be identified. Thus, consumers who always chose conventional school milk made two independent decisions. Consumers first decide whether to buy a novel school milk product and then select a specific product based on its attributes (in our case, they had no choice between different products).

The parameter estimates presented in Table 4 are valid for those respondents who chose a novel product at least once (421 youths). The remaining 64 youths always preferred conventional school milk over novel products (compare in Figure 1). Furthermore, 195 youths (38.3\%) chose the novel products exclusively. 


\section{Variables that explain the utility of school milk}

Both novel products have a positive constant, implying that product utility is, on average, higher for those who consume the novel products compared with the conventional products (the constant of the conventional product is normalised to zero). This result is consistent with the underlying nested structure because consumers who do not reject the novel products are explicitly analysed. The higher utility of the novel school milk is given by the constants' coefficient with a value of 0.78 , which is higher than the coefficient of the novel yoghurt. Thus, on average, novel milk is preferred over novel yoghurt.

Furthermore, the product price significantly determines utility functions. The estimated price parameter is negative, which means that utility decreases with increasing price. The dummy for artificial sweetener is also significantly negative. This result indicates that product utility declines with the use of an artificial sweetener. Artificial sweeteners are not preferred by the majority of our respondents. The attribute of increasing fat content is not significant; thus, the fat content is generally not relevant to the decisions of the respondents.

\section{Variables that influence the probability of choosing novel school milk}

The lower part of Table 4 shows the factors that significantly influence the probability of choosing one of the novel school milk products. The likelihood of choosing a novel product was greater for those youths who assessed themselves as overweight and who agreed that low fat and sugar content is important to milk product choices. However, the likelihood of choosing a novel product was lower when the product price was regarded as important.

Further, youth who stated that they enjoy milk products more often chose a novel school milk product. In general, the probability of choosing a novel product is lower for those youth who stated that they would like to eat milk products daily, who care about good nutrition and who would choose a plain milk product if they were allowed to choose only one product. These respondents also had fewer siblings compared with youths who always chose the conventional product.

Cross tables were calculated to detect possible relationships between the variables that could influence the probability of choosing novel school milk products. Youths who assessed themselves as overweight chose reduced-fat products significantly more often (significance level 0.01) or products sweetened with artificial sweeteners (significance level 0.01). However, the relationship is weak (< 0.1 ). The relationships between the assessment of being overweight and the expressed necessity of low fat or sugar content in milk products were slightly stronger. The relationship for fat was approximately 0.23 and that for sugar was approximately 0.16 (significance level both times 0.01 ). No relationship exists for the assessment of being overweight and for the number of siblings, the choice of plain milk products, the enjoyment of milk products, the desire to consume milk products daily or attention to good nutrition.

\section{Discussion}

\section{Variables that explain the utility of school milk}

The results clearly show that most respondents explicitly prefer novel milk over novel yoghurt, as 421 youths chose a novel product at least once. Milk drinks appear to be preferred over yoghurt for consumption at school. This preference may arise because of students' familiarity with this type of product in the context of school consumption. Furthermore, the handling of milk drinks is also easier for children, and the possibility of staining one's clothing by drinking milk is lower compared with 
yoghurt because of the drinking straw ${ }^{4}$. Christoph et al. (2012) conducted a pair comparison with children aged 10 to 14 , and some respondents explicitly explained that they were afraid of making a mess when eating yoghurt and preferred milk for that reason. In another study conducted by Stead et al. (2011), British youths between 13 and 16 explained in focus groups that a spoon is "not cool" and that yoghurt is thus not accepted for consumption at school. Because the novel yoghurt still has a higher level of utility compared with the conventional milk, this finding of Stead et al. (2011) appears to be less relevant to the respondents of this study.

In this study, 64 of the adolescent respondents never chose one of the novel products. The respondents belonging to this group did not prefer artificial sweeteners and reduced fat levels. Various reasons discussed in the literature could explain this behaviour. Lien et al. found that the majority of 14- to 21year-olds prefer maintain existing eating behaviours with regard to fruit and vegetables, sweets and soft drinks. In the present study, it can be interpreted that 64 youths do not consume artificially sweetened or reduced-fat milk products at home and maintain this behaviour at school. It is possible that habit-forming processes are already complete within this group of youths, which would support the claim for the need to initiate nutrition education early. However, it is also possible that these youths attempt to avoid unfamiliar food. At least for younger children, Loewen and Pliner (1999) were able to show a correlation between age and the rejection of an unfamiliar food, although younger respondents show a stronger correlation.

As expected, children care about prices, as younger children already exhibit economic behaviour and understanding (Strauss, A., 1952; Webley, 2005). Weible et al. (2013) conducted a price experiment and showed a significant but limited price effect. Nevertheless, in this study, the price parameter is close to zero (-0.086). This result may be interpreted as an indication of low levels of price sensitivity because of the small differences among the three product prices (30, 35 and 40 cents).

The negative parameter for artificial sweeteners is consistent with public discussions regarding artificial sweeteners in Germany. This ingredient is often considered unhealthy and unnecessary (Focus, 2011). The arguments raised in this context are that artificial sweeteners induce ravenous appetite, may trigger cancer and may promote attention deficit hyperactivity disorder (ADHD). Nevertheless, there is a lack of serious scientific studies proving these arguments (Academy of Nutrition and Dietetics, 2012, Shankar et al., 2013). However, because of the lower body weight of children, they are more likely to exceed the acceptable daily intake (ADI) of artificial sweeteners. For this reason, artificial sweeteners are not regarded as appropriate for children (Food-Monitor, 2010; Food-Monitor, 2013).

Although youths in general do not prefer artificially sweetened milk, this product was chosen 278 times when a sugar-sweetened product was available. Thus, it can be concluded that these products are at least interesting for a minority of students and are not rejected by the entire group. The youths identifying themselves as overweight appeared to have general interest in lower-calorie milk products, such as low-fat and low-sugar products as well as products containing artificial sweeteners. Artificial sweeteners are also controversial in the US, with Moe et al. (2001) finding that $36 \%$ out of 872 adults believe that artificial sweeteners are unhealthy.

The parameter for fat content is negative. A reduced-fat product was chosen 663 times (out of 1,419 choice sets), although a product with $3.5 \%$ fat was available. Nevertheless, the parameter is not significant. This finding implies that no conclusions of possible advantages or disadvantages of reduced fat content can be derived. Although the parameter is not significant within this study, it is

\footnotetext{
${ }^{4}$ Children in Germany are typically provided with packages of school milk and a drinking straw. They do not receive the milk in a glass.
} 
worth discussing because other studies show the relevance of different fat levels. Porubcan and Vickers (2005) found that one reason that people do not like milk in general is the perceived "sour" taste. The perception of sourness increases with higher fat content and decreases with increasing levels of sucrose. Another study analysing preferences regarding different fat levels is that of BabiczZielinska (1999), who found that Polish students increasingly prefer low-fat milk products rather than full-fat products. The same author found that fat content is an important factor in food choice in general, with low fat content being preferred (Babicz-Zielinska, 1998). Additionally, Kim et al. (2013) found that fat content is important to consumers in the case of chocolate milk. Conducting a conjoint analysis, these authors found $1 \%$ and $2 \%$ fat content is the most desired, followed by fat-free and whole milk. In summary, lower-fat milk drinks may help increase milk consumption for people who do not like milk because of its sourness. Pupils preferring lower-fat milk products for nutritional reasons will also benefit from such an offering.

\section{Variables that influence the probability of choosing novel school milk}

It is not surprising that those respondents who assessed themselves as overweight are more likely to choose novel milk products. These products largely have reduced calorie content because of artificial sweeteners and/or fat reduction. There is an obvious reason that youths who self-identify as overweight choose these products, but the reason is less clear for those who assess themselves as normal or even underweight. Previous studies have reported that overweight children tend to choose products with lower calorie content (Zinnecker et al., 1996). Snoek et al. (2013) found that youths aged 13 to 15 with higher BMIs demonstrated restricted eating behaviour. In a broader sense, artificially sweetened or reduced-fat food products can be viewed as part of a restricted eating behaviour.

As an aside, $31 \%$ of the respondents assessed themselves as overweight. In reality, $8.5 \%$ of German youth aged 14-17 were obese and 17.0\% were overweight between 2003 and 2006 (Kurth and Schaffrath-Rosario, 2010). Thus, more respondents describe themselves as overweight than the averages actually reflect. Although this inconsistency could have emerged by accident, it should be considered that disordered body perception is a frequently observed phenomenon, particularly during adolescence. A German study of health behaviour in school-aged children that asked children about their body perceptions reported that $49.8 \%$ of girls and $34.2 \%$ of boys regarded themselves as overweight. Only $37.6 \%$ of girls and $48.2 \%$ of boys described themselves as having a normal weight (HSBC-Team Deutschland, 2011).

The results regarding respondent preferences for low-fat and low-sugar milk products are consistent with the above-mentioned findings of body perceptions. Incorporating low-fat and low-sugar foods into one's diet is key to reducing obesity (Jensen et al., 2013). For school milk, MRI (2011) found that low sugar content is more important than low fat content. Parents and teachers of primary school children often ask for school milk containing less sugar. Even some children report not drinking school milk because of the sweet taste (MRI, 2011). However, the effects should not be overestimated, as Yon et al. (2012) found that slight changes in fat and sugar content have no significant effect on consumption. Furthermore, children consuming milk with slightly reduced levels of fat and sugar were found to consume less milk overall. However, as already noted, the difference was not significant. The results of Kim et al. (2013), who analysed the influence of different levels of sugar content in chocolate milk, are largely comparable to those of Yon et al. (2012). Although there was no difference between regular and reduced-sugar products, products with "sugar free" printed on their labels were less likely to be chosen. Additionally, Chollet et al. (2013) found that sugar content cannot be decreased infinitely. Although flavoured yoghurt with $10 \%$ sugar was significantly more liked than yoghurt with $5 \%$ or $7 \%$ sugar, yoghurt with $7 \%$ sugar was still tolerated. However, yoghurt with 5\% 
sugar was not accepted. Products with reduced fat levels were more preferred than whole-fat products. Finnish consumers appear to prefer reduced-fat milk, particularly for health reasons. Those respondents who switched from regular to reduced-fat milk indicated nutrition or health as their main reasons for the change (Tuorila, 1987).

Youths who report that a low price is important for them have a decreased probability of choosing novel products. This result is comprehensible, as some of the novel products were more expensive than the conventional school milk (40 cents versus 35 cents, respectively).

At first glance, it is surprising that youths have an increased probability of choosing novel products if they like milk products but a decreased probability if they like to eat milk products daily. Of course, it is possible that the first statement ("like milk products", with which $92 \%$ of the respondents agreed) is influenced by social desirability. The first statement likely represents a preference for the taste of milk but does not automatically indicate that these products are frequently consumed. The second statement could be influenced by a possible focus on calories. Perhaps such youths do not consume milk products daily and restrain their eating behaviour because they are afraid of excess calorie intake. This explanation would also match the finding that the respondents in this group assessed themselves as overweight and the findings of the aforementioned study by Snoek et al. (2013) examining the restrained eating habits of overweight youths.

Considering the other results of this study, it is not surprising that children who stated that they would choose a plain milk product among several alternatives had a lower probability of belonging to the group who chose a novel product at least once. The same holds true for those respondents who stated that they care about good nutrition. There is an on-going discussion in Germany as to whether artificial sweeteners and low-fat products are regarded as unhealthy for children and by those who pay attention to nutrition (Focus, 2011).

Youths with more siblings have a decreased probability of choosing novel products, although household size was not found to have a significant influence. Thus far, the following explanation is only a presumption: it is possible that children with fewer siblings are more involved in family shopping decisions. This greater involvement could result in a tendency to choose a broader set of new products, such as novel school milk.

Some variables that were expected to influence choices significantly failed to do so: surprisingly, there were no gender effects. Cross tables conducted before the NL analysis indicated strong gender effects. Compared with boys, girls assessed themselves as overweight more often (significance level: 0.01). Girls indicated significantly greater preference for artificial sweetener (significance level: 0.1), low-fat milk products (significance level: 0.1) and skimmed milk products (significance level: 0.05). Additionally, low calorie, fat and sugar contents were more important to girls (for all three, significance level: 0.05). One possible conclusion may be that the gender effect is masked by other variables and is therefore not observable within NL analysis. However, gender effects have been detected by other researchers. Boys have been found to be more likely to choose meals because of taste or flavour, whereas girls are more likely to choose meals based on health reasons (Noble et al., 2003). Because girls appeared to focus more on their size, they were also more likely to choose reduced-calorie products (Berg et al., 2000; Nu et al., 1996). Some studies indicated that brands were important in the food choices of adolescents and adults (Kim et al., 2013; Stead et al., 2011). This variable was also tested but did not lead to any significant results. In general, it appears that children's preferences and food choices are determined by attitudes and habits and that variables such as gender, age, immigration background and household size are less likely to explain consumption behaviour. Additionally, other studies have not found few or no socioeconomic variables significantly influencing consumption (Chapman and Boor, 2001; Yon et al., 2012). 


\section{Conclusion}

School milk choice is driven by various factors, but the results of this paper are valid only for the limited product range tested. Other products, such as kefir and curd and products with various flavours, should be considered in studies of school milk products. The choice experiment clearly showed that most youths preferred novel school milk products over conventional milk products. This finding implies that conventional school milk no longer meets youth preferences and that a wider range of products, including drinking yoghurt, could be useful. In developing or establishing additional school-based intervention programmes, it is important to allow children to choose between different milk products. An active choice among several options is essential to creating an environment in which habit formation can occur. In addition, politics may promote a wider product range comprising other and preferably healthier options in such a way that behaviours may shift in a self-interested direction. In accordance with Just and Wansink (2009), it is important to guide children's choices subtly to ensure that they are unaware of being guided and thus do not feel forced.

The results indicate that adolescents are aware of fat and sugar content and their effects on health and weight. However, this awareness is not directly observable in their chosen product attributes but is determined only in combination with answered statements. It is likely that the respondents may have occasionally answered the survey according to how their parents would have answered, although they themselves would have acted differently in reality (Brown and Ogden, 2004). The role of parents must be viewed as one of the key factors in children's nutrition at home and in related attitudes. Dennison et al. (2001) found that parents' beliefs about the healthiness of specific types of milk are essential drivers of their consumption. With respect to school milk or to children's nutrition in general, familybased interventions are strongly required to achieve sustainable changes in child and adolescent milk consumption and in nutrition in general.

Another apparent factor in the analysis is the existence of distinct groups within the age group considered. Children who perceive themselves as being overweight appeared to have attitudes and to make choices that differed from the average youth. These children had a higher tendency to choose novel products, particularly artificially sweetened products or lower-fat products. These children chose products that appeared to be healthier because they contained fewer calories. It seems obvious that for this group, self-perception rather than actual BMI affected their behaviour. Unfortunately, these results could not be supported by a distinct estimation, as the number of cases was insufficient to allow for an analysis. Hence, if these findings can be supported by further research, the development of programmes for this group may be important. What works for the average youth may not work for those perceiving themselves as overweight.

In conclusion, the findings presented indicate that modifying or widening the range of milk products offered in schools may be useful. Consideration of nutritional aspects (low sugar content, artificial sweetener and low fat content) and taste aspects are important to ensure successful modifications. If children neither enjoy (specific) milk products nor perceive them as "healthy", then interventions geared towards increasing milk consumption will have limited success.

Moreover, because children that perceive themselves as overweight have different attitudes and choice behaviours, this finding can be viewed as an opportunity to specifically address this distinct group with appropriate products that satisfy their preferences and that "nudge" children and youths towards healthier choices. 


\section{Acknowledgement}

The project on school milk in Germany "Schulmilch im Fokus"' was financially supported by funds from the German Federal Ministry of Food, Agriculture and Consumer Protection and from the Ministry for Climate Protection, Environment, Agriculture, Nature Conservation and Consumer Protection of the German State of North Rhine-Westphalia.

\section{References}

Adamowicz, V., Boxall, P., Williams, M., \& Louviere, J. (1998). Stated preference approaches for measuring passive use values: Choice experiments and contingent valuation. American Journal of Agricultural Economics, 80(1), 64-75.

Adamowicz, V., Swait, J., Boxall, P., Louviere, J., \& Williams, M. (1997). Perceptions versus Objective Measures of Environmental Quality in Combined Revealed and Stated Preference Models of Environmental Valuation. Journal of Environmental Economics and Management, 32(1), 65-84.

Academy of Nutrition and Dietetics (2012). Position of the Academy of Nutrition and Dietetics: Use of Nutritive and Nonnutritive Sweeteners. Journal of the Acedamy of Nutrition and Dietetics, 739-758.

Babicz-Zielinska, E. (1998). Food preferences among the university students. Polish journal of food and nutrition sciences, 48(7), 135-139.

Babicz-Zielinska, E. (1999). Food preferences among the Polish young adults. Food Quality and Preferences, 10, 139-145.

Baxter, S.D., Thompson, W.O., \& Davis, H.C. (2000). Fourth-Grade Children's observed consumption of, and preferences for, school lunch foods. Nutrition Research, 20(3), 439-443.

Ben-Akiva, M. (2000). Discrete choice analysis: theory and application to travel demand. Cambridge, Mass. [i.a.]: MIT Press.

Ben-Akiva, M., \& Lerman, S.R. (1974). Some estimation results of a simultaneous model of auto ownership and mode choice to work. Transportation, 3(4), 357-376.

Berg, C., Jonsson, I., \& Conner, M. (2000). Understanding choice of milk and bread for breakfast among Swedish children aged 11-15 years: an application of the Theory of Planned Behaviour. Appetite, 34(1), 5-19.

Biesalski, H.K., (1999). Vitamine, in: Biesalski, H.K., Fürst, P., Kasper, H., Kluthe, R., Pölert, W., Puchstein,C., Stähelin, H.B. (Eds.), Ernährungsmedizin, Nach dem Curriculum Ernährungsmedizin der Bundesärztekammer. Stuttgart, New York: Georg Thieme Verlag, 111-158.

BMELF (1985). Schulmilch-Beihilfen-Verordnung vom 8. November 1985 (BGBl. I S. 2099), die zuletzt durch Artikel 25 der Verordnung vom 13. Dezember 2011 (BGBl. I S. 2720) geändert worden ist, 〈http://www.gesetze-im-internet.de/bundesrecht/schulmbhv_1985/gesamt.pdf> (accessed 04.04.2012).

Breyer, F., Zweifel, P., \& Kifmann, M. (2005). Gesundheitsökonomik. Berlin [i.a.]: Springer.

Brown, R., \& Ogden, J. (2004). Children's eating attitudes and behaviour: a study of the modelling and control theories of parental influence. Health Education Research, 19 (3), 261-271.

Campell, D. (2008). Identification and analysis of discontinuous preferences in discrete choice experiments, Paper presented at the Annual Conference of the European Association of Environmental and Resource Economists, Gothenburg, Sweden, 25 - 28 June.

Chapman, K.W., \& Boor, K.J. (2001). Acceptance of $2 \%$ ultra-pasteurized milk by consumers, 6 to 11 years old. Journal of Dairy Science, 84(4), 951-954. 
Chollet, M., Gille, D., Schmid, A., Walther, B., \& Piccinali, P. (2013). Acceptance of sugar reduction in flavored yogurt. Journal of Dairy Science, 96, 5501-5511.

Christoph, I.B., Salamon, P., Bürgelt, D., Peter, G., Weible, D., Rothe, A., \& Weber, S.A. (2012). Projekt des BMELV im Rahmen der ökonomischen Begleitforschung zum Bundesmodellvorhaben "Schulmilch im Fokus": Teilprojekt 4: Akzeptanz und Zahlungsbereitschaft für neue Schulmilchprodukte. Braunschweig: Johann Heinrich von Thünen-Institut, <http://www.ti.bund.de/fileadmin/dam_uploads/Institute/MA/ ma_de/maallgemein/vTI_Schulmilch\%20-\%20Teilprojekt\%204.pdf> (accessed 11.04.2014).

Crawford, P.B., Woodward-Lopez, G., Ritchie, L., \& Webb, K. (2008). How Discretionary Can We Be with Sweetened Beverages for Children? Journal of the American Dietetic Association, 108(9), 1440-1444.

Dennison, B.A., Erb, T.A., \& Jenkeins, P.L. (2001). Predictors of dietary milk fat intake by preschool children. Preventive Medicine, 33, 536-542.

DGE (2008). Ernährungsbericht. Bonn: Deutsche Gesellschaft für Ernährung.

DGE (2013). DGE-Qualitätsstandard für die Schulverpflegung. Bonn: Deutsche Gesellschaft für Ernährung.

EC (2008). Commission Regulation (EC) No 657/2008 of 10 July 2008 laying down detailed rules for applying Council Regulation (EC) No 1234/2007 as regards Community aid for supplying milk and certain milk products to pupils in educational establishments. Off. J. Eur. Union L 183/17, pp. 1-10, <http://eurlex. europa.eu/LexUriServ/ LexUriServ.do?uri=OJ:L:2008:183:0017:0026:EN:PDF> (accessed 02.04.14).

EC (2007). Council Regulation (EC) No 1234/2007 of 22 October 2007 establishing a common organisation of agricultural markets and on specific provisions for certain agricultural products (Single CMO Regulation). Off. J. Eur. Union L 299/1, pp. 1-149, <http://eurlex.europa.eu/LexUriServ/LexUriServ.do?uri=OJ:L:2007: 299:0001:0001:EN:PDF> (accessed 02.04.14).

EEC (1977). Council Regulation (EEC) No 1080/77 of 17 May 1977 on the supply of milk and certain milk products at reduced prices to schoolchildren. Off. J. Eur. Commun. L131/8, pp. 1-2, <http://eur-lex.europa.eu/LexUriServ/LexUriServ.do?uri=OJ:L: 1977:131:0008:0009:EN:PDF> (accessed 02.04.2014).

Fayet, F., Ridges, A., Wright, J.K., \& Peter, P. (2013). Australien children who drink milk (plain or flavored) have higher milk and mikronutrient intakes but similar body mass index to those who do not drink milk. Nutrition Research, 33, 95-102.

Focus (2011). Die Wahrheit über Süßstoff. <http://www.focus.de/gesundheit/ernaehrung/tid13247/gesund-essen-die-wahrheit-ueber-suessstoff_aid_366088.html> (accessed 14.05.2014).

Food-Monitor (2010). Kalorienreduzierte Getränke: light, zero oder diät? <http://www.foodmonitor.de/2010/10/kalorienreduzierte-getraenke-light-zero-oder-diaet/ lebensmittel/ratgeber/> (accessed 14.05.2014).

Food-Monitor (2013). Süßstoffe sind kalorienfreie Dickmacher: So einfach ist das nicht. $<$ http://www.food-monitor.de/2013/06/suessstoffe-sind-kalorienfreie-dickmacher-so-einfachist-es-nicht/themenfelder/ernaehrung-gesundheit/> (accessed 14.05.2014).

Hair, J. F., Anderson, R. E., \& Tatham, R. L. (1998). Multivariate data analysis. Upper Saddle River, NJ [u.a.]: Prentice-Hall.

Hanley, N., Wright, R., \& Adamowicz, V. (1998a). Using Choice Experiments to Value the Environment. Environmental and Resource Economics, 11(3), 413-428.

Hanley, N., MacMillan, D.W.R., \& Bullock, C.S. (1998b). Contingent Valuation versus Choice Experiments: Estimating the benefits of environmentally sensitive areas in Scotland. Journal of Agricultural Economics, 49(1), 1-15. 
Heine, W. (1999). Ernährung vom Säuglings- bis zum Jugendalter, in: Biesalski H.K., Fürst P., Kasper H., Kluth R., Pölert W., Puchstein C., \& Stähelin H.B. (Eds), Ernährungsmedizin, Nach dem Curriculum Ernährungsmedizin der Bundesärztekammer. Stuttgart, New York: Georg Thieme Verlag, 201-211.

Hensher, D.A., Rose, J.M., \& Greene, W.H. (2006). Applied choice analysis: a primer. Cambridge [i.a.]: Cambridge Univ. Press.

HSBC-Team Deutschland (2011). Studie Health Behaviour in School-aged children - Faktenblatt "Körperbild und Diätverhalten von Kindern und Jugendlichen". Bielefeld: WHO Collaborating Centre for Child and Adolescence Health Promotion.

Jacobson, R.E. (1961). The School Milk Program in Illinois. Circular 831, Urbana, Illinois.

Jensen, M.D., Ryan, D.H., Apovian, C.M., Ard, J.D., Comuzzie, A.G., Donato, K.A., Hu, F.B., Hubbard, V.S., Jakicic, J.M., Kushner, R.F., Loria, C.M., Millen, B.E., Nonas, C.A., PiSunyer, F.X., Stevens, J., Stevens, V.J., Wadden, T.A., Wolfe, B.M., \& Yanovski, S.Z. (2013). 2013 AHA/ACC/TOS Guideline for the Management of Overweight and Obesity in Adults, <http://circ.ahajournals.org/content/early/2013/11/11/01.cir.0000437739.71477.ee> (accessed 09.04.2014).

John, D.R. (1999). Consumer Socialization of Children: A Retrospective Look at Twenty-Five Years of Research. Journal of Consumer Research, 26, 183-213

Johnson, R.K., Frary, C., \& Wang, M.Q. (2002). The nutritional consequences of flavored-milk consumption by school-aged children and adolescents in the United States. Journal of The American Dietetic Association, 102, 853-856.

Just, D.R., \& Wansink, B. (2009). Smarter Lunchrooms: Using Behavioral Economics to Improve Meal Selection. Choices, 24 (3). Johnson, R.K., Frary, C., \& Wang, M.Q. (2002). The nutritional consequences of flavored-milk consumption by school-aged children and adolescents in the United States. Journal of the American Dietetic Association, 102(6), 853856.

Kelder, S.H., Perry, C.L., Klepp, K.I., \& Lytle, L.L. (1994). Longitudinal Tracking of Adolescent Smoking, Physical Activity, and Food Choice Behaviors. American Journal of Public Health, 84, 1121-1126.

Kemm, J.R. (1987). Eating patterns in childhood and adult health. Nutrition and Health, 4, 205-215.

Kim, M.K., Lopetcharat, K., \& Drake, M.A. (2013). Influence of packaging information on consumer liking of chocolate milk. Journal of Dairy Science, 96(8), 4843-4856.

Köster, E.P. (2009). Diversity in the determinants of food choice: A psychological perspective. Food Quality and Preference, 20, 70-82.

Kurth, B.-M., \& Schaffrath-Rosario, A. (2010). Übergewicht und Adipositas bei Kindern in Deutschland. Bundesgesundheitsblatt 2010-53: 643-652.

Lancaster, K.J. (1966). A New Approach to Consumer Theory. Journal of Political Economy, 74(2), 132-157.

Lien, N., Lytle, L.A., \& Klepp, K.-I., (2001). Stability in Consumption of Fruit, Vegetables, and Sugary Foods in a Cohort from Age 14 to Age 21. Preventive Medicine, 33, 217-226.

Loewen, R., \& Pliner, P. (1999). Effects of Prior Exposure to Palatable and Unpalatable Novel Foods on Children's Willingness to Taste Other Novel Foods. Appetite, 32(3), 351-366.

Louie, J.C.Y., Flood, V.M., Hector, D.J., Rangan, A.M., \& Gill, T.P. (2011). Dairy consumption and overweight and obesity: a systematic review of prospective cohort studies. Obesity Reviews, 12(7), 582-592.

Louviere, J.J., Hensher, D.A., \& Swait, J. (2000). Stated choice methods: analysis and application. Cambridge [i.a.]: Cambridge University Press. 
Louviere, J.J. (2001). Choice Experiments: an Overview of Concepts and Issues, in: Bennet, J., Blamey, R. (Eds.), The Choice Modelling Approach to Environmental Valuation. Chaltenham [i.a.]: Edward Elgar, 13-36.

Lusk, J.L., \& Schroeder, T.C. (2004). Are Choice Experiments Incentive Compatible? A Test with Quality Differentiated Beef Steaks. American Journal of Agricultural Economics, 86(2), 467482.

Lusk, J.L., Roosen, J., \& Fox, J.A. (2003). Demand For Beef From Cattle Administered Growth Hormones Or Fed Genetically Modified Corn: A Comparison Of Consumers In France, Germany, The United Kingdom, And The United States. American Journal of Agricultural Economics, 16-29.

McFadden, D. (1999). Computing willingness-to-pay in random utility models, in: Moore, J.R., Riezman J.C., \& Melvin, R. (Eds.), Trade, Theory and Economics: Essays in Honour of John S. Chipman. London, New York: Routledge, 253-274.

McFadden, D. (1974). Conditional logit analysis of qualitative choice behaviour, in: Zarembka, P. (Eds.), Frontiers in Econometrics. New York, London: Academic Press, 105-142.

Mensink, G.B., Heseker, H., Richter, A., Stahl, A., \& Vohmann, C., (2007a). Forschungsbericht: Ernährungsstudie als KIGGS Modul (EsKiMo). <http://www.bmelv.de/SharedDocs/Downloads/Ernaehrung/EsKiMoStudie.pdf?_blob=publi cationFile> (accessed 18.02.13).

Mensink, G.B., Kleiser, C., \& Richter, A., (2007b). Lebensmittelverzehr bei Kindern und Jugendlichen in Deutschland. Bundesgesundheitsblatt - Gesundheitsforschung Gesundheitsschutz, 50, 609-623.

Moe, G., Neuhouser, M., Kristal, A ., Rock, C., \& Neumark-Sztainer, D. (2001). Consumer acceptability of fertilizers, pesticides, preservatives, artificial sweeteners, fat substitutes, and genetically modified foods. Journal of the American Dietetic Association, 101(9, Supplement), A-40.

Morey, E.R., \& Rowe, R.D. (1993). A repeated nested-logit model of Atlantic salmon fishing. American Journal of Agricultural Economics, 75(3), 578-592.

MRI (2008). Ergebnisbericht, Teil 2: Nationale Verzehrsstudie II. Karlsruhe: Max-Rubner Institut, <http://www.bmelv.de/SharedDocs/Downloads/Ernaehrung/NVS_ErgebnisberichtTeil2.pdf? _blob=publicationFile> (accessed 02.04.14).

MRI (2011). Ergebnisbericht: Einflussfaktoren auf die Nachfrage nach Schulmilch in Grundschulen in Nordrhein-Westfalen. Karlsruhe: Max-Rubner Institut, < http://www.mri.bund.de/fileadmin/Institute/EV/Schulmilch/Schulmilch_NRW_020212.pdf> (accessed 14.05.14).

Murphy, M.M., Douglass, J.S., Johnson, R.K., \& Spence, L.A. (2008). Drinking flavored or plain milk is positively associated with nutrient intake and is not associated with adverse effects on weight status in US children and Adolescents. Journal of the American Dietetic Association, 108(4), 631-639.

Murphy, M.M., Douglass, J.S., Johnson, R.K., \& Spence, L.A. (2007). Macronutrient Intakes, BMI and Metabolic Syndrome Components of Children and Adolescents in the United States Drinking Flavored, Plain or No Milk. Journal of the American Dietetic Association, 107(8, Supplement), A25.

Noble, C., Corney, M., Eves, A., Kipps, M., \& Lumbers, M. (2003). Food choice and secondary school meals: the nutritional implications of choices based on preferences rather than perceived healthiness. Hospitality Management, 22, 197-215.

$\mathrm{Nu}$, C.T., MacLeod, P., \& Barthelemy, J. (1996). Effects of age and gender on adolescents' food habits and preferences. Food Quality and Preferences, 7(3/4), 251-262. 
Porubcan, A.R., \& Vickers, Z.M. (2005). Characterizing milk taste: The effects of salivation rate, PROP taster status, or small changes in acidity, fat, or sucrose on acceptability of milk to milk dislikers. Food Quality and Preferences, 16, 608-620.

Promar International (2002). School Milk Pilot Test: Estimating the Effects of National Implementation. Report prepared for National Dairy Council and American School Food Service Association. <http://www.nationaldairycouncil.org/SiteCollection Documents/child_nutrition/milkinschools/pilotTest.pdf> (accessed 10.04.14).

Ryan, M., \& Skåtun, D., (2004). Modelling non-demanders in choice experiments. Health Economics, 13(4), 397-402.

Salamon, P., Pfau, C., Grillenberger, M., Christoph, I.B., Straßburg, A., Weber, S.A., Peter, G., Gonzalez-Mellado, A.A., Bonfig, J., \& Weible, D. (2010). School milk demand: design and first results of the German federal research project "Focus on school milk". vTI agriculture and forestry research, 60, 1-11.

Salamon, P., Weible, D., Bürgelt, D., Christoph, I.B., Peter, G., González-Mellado, A.A., Rothe, A., \& Weber, S.A. (2012). Projekt des BMELV: Ökonomische Begleitforschung zum Bundesmodellvorhaben "Schulmilch im Fokus", Endbericht. Braunschweig: Johann Heinrich von Thünen-Institut, <http://www.ti.bund.de/fileadmin/dam_uploads/Institute/MA/Aktuelles_und_Service/Endberi cht\%20-\%20\%C3\%96konomische\%20Begleitforschung\%20zum\%20

Bundesmodellvorhaben\%20-\%20Schulmilch\%20im\%20Fokus.pdf> (accessed 02.04.14).

Shankar, P, Ahuja, S., \& Sriram, K. (2013). Non-nutritive sweeteners: Review and update. Nutrition, 29(11), 1293-1299.

Snoek, H.M., Engels, R.C.M.E., van Strien, T., \& Otten, R. (2013). Emotional, external and restraint eating behaviour and BMI trajectories in adolescence. Appetite, 67, 81-87.

Stead, M., McDermott, L., MacKintosh, A.M., \& Adamson, A. (2011). Why healthy eating is bad for young people's health: Identity, belonging and food. Social Science and Medicine, 72, 11311139.

Story, M., Neumark-Sztainer, D., \& French, S. (2002). Individual and Environmental Influences on Adolescent Eating Behaviors. Journal of the American Dietetic Association, 102 (3, Supplement), S40-S51.

Strauss, A.L. (1952). The development and transformation of monetary meanings in the child. American Sociological Review, 17(3), 275-286.

Tuorila, H. (1987). Selection of milk with varying fat contents and related overall liking, attitudes, norms and intentions. Appetite, 8, 1-14.

Tutz, G. (2000). Die Analyse kategorialer Daten: anwendungsorientierte Einführung in LogitModellierung und kategoriale Regression. München [i.a.]: Oldenbourg.

Urban, D. (1993). Logit-Analyse: statistische Verfahren zur Analyse von Modellen mit qualitativen Response-Variablen. Stuttgart [i.a.]: Fischer.

von Haefen, R.H., Massey, D.M., \& Adamowicz, W.L. (2005). Serial Nonparticipation in Repeated Discrete Choice Models. American Journal of Agricultural Economics, 87(4), 1061-1076.

Vereecken, C., Huybrechts, I., Maes, L., \& De Henauw, S. (2008). Food consumption among preschoolers. Does the school make a difference? Appetite, 51, 723-726.

Ward, S., \& Wackman, D.B. (1972). Children's purchase influence attempts and parental yielding. Journal of Marketing Research, 9(3), 316-319.

Webley, P. (2005). Children's understanding of economics. in: Barrett, M.D., \& Buchanan, E. (Eds.), Children's understanding of society, Hove: Psychology Press, 43-67. 
Weible, D. (2013). Gender-driven food choice: explaining school milk consumption of boys and girls. Journal of consumer policy, 36(4), 403-423.

Weible, D., Salamon, P., Christoph-Schulz, I.B., \& Peter, G. (2013). How do political, individual and contextual factors affect school milk demand? Empirical evidence from primary schools in Germany. Food policy, 43, 148-158.

Weindlmaier, H., \& Fallscheer, T. (1997). Schulmilchversorgung in Deutschland: Situation, Problembereiche, Ansatzpunkte für eine Erhöhung des Distributionsgrades. Wiesbaden: Special Publication of the Trade Association for Carton Packaging of Liquid Foodstuffs (FKN).

WHO (2007). The challenge of obesity in the WHO European Region and the strategies for response. Geneva: World Health Organisation, <http://www.euro.who.int/ data/assets/ pdf file/0010/74746/E90711.pdf?ua=1> (accessed 14.05.14).

Wietbrauk, H. (1976). Vorschläge zur Verbesserung des Schulmilchabsatzes und der Distribution von Schulmilch. Abschlussbericht eines Forschungsauftrages des Bundesministeriums für Ernährung, Landwirtschaft und Forsten, Bundesanstalt für Milchforschung, Kiel.

Wilson, J.W., Enns, C.W., Goldman, J.D., Tippett, K.S., Mickle, S.J., Cleveland, L.E., \& Chahil, P.S. (1997). Data tables: Combined results from USDA's 1994 and 1995 Continuing Survey of Food Intakes by Individuals and 1994 and 1995 Diet and Health Knowledge Survey. ARS Food Surveys Research Group, <http://www.ars.usda.gov/SP2UserFiles/Place/12355000/pdf/Tbchts95.PDF> (accessed 14.05.14).

Yon, B.A., Johnson, R.K., \& Stickle, T.R. (2012). School children's consumption of lower-calorie flavored milk: A plate waste study. Journal of the Academy of nutrition and dietetics, 112(1), 132-136.

Zinnecker, J., Silbereisen, R.K. (1996). Kindheit in Deutschland: Aktueller Survey über Kinder und ihre Eltern (Kindheiten). Weinheim: Beltz Juventa. 


\subsection{Does the society perceive its own responsibility for modern pig production?}

Daniela Weible, Inken B. Christoph-Schulz, Petra Salamon

In: The ethics of consumption: The citizen, the market and the law. Ed. by H. Röchlingsberg and P. Sandin. EurSafe Conference Proceedings (2013), pp. 386-392

(Wageningen Academic Publishers, Wageningen, the Netherlands)

This article was presented at the 11th Congress of the European Society for Agricultural and Food Ethics (EurSafe) "The Ethics of Consumption: The Citizen, The Market, and The Law" from 11-14 September 2013 in Uppsala, Sweden. 


\title{
Does the society perceive its own responsibility for modern pig production?
}

\author{
D. Weible, I.B. Christoph-Schulz, P. Salamon \\ Thünen Institute of Market Analysis, Bundesallee 50, 38116 Braunschweig, Germany \\ daniela.weible@ti.bund.de
}

\begin{abstract}
Lately, the present system for agriculture and food production has been topic in many public discussions; especially modern animal husbandry does no longer match consumers' expectations or societal needs. This paper concentrates on the society's perspective regarding intensive pig production. By combining focus groups with a quantitative survey, a mixed method approach is pursued. Focus groups carried out in three German cities are to capture a variety of opinions and concerns among the population: perception, assessment, responsibility and expectation of the participants regarding pig production. Results showed participants' attention to the following topics: space available per pig was considered as insufficient and not species-appropriate, frequency of medications as too high, and in particular the prophylactic use of antibiotics as problematic. Also interaction among the lack of space, the higher use of medication and the behavioural disorders (e. g., pigs bite each other's tails) were also discussed. Participants often criticized that animals are only seen as a technical product in a production system and there is no "real caring" due to fact that pigs are means of generating profit. Regarding the question of "who is responsible for modern animal husbandry?" it is striking, that respondents have also mentioned consumers' responsibility as well as the role of the state. None of the participants expressed missing knowledge as reason for criticizing and simultaneously consuming meat from modern animal production. Based on these focus groups a quantitative online survey was developed to examine those topics in more detail and to quantify the outcome representatively. Based on 1519 participants, the survey confirmed many of the critical views gained in the focus groups. Besides a very engaged group which is characterised by a strong criticism in general and a strong critical perception of current production systems, also a considerable group accepting modern animal husbandry was identified. The question about responsibility showed that more than $80 \%$ of the respondents stated to accept increasing prices as consequences of regulations which gain at animal friendly husbandry.
\end{abstract}

Keywords: modern pig production, societal expectations, responsibility, mixed method approach

\section{Introduction}

Today's agriculture and food production has been a topic in public discussions and the media during the last years. On one hand, modern animal husbandry does not match consumers' or societal expectations. And on the other hand, animal production is an important sector in German agriculture and in whole food processing chain. And what is more, it is a growing sector comprising about $60 \%$ of farmers' sales, but often suffering by small margins. There is no indication of a declining gap between consumers' expectations and their perception of animal husbandry which might affect consumption patterns in the long-run due to changes in the basic narratives. Objective of the overall study ${ }^{1}$ is to compile information to enabling the development of strategies for all involved agents including farmers, politicians, processors, and distributors to shape agriculture production better towards society's expectation. In this context the following paper concentrates on society's views and expectations concerning

\footnotetext{
${ }^{1}$ This research has been funded by "Stiftung Westfälische Landschaft"
} 
intensive pig husbandry. Based on a literature review guidelines for focus groups are developed to capture and discuss society's views and expectations on pig husbandry in detail. Outcomes of these focus groups are used, in a second step, to setup an online survey to quantify the results of the focus groups. In a last step strategies will be deduced to allow farmers and other actors to fit agriculture better to society's needs.

\section{Literature review}

Although expectations concerning animal husbandry in agriculture had already been touched in several studies their main topics lay elsewhere e. g., on animal welfare, hampered food quality, or on agriculture's role for the society.

Importance of animal welfare is rated by European population with 8.1 on a scale of 10 , but most people $(85 \%)$ stated that they know little or even less about husbandry and $77 \%$ think that improvements are required (Eurobarometer, 2007). Animal welfare in husbandry is seen as the third important objective of European agriculture (Eurobarometer, 2010). 55\% of the respondents stated that agriculture policy does not give enough prominence to animal welfare (Eurobarometer 2005). In the survey of TNS Emind (2012), only 46\% of 1000 European respondents are interested in agricultural topics in general, while $85 \%$ mentioned good governance in animal husbandry as a desired property of German agriculture which is only partly achieved. But spontaneously, animal welfare is not mentioned as criteria of food quality. Only when questioned directly, concerns against modern animal husbandry are raised and often identified as reason for changes in individual consumption pattern (Harper and Henson, 2002) supported by Lassen et al. (2006). Kayser et al. (2012) evaluate attitudes on intensive animal husbandry in Germany indicating that animal welfare deficits in industrialized animal husbandry are perceived due to a limited available space per animal. The DLG (2009) determined a deep emotional relationship of the German population towards animal husbandry based on farmsteads in children's picture books. As a consequence, despite expected prices increases, society (79\% of respondents) called for animal friendly husbandry; however, respondents perceived a partly improvement in animal welfare. Biggest room for further improvement is seen in pig production (Eurobarometer, 2005). Although negative impressions about animal welfare lead to latent unease, other criteria affect buying decisions (Alvensleben, 2002). Although currently animal welfare has little relevant for buying decisions it is gaining on importance (Alvensleben, 2002). Consumers presume they can improve animal welfare by buying respective products and state they would be prepared to pay a higher price for products of a higher animal welfare standard. However, when it comes to the buying decisions inadequate label [and awareness towards other criteria] hamper consumers' decision making (Eurobarometer, 2005). Nestle (2012) found 58\% of respondents mentioning higher animal welfare standards among other criteria like sustainability as relevant for buying decisions. In the SGS Fresenius survey (2011) 69\% of the population regarded animal welfare as an important factor of quality outscoring regional origin and ecological production. In general $(83 \%)$, Germans are against the application of human antibiotics in animal husbandry (Forsa, 2012). In Lassen et al. (2006), Krystallis et al. (2009), and Boogard et al. (2011), also topics defining animal welfare from a society's perspective were analyzed like physical integrity and sound conditions or access to open land. "Industrialized" animal husbandry was refused. Heid and Hamm (2011) drilled deeper to aspects of physical integrity.

\section{Methodology}

Based on the above mentioned findings in the literature focus groups and a representative online survey were used to generate necessary information developing strategies to abate the gap between society's perception of animal husbandry and the society needs. 
Focus groups are moderated discussions of several people that are focussed on one topic such as animal welfare or like in our case pig production. It is "a method for eliciting respondents' perceptions, attitudes and opinions" (Wilson, 1997: 209) and takes advantage of group interactions to determine participant's motives, which cause their behaviour. Participants are confronted with other participants' opinions, attitudes or perceptions, and may have to justify the own opinion, attitude or perception. Hence, "individual response becomes sharpened and refined, and moves to a deeper and more considered level" (Finch et al., 2003: 171). Usually, a guideline is written in advance to structure the discussion.

Six focus groups were carried out in September 2012 in the cities of Rheine (high concentration of pig farms), Mainz (low concentration of pig farms and Leipzig (close to an area with Germany's largest pig farms). Groups involved up to 11 participants, lasted about 90 minutes and were documented in audio and video format. Participants had no professional background. Focus groups included in a first part aspects like perception and knowledge of modern pig production. Main point of interest was to evaluate how much knowledge already exists regarding pig production among German society. After a more or less unstructured part, the perception of the stable, the pigs and the farmer were discussed in detail. An assessment of modern pig production followed in a second part. Positive as well as negative aspects were discussed in detail. In some groups, it was possible to go one step beyond. Here, conflicts of interest were regarded as well. In the end, discussants expectations' towards modern pig production and the question of responsibility were discussed.

Knowledge gained from the focus groups was used to develop the quantitative survey. An online survey was carried out with 1519 adults in Germany in spring 2013. Participants were equally distributed regarding gender, region and income. But people older than 65 years were underrepresented. Respondents faced several seven-point likert scales about their attitudes, perception and expectations towards modern pig production. A special point surveyed was the question about responsibility for modern pig production. Respondents got specific actions on how pig production could be improved by the state, retailing companies or the consumers themselves. All of these actions were described with specific consequences like increasing prices or migration of producers abroad. Sociodemografic variables were questioned as well. Items regarding attitudes, perceptions or expectations were pretested using the Kaiser-MeyerOlkin test (KMO), the measure of sampling adequacy (MSA) test and the Bartlett test of sphericity. The complete questionnaire was tested using cognitive pretesting.

\section{Results}

\section{Focus groups}

An enormous amount of information was gained from the focus groups. This makes it necessary to concentrate on a few outstanding results. Discussants had a quite good understanding of modern pig production. Although not being told that the focus should be on intensive pig production discussants started to express their perception and opinion about it. During the discussion the opinion emerged that the lack of space in modern stables is the root for the main problems. Pigs were described as "depressive", "frightful" and "maladjusted". It was mentioned that "they become somehow mentally deteriorated due to the way they are kept". It is assumed that pigs start fighting for space and biting into other pigs tails ("that they become aggressive to each other or even against themselves, that they hurt each other. Because they are not together in their natural groups and they have a certain social behaviour that is not respected", "If they have to eat a lot to become big on the one hand and on the other they have no possibility to move, then I think that they have energy what they cannot [discharge]..., they cannot run, maybe they also become aggressive").

Most of the discussants agreed that due to that lack of space pigs cannot behave naturally. But some respondents assumed that the pigs might have lost their natural behaviour ("born in 
captivity, the animal never got to learn something else. ... That is the question, because maybe that the mother was also born in captivity and cannot impart natural behaviour ... "). In most of the focus groups participants also established the link between farming practice and use of antibiotics ("If I have so many animals living on one spot, then I need antibiotics, because otherwise they all become ill", "If they could move more freely [they did not need] the use of antibiotics", "vicious circle").

Discussants argued much differentiated. Especially the relative low price of pork in Germany was seen as positive and negative as well. Again, a vicious circle was described but not mentioned explicitly. It was argued that people eat more and more pork due to the cheap price and therefore farmers will produce even more pork ("pork is relatively (...) cheap", "giveaway prices for pork", "meat for all", "Price sensibility of consumers, because Germany is one of the countries that pay the less for their food. Problems are homemade", "It is produced more and more meat for a cheap price and therefore it is consumed more because one can afford it").

Consumers' own responsibility was raised several times in all groups. The two main aspects were consumers' responsibility for the actual way pigs are produced and their responsibility for improving modern pig production. The former aspect was described with the conflict of interest between immoderately meat consumption and the price for pork. One respondent argued "actually we consumers are the problem; also because we need to eat one kilo of meat per day, exaggerated...". The same person mentioned "... [ I should spent] few more Euros to get something of high-quality and then (...) [I would] moderate my meat consumption". And another respondent argued that "(...) if people started to eat meat only on Sundays, there would be eaten less meat and then agricultural industry would be not so important. You have to look [first] at the consumer (...) and [then] agriculture is adapting".

Regarding their expectations towards future pig production discussants also argue that all consumers have to change habits. Respondents were confident that these new habits would be retained. One discussant argued that "humans are creatures of habit. They will pay more for pork und will go on eating it. We currently have it with coffee [explanation: the price for coffee increased by $15-20 \%$ during the last months but people still buy it].... . And we would also buy more expensive pork because it tastes better." And another mentioned that "we should not deal for this very cheap meat. Maybe with a higher price, meat will have a higher quality and then [we will] adjust our shopping habits".

Asked who would be mainly responsible for the current situation most of the discussants stated the consumers are responsible for the pig meat he/she is buying ("the customer determines the price and in the end also the production system" or "that the consumer can determine [the system] based on the fact that I buy or that I do not buy"). Some mentioned that more information would help to change consumers' habits ("one should try to change one's view based on more information"). The government is seen as responsible for the implementation of "strict guidelines, to receive subsidies" and the "monitoring of the guidelines". And it was mentioned that monitoring has to be more continually.

\section{Online survey}

The analysis of the online survey confirmed many results of the focus groups. Based on the outcomes of the focus groups ten possible improvements in modern pig production were quantified in the online survey. More available space per pig and more materials available for pigs (65\%), more outdoor access (60\%) and no prophylactic use of antibiotics (48\%) were considered as the most important aspects. Further, for $45 \%$ of the respondents no genetically modified feed was considered as one of the most important aspects and no surgical treatments without anesthesia such as piglet castration, tail-docking and/or grinding canines for almost 
40\%. The other possible improvements derived from focus groups, however, appeared less important in the quantitative survey ${ }^{2}$.

Using the data of 19 statements regarding attitudes, perception and expectations towards modern pig production (carried out with a seven-point likert scale), an exploratory factor analysis was used to define the underlying structure in the data matrix (Hair et al., 1998: 90) and to describe society's perception towards modern pig production in more detail.

A principal component analysis was carried out ${ }^{3}$. Based upon these findings of the factor analysis, a cluster analysis was applied (Churchill and Nielsen, 1995: 985).

As shown in Figure 1, three clusters with enormous differences regarding the four extracted factors were found. The first cluster, the "opponents", can be described as very engaged people since every single factor is strongly above or below the average. General criticism towards modern pig production and a critical perception of the farmers are (very) strong in this cluster, whereas the acceptance of the current system is very weak. Further, the opponents depicted strong claims regarding the behaviour of others. The second cluster, the "tolerating" segment, is complementary to the opponents and thus, this cluster also shows a high engagement. They have a very high acceptance of the current system and no criticism towards modern pig production at all. Thus, the behaviour of others is not an issue. The third cluster can be described as the moderates or the indifferent persons who have no real opinions towards modern pig production. This interpretation appears from factor 1 (general criticism) and factor 3 (acceptance) which are both on average. Even factor 4 (behaviour of others) which is above the average, confirms the indifferent attitude as they have no claims regarding the current system. Nevertheless, the critical perception of this cluster is above the average. Finally, all three clusters are of comparable sizes.

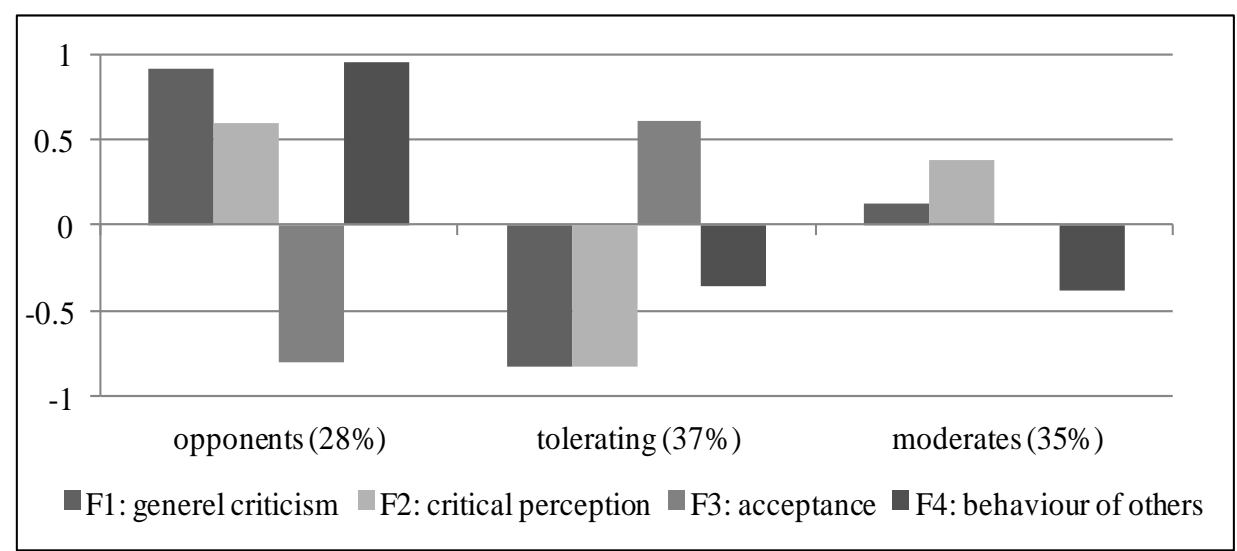

Figure 1: The affiliation of the clusters according to the extracted factors (mean deviation of each cluster from the grand factor mean of the overall sample)

Furthermore, the question whether respondents perceive their own responsibility for an improved pig production due to their purchase behaviour or whether they expect the state or retailers to be responsible was part of the online survey. All of these actions were described with specific consequences like increasing prices or migration of producers abroad.

$83 \%$ of the respondents stated to accept increasing prices as consequence of stronger regulations or other similar measures to push animal friendly production systems. In contrast, only $38 \%$ of the respondents would accept it if several farms go abroad because of stronger regulations and $60 \%$ of the respondents would accept it if a couple of farms had to close. Thus, higher prices are only for few persons (17\%) a reason to refuse improvements in

\footnotetext{
${ }^{2}$ Respondents had to indicate the three improvements that were most important for them.

${ }^{3}$ A table with estimation results of the factor analysis is available from the author on request.
} 
modern husbandry, whereas migrating or closing farms seem to be more problematic. However, it is not clear to us, whether respondents realized their own responsibility in so far that the possibility to support animal friendly production systems is also a purchase decision. Moreover, the final question about the main responsibility for modern pig production resulted rather different. Here, only $13 \%$ of the respondents answered that consumers are mainly responsible and they see farmers $(47 \%)$ and the state $(31 \%)$ carrying responsibility for improving modern husbandry.

\section{Discussion and Conclusion}

The findings partly support the outcome of older studies: respondents often identified limited space in modern pig keepings as a major source of their concerns. Related to this insufficient room other problems may arise according to their views, such as the need of tail docking or the use of antibiotics (legal and illegal) in pig production. Respondents displayed ambivalent attitudes towards the pricing of pork. German pork prices were perceived as relatively low in general, and price levels were regarded as inadequate to cover the cost of good governed pig production with sufficient space. In this respect also the responsibility of the consumers for the current pig production system and its improvement was very clearly stressed. The train of thought was that people need too much meat and thus requiring too much space respectively resources or that the prices paid do not cover costs of animal friendly production systems. In general, there was a feeling that consumers determine the handling of pig production systems to a greater extent. In addition, the government is seen in charge for the implementation of strict guidelines the monitoring hereof which to the mind of the respondents needs to be conducted more frequently.

Concerning further developments of the system several strategies can be followed; however, the picture is far from being clear cut und strategies need to be underpinned and clarified by new and additional results:

1) As the society expresses a very strong concern towards a more animal friendly production process the government may introduce obligations without compensation for the farmers towards animal welfare. Due to the fact that German farmers are integrated in an EU Common Market this strategy requires a common introduction in all EU Member States to avoid a reallocation of production into other countries without those obligations. Due to the cost of compliance market prices will increase.

2) As the consumers see their responsibility for the pig production systems they need to adjust their buying decisions. This is only possible if they have a choice to separate animal friendly produced meat form others which would require a labelling. However, when asked people showed weariness towards labels and in particular, the credibility of labels is regarded as low. Thus a special emphasis needs to be put on the compliance with label rules very frequently controlled by a really trustworthy organisation.

3) Respondents displayed a very limited knowledge of production and tend to reveal a retrospective, nostalgic view on pig production based on a picture book farmstead, but when questioned they were self conscious to this fact. To overcome this shortage group specific communication strategies will be required. A possible strategy may include a wide range of measures which might cover the opening farm gates to the public by e.g., frequent visits on farms, better representation on TV respectively the internet and inclusion of farms into TV series, better representation of farms in picture books etc.

Based on these results there is no high road to overcome the problem in pig production, but a mixed of the different strategies might lead to a step by step improvement. 


\section{References}

Alvensleben, R. v. (2002): Neue Wege in der Tierhaltung - Verbraucheransichten und -einsichten. In: KTBL (eds.): Neue Wege in der Tierhaltung. KTBL-Schrift 408 (2002), pp. 25-32.

Boogaard, B.K., Boekhorst, L.J.S., Oosting, S.J. and Sorensen, J.T. (2011). Socio-cultural sustainability of pig production: Citizens perceptions in the Netherlands and Denmark. Livestock Science, 140, 189-200.

Churchill, G.A. and Nielsen, A.C. (1995). Marketing Research: Methodological Foundations, Fort Worth, Texas, The Dryden Pree.

DLG (2009). Image der Landwirte deutlich verbessert, Pressemitteilung 15.01.2009. Available at: http://presse.dlg.org/publicArtikelDetail.do;jsessionid=3909BAD40BD82154B4BB17DF72CA7 570? artikelId=2189\&spracheId=1\&kategorieId=1\&bereich=Aktuelles\&type=pdf

Eurobarometer (2005). Attitudes of consumers towards the welfare of farmed animals, Eurobarometer Spezial 229. Available at: http://ec.europa.eu/food/animal/welfare/euro_barometer25_en.pdf

Eurobarometer (2007). Attitudes of EU citizens towards animal welfare, Eurobarometer Spezial 270. Available at: http://ec.europa.eu/public_opinion/archives/ebs/ebs_270_en.pdf

Eurobarometer (2010). Europäer, Landwirtschaft und Gemeinsame Agrarpolitik, Eurobarometer Spezial 336. Available at: http://ec.europa.eu/public_opinion/archives/ebs/ebs_336_de.pdf

Finch, H. and Lewis, J. (2003). Focus groups. In: Ritchie, J. and Lewis, J. (2003): Qualitative Research Practice, Sage Publications Ltd., London, pp. 170-197.

Forsa (2012): Meinung zum Einsatz von Humanantibiotika in der Tierhaltung. Available at: http://bund.net/fileadmin/bundnet/pdfs/landwirtschaft/120508_bund_landwirtschaft_forsa_huma nantibiotika_umfrage.pdf

Harper, G. and Henson, S. (2001). Consumer Concerns about Animal Welfare and the Impacton Food Choice. EU FAIR CT98-3678. Final Report, 38 p

Heid, A. and Hamm. U. (2011). Consumer Attitudes Towards Alternatives to Piglet Castration Without Pain Relief in Organic Farming: Qualitative Results from Germany. Journal of Agricultural and Environmental Ethics, forthcoming, 1-20.

Hair, J. F., Anderson, R. E. and Tatham, R. L. (1998). Multivariate data analysis. Upper Saddle River, New Jersey: Prentice-Hall International.

Kayser, M., Schlieker, K. und Spiller, A. (2012). Die Wahrnehmung des Begriffs „Massentierhaltung“ aus Sicht der Gesellschaft. Berichte über Landwirtschaft 90 (3), 417-428.

Krystallis, A., de Barcellos, M.D., Kügler, J.O., W. Verbeke and K.G. Grunert, (2009). Attitudes of European citizens towards pig production systems. Livestock Science, 126, 46-56.

Lassen, J., Sandøe, P., and Forkman, B. (2006). Happy pigs are dirty! - conflicting perspectives on animal welfare. Livestock Science, 103 (3), 221-230.

Nestlé Deutschland AG (2012). Die „, Quality Eater“ erobern den Supermarkt, Pressemitteilung „Das is(s)t Qualität“. Available at: http://www.nestle.de/Unternehmen/Nestle-Studie/Nestle-Studie2012/Documents/Pressemitteilung_Studie_Das_isst_Qualitaet.pdf

SGS Fresenius (2011). Verbraucherstudie 2011 ,LLebensmittelqualität \& Verbrauchermacht.

TNS Emnid (2012). Das Image der deutschen Landwirtschaft: Ergebnisse einer Repräsentativbefragung, März 2012. Available at: http://www.imaagrar.de/fileadmin/redaktion/download/image-studie/2012/ima-imagestudie landwirtschaft_charts-2012.pdf

Wilson, V. (1997). Focus Groups: A useful qualitative method for educational research? British Educational Research Journal, 23 (2), 209-224. 


\section{Concluding discussion}

The purchase and consumption of food in today's society is not simply an activity to obtain required nutrients. Given the abundance of options in the food market, it is rather an expression of preferences for specific products, product attributes and production systems. Many consumers are aware of the social and environmental dimension of consumption and the power they have through their food choices. Consequently, this led to a situation in which consumption becomes less a matter of utility and more a matter of social, cultural and political meaning (Solomon et al., 2010). Looking after one's self-interest does not necessarily preclude more altruistic, society-orientated goals that an individual tries to achieve when purchasing and consuming food. Altogether, the choices people make in terms of food are complex and relate to several concerns and problems which affect not only individual well-being but also societal welfare. A better knowledge of consumer preferences and an understanding about the underlying reasons for people's consumption behaviour is of great interest. The empirical research presented in this dissertation addresses the topics school milk and animal husbandry, and studies consumer preferences for food products as well as production systems. The findings provide, each on its own, implications and recommendations. But which general conclusion can be drawn from the empirical studies?

In the following, key findings are described in a general context. Several aspects are critically reflected, the contribution to scientific literature and further research questions are pointed out. The concluding discussion ends with a closing statement regarding the contribution of this dissertation to the general scientific debate in the field of consumer research.

Perspective on consumer behaviour

There is no universal definition of the term consumer in consumer research. Are consumers only those people who consume goods? Or are they also those people who decide to purchase and pay for goods? What about the consumption of services and what about behaviour that is independent of "deciding", "purchasing" and "consuming"? A precise distinction of consumer behaviour from other human behaviour is difficult (Kroeber-Riel et al., 2009, p. 4). It differs between authors and also depends on the purpose of investigation (e.g., commercial marketing or consumer policy).

Solomon et al. describe consumer behaviour as "the process involved when individuals or groups select, purchase, use or dispose of products, services, ideas or experiences to satisfy needs or desires" (2010, p. 644). This comprehensive concept results in consumers that are able to take many forms. The goods, they consume, can include more than food and services. As described in the introduction, Solomon et al. support the role theory in which consumers can act out different roles. Another description is provided by Kroeber-Riel et al. (2009). According to them, the term consumer is understood in a narrow and broader sense: Narrowly defined, consumer behaviour is understood as the observable ("external") and unobservable ("internal") behaviour of people during the purchase and consumption of economic goods. More broadly defined, consumer behaviour 


\section{Concluding discussion}

refers to the behaviour of final consumers of material and immaterial goods of society, including the behaviour of voters, museum visitors or patients (2009, p. 3).

The narrow consumer term from Kroeber-Riel et al. corresponds to the classical assumption when consumers are studied in economic research. Consumers are understood as people who make purchase decisions. That is, people choose between different alternatives and explore various criteria for making choices. This classical perspective is applied in articles (1) to (3), in which the decisions to choose school milk are studied. The study presented in the articles (1) and (2) assumes that pupils and their parents are a single decision-making unit because parents pay for the school milk and children carry out their intentions by actually ordering and drinking school milk. In the study presented in article (3), choices are made by children alone. However, it is possible that parents influenced their child while answering the questionnaire. In addition, the dissertation also goes beyond this classical perspective (narrow consumer term) and describes preferences for pig production from a societal point of view in article (4). This is motivated by the fact that animal welfare is a societal concern where a focus on purchase behaviour would be too one-sided. Hence, the research topic makes it necessary to study preferences from the perspective of different groups, such as society (see Christoph-Schulz et al., 2012a). According to the broader understanding of consumer behaviour of Solomon et al. (2010) and Kroeber-Riel et al. (2009), it can be argued that the objects under observation in the empirical study presented in article (4), are consumers that behave or communicate from their perspective as citizens or a member of society. The findings of article (4) show a generally critical attitude towards modern pig production in society. However, this is not observed when regarding people's demand in the meat market. The bigger part of purchased meat is produced in modern production systems. Empirical results indicate that respondents assume that the government is also seen as responsible for conditions in farm animal husbandry. People's knowledge of animal husbandry might be another aspect because a relationship between knowledge and attitude is confirmed by the data. People belonging to the group of opponents tend to have a better knowledge.

Overall, the example of animal husbandry shows why different perspectives on consumer behaviour are beneficial for a detailed understanding of the concern. A possible next step for further research might be a more detailed characterisation of identified segments and the evaluation of the reasons for the detected discrepancies.

Applied method to analyse choice behaviour and attitudes

Choice analyses that are applied in the area of school milk base on revealed and stated preference data. In general, data of revealed and stated choices lead to different approaches for analysing consumer preferences in markets. Depending on how preference data is captured, these two general types of choice analysis are distinguished. Preferences can be observed in actual choices made in the market, either directly observed or self-reported. These refers to revealed preferences (RP). Furthermore, preferences can be obtained in hypothetical choice scenarios, i. e., within experiments. Researchers collect data on what consumers say they would do. Due to their hypothetical character, these are termed stated preferences (SP) (Hensher et al., 2005). Both approaches have their strengths and weaknesses.

Data used for the analyses in the articles (1) and (2) is revealed preference data on an individual basis for a school year. Purchases are made by pupils and their parents at school. That means 
choices are made in a real school milk market by individuals who committed their actual and limited resources to make the choice possible. Thus, the data generally shows high reliability and face validity (Louviere et al., 2000, p. 230). However, only preferences of product alternatives that already exist in the school milk market are available for analysis. The only attribute-levels that vary in terms of school milk data are the flavour and price of the milk. Other product characteristics, e. g., fat and sugar content, do not vary due to the lack of available alternatives at schools 1 Such a limited variability regarding the attribute-levels, that are of interest for modelling purposes, can be a disadvantage of revealed preference data. Also, the data used for the analysis in the articles (1) and (2) does not allow for deriving implications with respect to preferences for other product attributes, such as the fat and sugar content. Article (3) takes up this deficit. On the basis of stated preference data, discrete choices for different fat and sugar contents as well as for drinking milk and yoghurt are examined. In general, stated preference data has the advantage to cover a wide range of attributes and levels. Hence, this type of data provides reliable estimates of the relative importance of each of the product attributes. It enables testing new product attributes that do not currently exist on the school milk market in Germany. Stated preference data also allows for calculating willingness to pay for products and product attributes. However, this is of limited reliability due to socially desirable responses, missing budget or time restrictions. The hypothetical market situation makes it difficult to transfer results into the real world without bias (Louviere et al., 2000, p. 231).

Altogether, both methods are complementary to each other and provide a comprehensive picture of children's preferences for school milk and the factors that affect their choices. The mix of revealed and stated methods increases the significance of derived implications and recommendations.

With regard to the area of animal husbandry, in article (4), empirical findings that are derived with a mixed-method approach also benefit considerably of combining two completely different approaches. The combination of qualitative with quantitative methods allows generating a deeper understanding of the research object. Focus groups as well as exploratory factor and cluster analysis do not require making assumptions regarding the structures of variables. Thus, these methods are flexible and allow exploring something new. The aim of the study is to uncover attitudes in an exploratory way and discover structures. An exploratory approach to analyse attitudes has also been applied to previous studies in the context of questions regarding animal welfare (Heid and Hamm, 2012. Evans and Miele, 2008; Harper and Henson, 2001) and food and food quality (Lassen et al., 2006 Alvensleben, 2002). The combination of a qualitative with quantitative methods is found, for example, in Bernués et al. (2003) and Vanhonacker et al. (2012).

In comparison to choice analysis, the empirical study in article (4) observes citizens. Hence, no conclusions about the relevance when buying meat could be drawn from the extracted attitudes. The study does not cover any information about people's intention to buy meat. Furthermore, people who do not purchase and consume meat might be among the observed objectives. Even if meat buyers had been analysed explicitly, their attitudes are only one aspect among many factors that affect the decision for choosing a specific product at the purchase of meat. Consequently, such an exploratory approach can be seen in addition, or as a preliminary stage, to choice analysis.

\footnotetext{
${ }^{1}$ This is because schools are supplied by products of one dairy. Normally, each dairy produces a limited range of school milk products, i. e., without variation in fat and sugar content. As described in Salamon12a, only one targeted dairy produces full- and half-fat school milk products. However, the half-fat option is available among fresh milk products and the full-fat option among UHT-milk products, and each school decides to take either of them.
} 
A possible next step for further research might be the analysis of consumers' purchasing behaviour.

Overall, the combination of methods, such as qualitative and quantitative methods as well as methods basing on stated and revealed preference data, considerably increases the significance of derived implications and recommendations.

Furthermore, attitudes have an important role in the decision-making processes and affect individual preferences and behaviour. Opinions, attitudes or images are an issue in all empirical studies. Attitudes are learned, relate to knowledge and express a willingness to respond more or less positively or negatively to a respective object (Trommsdorff and Teichert, 2011). Hence, attitudes are closely linked to preferences and are important for explaining preferences. In contrast to choices, attitudes are not observable circumstances because they are internal conditions inside a person.

Article (4) proceeds from the assumption that attitudes towards animal husbandry are expressed in people's perceptions, opinions and expectations. The method of focus groups is used to elicit them and take advantage of group interactions to determine participants' motives. Hence, "individual response becomes sharpened and refined, and moves to a deeper and more considered level" (Finch and Lewis, 2003, p. 171). Next, opinions that are obtained from focus groups are quantified in an online-survey. 19 statements that are carried out with a seven-point Likert scale are aggregated in an exploratory factor analysis to four factors describing respondents' attitudes.

Such extracted factors could be a starting point for further analyses. One possibility is presented in article (4), where extracted factors are the basis for the identification of groups with enormous differences regarding the four extracted factors in a cluster analysis. Another possibility is to include the extracted factors in a demand analysis. This would have been an option for the models in articles (1) to (3) as well. The advantage would have been a reduction of model complexity, as less explanatory variables are modelled. Although opinions are queried in a similar way 2 to the animal husbandry-study, these empirical models cover opinions of all surveyed persons through single statements, which are included in the model as categorical variables with three values: agreement, indifference and disagreement. The reason for this can be found in the number of available statements, which are too low for included topics (ranging between 9 and 13).

Finally, this dissertation shows that the multilevel approach applied in the articles (1) and (2) is appropriate to reflect the hierarchical structure of the data base. With respect to pupils, this approach can be found in the field of educational sociology (e. g., Schulze et al., 2009) or in consumer research (e.g., Vereecken et al., 2008, Reinaerts et al., 2007) but is also applied to children, for example, in the field of health economics (e. g., Gwozdz et al., 2013). Applications of empirical models that illustrate individuals in both the classroom setting as well as the school context are relatively seldom. The demand models in the articles (1) and (2) include both, and are additionally extended by a further level to cover the price effect. In sum, four levels are distinguished to reflect the nested structure. A random intercept model is chosen which is a multilevel model with a relatively simple structure and allows for focusing on the identification of fixed effects. Although the theory of multilevel also allows for specifying interaction effects and particularly cross-level interactions, the demand models in the articles (1) and (2) do not integrate them in order to reduce complexity. However, concentrating on fewer level and, in turn, testing for plausible cross-level interaction and random slopes would be a good starting point for further research activity.

\footnotetext{
${ }^{2}$ Through several statements within a five-point Likert scale, affective, cognitive and intentional components of attitudes towards milk, school milk and healthy diet are captured for parents, teachers, school milk managers and school principals.
} 
Theoretical model to identify determinants of choice behaviour

As mentioned initially, all disciplines involved in consumer research provide a wide range of theoretical models to explain consumer behaviour. Examples are the concept of Homo oeconomicus, the Theory of Reasoned Action (TRA) and the Theory of Planned Behaviour (TPB) of Fishbein and Ajzen, the Social Cognitive Theory (SCT) of Bandura or the Health Belief Model (HBM) of Rosenstock. Because each of them has a different perspective on human behaviour and bases on other assumptions, it can be argued that each of them has a specific focus on consumer behaviour and only illustrates a section of behaviour. For example, behaviour is expressed as a consequence of rationality, socialisation or genes. Because of the complexity of human behaviour, consumer researchers stress that the different approaches are not seen as exclusive but rather as complementary to each other (e. g., Kroeber-Riel et al., 2009. Trommsdorff and Teichert, 2011). A focus on single components would be too one-sided. According to Trommsdorff and Teichert (2011, p. 24), the current approach of the theory of consumer behaviour is merged from different perspectives. A general model explaining consumer behaviour in all possible situations and comprising all relevant theoretical constructs, might be close to a real picture of human behaviour. However, such a model, that has been explored and empirically tested, does not exist (Trommsdorff and Teichert, 2011, p. 27).

A basic assumption in economics is rational human behaviour, that is, an individual will behave in all situations rational and will maximise his/her utility. With a focus on the explanation of prices and their formation on markets, economic analysis assume the stability of preferences, which is a core element of neoclassical theory until today can be especially traced back to Gary S. Becker (Fellner, 2014 . pp. 13, 16). According to Becker (1982, p. 3), preference stability means that preferences do not substantially differ over time and across individuals. This implies the exogeneity of preferences in economic models, and hence, changes in modeled relations have no effect on individual preferences. Either the process of decision making nor the underlying values are considered as determinable from outside. Accordingly, Becker describes behavioural differences not as differences in individual preference structures, but rather as a result, which comes up due to different realisations of the identical preference bundle (Becker, 1982, p. 163). Thus, impact of prices and price changes can be analysed because preference stability ignores all other influences on behaviour such as changes in values. This preference stability that is assumed to explain human behaviour has been critical discussed in regard to their consequences concerning the contents. It would imply that people already know everything about their environment and do not learn something new (Fellner, 2014. p. 14). This issue also becomes apparent in the dissertation when choice behaviour of children is considered. The assumption of exogenous preferences would imply that children's preferences have been already developed. Thus, it would not be of interest where these preferences come from and whether they will be further formed during adolescence. In addition, educational activities and food policies at school would be also seen as having no impact on children's preferences. Instead, this dissertation assumes that in the context of children's behaviour, i. e., of consumers who are under development and on primary socialisation, specific preference-influencing and preference-forming factors are important to be considered. It is already the practice in empirical social sciences for allowing changes in preferences as it has been shown that "human behaviour deviates from the rational model in predictable ways" (Levitt and List, 2008, p. 909). For example, insights of 
psychology are incorporated into economic models with the intention to improve the ability to explain observed behaviour within economic models .

Hence, the articles (1) to (3) concentrate on behaviour of children and assume that two aspects play an important role for a conceptual model explaining behaviour for this age group: socialisation and learning. First, children's behaviour is strongly affected by primary socialisation agents. Although socialisation is a lifelong process, skills, values, norms, etc., are acquired particularly in childhood (Beardsworth and Keil, 1997, p. 54). This also includes consumption behaviour and food choices. Second, children learn behaviour as they grow up. Observational learning is the process, in which "people learn not only from their own experiences, but by observing the actions of others and the benefits of those actions" (Glanz and Rimer, 2005, p. 20). Thus, learning is a cognitive process that takes place in a social context (e.g., family, peers, class, school) and is particularly important for the process of socialisation (Kuhlmann, 1983). To explain how children acquire skills, the concept of modeling, i. e., learning by observing behaviour, is often applied (Reinaerts et al., 2007. Weber Cullen et al., 2001; Vereecken et al., 2005). Children observe the behaviour of others and learn from these actions and from the consequences of the observed behaviour. Learned skills, attitudes and behaviour are adopted and can be transferred to other contexts. Parents, teachers and (older) peers serve as role models and count among key socialisation agents (Crockett and Sims, 1995). The consideration of these aspects in a model for explaining children's behaviour is in accordance with literature. A review of models for explaining children's and adolescents' behaviour, for example in regard to the development of childhood obesity (Reisch and Gwozdz, 2010. Dresler-Hawke and Veer, 2006) or eating behaviour (Story et al., 2002, Fitzgerald et al., 2010), results in different approaches, which all cover constructs such as environmental influences (primary socialisation agents) and the interaction between individuals and their environments.

The conceptual models in the articles (1) and (2) attempt to cover the aspects of learning and socialisation in a demand model that bases on consumer theory. Thus, underlying theoretical models of school milk demand focus on factors which are assumed to affect individual decision and go beyond these individual factors also to reach context factors. Individual aspects include socioeconomic factors and preferences of pupils whereas their preferences may be determined based on their attitudes, knowledge and habits. The question of how pupils are affected and shaped by their family and school environment is particularly answered in order to explain preferences for school milk. In both articles the social and physical environment is referred to as context.

Empirical findings of the articles (1) and (2) confirm the relevance of the immediate environment (parents and teachers) for children's preferences. The findings show that the school milk price has a limited effect on children's choices. This provides valuable implications for behavioural economics and socialisation research as effects of socialisation and learning are described at all levels. From this, the dissertation argues that socialisation agents have to be considered for designing appropriate school milk policies and that the consumption aid alone is insufficient. Results and recommendations from the example of school milk could also be transferred to other areas. For instance, they might provide the basis for programmes regarding school food policies or nutritional programmes. The development or revision of such programmes could build upon the findings of this research. Thus, school milk serves as an example for how specific measures affect children's food choices in the school setting.

Moreover, the empirical models of articles (1) and (2) also contribute to the scientific literature. The applied demand models that consider influences of socialisation and learning are the first ones in 
regard to this topic. A huge set of explanatory variables is available in this unique pooled data base including information on different agents belonging to different levels of the "system" surrounding pupils. The study illustrates the costliness of providing data that allows for explaining individual choice behaviour within a system of social environmental levels. Although the school setting is relatively manageable, capturing information of all involved agents causes a major effort. Hence, the application of such an approach to similar school topics of interest is seldom found in literature. One survey, which is similar to the school milk study, was set up afterwards for the evaluation of the school fruit programme in Germany (see Wingensiefen et al., 2012). Although the relevance of social environmental information is generally considered as important for explaining consumer preferences, it is assumed that the transferability of the presented approach to other settings of interest is limited to those that are identifiable and appropriate for studying. A further setting might be, for example, employees in companies.

The empirical model of article (3) exclusively comprises individual factors for explaining children's choices. Although it is assumed that particularly parents have a key role for children's decisions, factors of the immediate environment of observed children are not covered due to limitations in the data collection process. Instead, attitudes and behaviour of parents are examined within the same project in a separate survey. The questionnaires consist of almost identical questions to the children's case but with the disadvantage that surveyed parents do not belong to surveyed children. Hence, no merging of both data is possible. Results of the parents' study show that parents' preferences for school milk products are similar to those that are observed from children. On average, parents prefer sugar- and fat-reduced milk products and reject artificially sweetened ones. For further details see Christoph et al. (2012).

Overall, the understanding of how children interact with their environment can be used to design multilevel policies to affect behaviour, for instance, towards a more healthful consumption. In accordance to Glanz and Rimer (2005, p. 482), "providing individuals with motivations and skills to change behaviour cannot be effective if environments and policies make it difficult or impossible to choose healthful behaviours". The research presented in articles (1) and (2) provide evidence for socialisation and learning effects.

In the context of healthy behaviour and consumption, the understanding of the relationship between health status and children's preferences for school milk seem to be important and interesting points for future research. Are children who decide to drink school milk on average more or less overweight? And which role does parent's health status play for their children's choices? Scientific literature is not consistent about the effects of dairy consumption for being overweight in childhood (Louie et al., 2011). Furthermore, previous studies describe the social environment as a contributory factor for childhood obesity (Kime, 2008). Hence, the multilevel perspective might be an appropriate approach to study this topic in detail. Although the school milk studies contain attitudes regarding a healthy diet as well as the knowledge about nutrition and children's perceived body weight, health parameters (e. g., real body weight, body fat distribution, daily calorie intake, physical activity) are not covered.

\section{Addressed policy area}

The dissertation addresses policies which are embedded in the Common Agricultural Policy concentrating primarily on markets and agricultural production and not on the demand side. The EU 


\section{Concluding discussion}

School Milk Scheme, with its consumption aid, is established in the area of market provision (market price support), whereas conditions in animal husbandry are regulated in order to protect animals and to improve the conditions of keeping livestock. Nowadays, it can be recognised that there are attempts to change the orientation towards the consumer side. For example, with the adoption of Commission Regulation (EC) No. 657/2008 in 2008 (EC, 2008) the objective of the EU School Milk Scheme has recently been modified and is now described as follows: "The EU School Milk Scheme is intended to encourage consumption among children of healthy dairy products containing important vitamins and minerals. The scheme does not only have a nutritional character but also an educational character and contributes therefore greatly to the fight against obesity among children" (EC, 2014a). Contrary to what was originally intended, the current School Milk Scheme expresses a clear link to consumer and health policies. However, until now, only the aid originally established in 1977 is subject of the regulation. The regulation implements neither informational nor educational instruments. It remains open in what way healthier lifestyles and the knowledge about nutrition will be encouraged.

Empirical studies of articles (1), (2) and (3) show the importance of behavioural components and the relevance of the school context for pupils' preferences. These constitute an important basis for the understanding of preferences and for successful policies. An influence of the price subsidies is also shown, however, effects are limited. In regard to the EU School Milk Scheme, this indicates that policy has to go beyond price politics and adjust school food policies to more tailored programmes (e.g., gender-specific programmes or programmes for children with immigration background). The recommendations can be transferred to school-based intervention and prevention programmes. Adolescence is characterised through higher nutritional requirements for the physical development of the body and it is also responsible for the overall health status in later years. Accordingly, targeting on adolescents' nutrition behaviour and building the foundation for healthy food preferences during childhood and adolescence seems to promote public health and support the fight against obesity. In addition to subsidies, the implementations of such policies that create a health-supportive infrastructure are important. For instance, the access to a wide range of healthy and affordable food items that meet pupils' preferences, information measures for parents and teachers, accompanying educational material and elements for lessons, or the use of healthy default options.

Against the background of the ongoing public and scientific debate about the general nutritional value of flavoured milk products, the question must be raised whether the current policy intervention is appropriate. Because the acceptance and share of purchases of plain school milk products is very low and only few schools decide to provide plain milk as the only product, the consumed school milk products are normally the flavoured ones. Although the daily consumption of milk and milk products in children's diet is recommended, the German Nutrition Society (DGE) notes that they can be high in fat and sugar. Consequently, the DGE recommends the consumption of only halffat and unsweetened milk products (DGE, 2013). Thus, it seems useful to pay more attention to interactions between health behaviour, health parameters and school milk consumption. These aspects have not yet been evaluated. As postulated above, it would be particularly important and interesting to know, whether pupils who choose school milk differ in their health status and health behaviour from those who do not choose school milk. Findings about existing or nonexisting differences might support the on-going discussions. Finally, the understanding of how health parameters determine children's choices would contribute to and increase of the overall 
significance of the study and provide important policy implications.

The conditions in farm animal husbandry are regulated by law. As customary in a democracy, the right balance between different interests has to be achieved within rules and regulations. This comprises farmers and citizens as well as specifications of the animal welfare law (EC, 2012. EC, 2014c). That is, governments have to make sure that in addition to the interests of the agricultural sector itself, societal and consumers' interests over production systems are taken into account.

The empirical study presented in article (4) looks at preferences of citizens and detects that citizens are strongly critical about modern pig production systems, accompanied by a limited knowledge and the tendency to reveal a retrospective, nostalgic view of agriculture. Because the analysis focuses only on pig production, findings are not valid for animal production systems in general. Preferences for other animal species (e.g., poultry, cattle) are not investigated. Moreover, results of the study indicate that criticism towards modern agriculture concentrates predominately on animal production and on specific aspects of husbandry (Salamon et al., 2014; Zander et al., 2013). This dissertation indicates that the functioning of the meat market might need to be examined in more detail and animal husbandry might need to be improved. In particular the available space per animal should change fundamentally. Implications derived in article (4) suggest that a mix of different strategies might lead to an improved societal perception of animal husbandry. First, this would include specific communication strategies to overcome the nostalgic view of modern animal production systems. Second, governmental incentive instruments could improve animal welfare and allow consumers to separate animal-friendly produced meat from others (e. g., either through state or private labelling). These strategies need to be underpinned and clarified by new and additional results.

Overall, the implications drawn in articles (1) to (4) show that governments should concentrate on specific groups of society. There is not only one type of consumer but there are various consumer groups or, respectively, segments with each still having big differences regarding specific needs and challenges (e.g., girls, the youths who perceive themselves as overweight and persons with strong concerns about modern animal husbandry). It is important to address each of these groups specifically: encouraging overweight children and youths to adopt healthy lifestyles, or girls to meet their nutritional requirements, and creating more animal-friendly alternatives or stronger regulations to improve the welfare of farm animals.

Moreover, governments and policy-makers should take into account that there might be a huge range of factors that affect consumer preferences and behaviour. Until now, the consumer policy point of view still proceeds mostly from a rational purchasing behaviour of consumers (Kroeber-Riel et al., 2009 Levitt and List, 2008). Indeed, when people are faced with choices, "they are just likely to do what they have always done, what impulse tells them to do or what their neighbours or friends generally do as to do what is most beneficial (Prendergrast et al., 2008, p. 6). These drivers of consumer behaviour can be manifold and are discussed in different contexts. They are also presented in the empirical findings of this dissertation. If governments intend to achieve behavioural change, such as encouraging people to adopt healthy dietary habits, financial incentives alone might be too one-sided and might result in a low effect. It can be concluded that the impact and effectiveness of interventions in the area of consumer-related policies will strongly depend on the implementation of policies that target on behavioural drivers. 
On the whole, the dissertation shows that applied methodological approaches benefit from the interdisciplinarity of the field of consumer research. Demand models are developed on the basis of a multilevel approach. This allows explaining choice behaviour of pupils in the school context. Further, the empirical research indicates that different data types and the combination of methods are beneficial. A deeper understanding of choice behaviour and attitudes is gained, and the significance of derived implications increases. Choice analyses of revealed and stated preference data allow for identifying a huge range of influencing factors on children's choices regarding school milk products. Attitudes towards modern pig production are explored by qualitative and quantitative methods. In contrast to classical consumer research, the empirical research takes up different perspectives on consumers. Hence, consumers are not only analysed in their role as decision-makers but also as citizens or members of society. The example of animal husbandry points out how beneficial varying perspectives on consumers are for a detailed understanding of their concern. For future research, it would be of interest to raise the question whether there are interactions between children's consumption choices, health behaviour and health parameters. Further research could also analyse different strategies that might lead to an improved societal perception of animal husbandry.

To conclude, the dissertation contributes to the general scientific debate in the field of consumer research by demonstrating the relevance of inter- and intra-personal factors in consumer preferences. With respect to inter-personal factors, the influence of socialisation agents, such as parents and teachers, is described for children's choices. The importance of observational learning is particularly emphasised. Moreover, intra-personal factors play an important role for children's school milk preferences, as consumption habits and attitudes influence individual choices. The relevance of perceptions, opinions and expectations is shown with regard to people's preferences for modern pig production. In doing so, different populations groups are identified that establish a basis for formulating specific communication strategies. If governments take psychological and context factors into account for policy interventions, this would result in an increased impact compared to financial incentives alone. Overall, for the design of policy measures the empirical findings call for paying more attention to information- and education-based interventions. 


\section{References}

Alvensleben, R. v. (2002). "Neue Wege in der Tierhaltung - Verbraucheransichten und Verbrauchereinsichten". In: Neue Wege in der Tierhaltung. Ed. by Kuratorium für Technik und Bauwesen in der Landwirtschaft e.V. KTBL-Schrift 408. Darmstadt, pp. 25-32.

Andersen, L. M. (2011). Animal Welfare and Eggs - Cheap Talk or Money on the Counter? Journal of Agricultural Economics 62 (3), 565-584.

Beardsworth, A. and Keil, T. (1997). Sociology on the Menu: An Invitation to the Study of Food and Society. London, New York: Routledge.

Becker, G. S. (1982). Der ökonomische Ansatz zur Erklärung menschlichen Verhaltens. Tübingen: Mohr.

Bernués, A., Olaizola, A., and Corcoran, K. (2003). Extrinsic attributes of red meat as indicators of quality in Europe: an application for market segmentation. Food Quality and Preference 14 (4), 265-276.

BMELF (1985). Schulmilch-Beihilfen-Verordnung vom 8. November 1985 (BGBI. I S. 2099), die zuletzt durch Artikel 25 der Verordnung vom 13. Dezember 2011 (BGBI. I S. 2720) geändert worden ist, pp. 1-3. URL: http://www.gesetze-im-internet.de/bundesrecht/schulmbhv_1985/ gesamt.pdf (visited on Apr. 4, 2012).

Buergelt, D., Christoph-Schulz, I. B., Salamon, P., and Weible, D. (2013). "Impacts of sustainability labels on consumers' purchasing decisions for fish". In: The ethics of consumption: The citizen, the market, and the law. Ed. by H. Röchlingsberg and P. Sandin. Uppsala, Sweden: Wageningen Academic Publ., pp. 39-45.

Christoph, I. B., Salamon, P., Bürgelt, D., Peter, G., Peter, G., Weible, D., Rothe, A., and Weber, S. A. (2012). Endbericht: Ökonomische Begleitforschung zum Bundesmodellvorhaben"Schulmilch im Fokus" - Teilprojekt 4: Akzeptanz und Zahlungsbereitschaft für neue Schulmilchprodukte, Projekt des BMELV. Johann Heinrich von Thünen-Institut. URL: http://www.ti.bund.de/ media/institute/ma/Downloads/vTI_Schulmilch_- _ Teilprojekt_4.pdf (visited on Sept. 11, 2014).

Christoph-Schulz, I. B., Buergelt, D., Salamon, P., Weible, D., and Zander, K. (2012a). "A holistic approach to consumer research on exceptions regarding animal husbandry". In: System Dynamics and Innovation in Food Networks 2012. Ed. by U. Rickert and G. Schiefer. Innsbruck - Igls, Austria: Universität Bonn, ILB Press, pp. 292-304.

Christoph-Schulz, I. B., Buergelt, D., Peter, G., Salamon, P., and Weible, D. (2012b). "The small difference: how does gender affect preferences for school milk?" In: Microcosm of Economic Psychology: Proceedings of the IAREP CONFERENCE WROCLAW 2012. Ed. by A. Gasiorowska and T. Zaleskiewicz. Warsaw, Breslau: Warsaw School of Social Sciences and Humanities, pp. 6575.

Crockett, S. J. and Sims, L. S. (1995). Environmental Influences on Children's Eating. Journal of Nutrition Education 27 (5), 235-249. 
Daniel, H., Reisch, L., and Hamm, U. (2014). Förderkonzept des Bioökonomierates "Lebensmittelkonsum, Ernährung \& Gesundheit". Geschäftsstelle des Bioökonomierates, Berlin.

DGE (2008). Ernährungsbericht. Bonn: Deutsche Gesellschaft für Ernährung e. V.

DGE (2013). DGE-Qualitätsstandard für die Schulverpflegung. 3. überarbeitete Auflage. Bonn: Deutsche Gesellschaft für Ernährung e. V.

Dresler-Hawke, E. and Veer, E. (2006). Making healthy eating messages more effective: combining integrated marketing communication with the behaviour ecological model. International Journal of Consumer Studies 30 (4), 318-326.

EC (2008). Commission Regulation (EC) No 657/2008 of 10 July 2008 laying down detailed rules for applying Council Regulation (EC) No 1234/2007 as regards Community aid for supplying milk and certain milk products to pupils in educational establishments. L 183/17. Official J. Eur. Union, pp. 1-10. URL: http://eur-lex.europa.eu/LexUriServ/LexUriServ.do?uri=OJ:L:2008: 183:0017:0026:EN:PDF (visited on Apr. 4, 2013).

EC (2012). EU Animal Welfare Strategy: 2012-2015. Bruessels: European Commission. URL: http: //ec. europa.eu/food/animal/welfare/docs/brochure_aw_strategy.pdf (visited on June 3, 2014).

EC (2014a). European School Milk Scheme. Website ed. by European Commission, DirectorateGeneral Agriculture and Rural Development. URL: http://ec.europa.eu/agriculture/milk/schoolmilk-scheme/index_en.htm (visited on Apr. 24, 2014).

EC (2014b). Population Groups - Policy. Website ed. by European Commission, DirectorateGeneral Health \& Consumers. URL: http://ec.europa.eu/health/population_groups/policy/ index_en.htm (visited on Apr. 24, 2014).

EC (2014c). Animal welfare: achievements and challenges at the mid-point of 2012-2015 strategy. IP/14/134. Bruessels: European Commission. URL: http://europa.eu/rapid/press-release_IP14-134_en.htm (visited on June 3, 2012).

Eurobarometer (2005). Attitudes of consumers towards the welfare of farmed animals. Eurobarometer Spezial. European Commission. URL: http://ec.europa.eu/food/animal/welfare/euro _ barometer25_en.pdf (visited on June 3, 2014).

Eurobarometer (2007). Attitudes of EU citizens towards animal welfare. Eurobarometer Spezial. European Commission. URL: http://ec.europa.eu/public_opinion/archives/ebs/ebs_270_en. pdf (visited on June 3, 2014).

Eurobarometer (2010). Europäer, Landwirtschaft und Gemeinsame Agrarpolitik. Eurobarometer Spezial. European Commission. URL: http://ec.europa.eu/public_opinion/archives/ebs/ebs 336_de.pdf (visited on June 3, 2014).

Evans, A. and Miele, M. (2008). Consumers' Views about farm Animal Welfare, Part II: European Comparative Report Based on Focus Group Research. Welfare Quality Reports No. 5. Cardiff University.

Fellner, W. J. (2014). Von der Güter- zur Aktivitätenökonomie: Zeitnutzung und endogene Präferenzen in einem Konsummodell. Wiesbaden: Springer.

Finch, H. and Lewis, J. (2003). "Focus Groups". In: Qualitative Research Practice. Ed. by J. Ritchie and J. Lewis. London: Sage Publications Ltd., pp. 170-198.

Fitzgerald, A., Heary, C., Nixon, E., and Kelly, C. (2010). Factors influencing the food choices of Irish children and adolescents: a qualitative investigation. Health Promotion International 25 (3), 289-298. 
Furst, T., Connors, M., Bisogni, C. A., Sobal, J., and Falk, L. W. (1996). Food Choice: A Conceptual Model of the Process. Appetite 26 (3), 247-266.

GfK-EU3C (2012). FINAL REPORT Consumer Market Study on the Functioning of the meat market for consumers in the European Union SANCO/2009/B1/010. Prepared by GfK EU3C (EU Custom Research and Coordination Centre).

Glanz, K. and Rimer, B. (2005). Theory at a Glance: A Guide for Health Promotion and Practice. Second edition. NIH Publication No. 05-3896: U.S. Department of Health and Human Services, Public Health Service, National Institutes of Health, National Cancer Institute.

Grunert, K. G. (2011). Sustainability in the Food sector: A Consumer Behaviour Perspective. International Journal on Food System Dynamics 2 (3), 207-218.

Gwozdz, W., Sousa-Poza, A., Reisch, L. A., Ahrens, W., Eiben, G., M. Fernandéz-Alvira, J., Hadjigeorgiou, C., De Henauw, S., Kovács, E., Lauria, F., Veidebaum, T., Williams, G., and Bammann, K. (2013). Maternal employment and childhood obesity - A European perspective. Journal of Health Economics 32 (4), 728-742.

Harper, G. and Henson, S. (2001). Consumer Concerns about Animal Welfare and the Impacton Food Choice. EU FAIR CT98-3678. Final Report. Centre for Food Economics Research (CeFER), Department of Agricultural and Food Economics, University of Reading.

Heid, A. and Hamm, U. (2012). Consumer Attitudes Towards Alternatives to Piglet Castration Without Pain Relief in Organic Farming: Qualitative Results from Germany. Journal of Agricultural and Environmental Ethics 25 (5), 687-706.

Hensher, D. A., Rose, J. M., and Greene, W. H. (2005). Applied Choice Analysis: A Primer. Cambridge: Cambridge University Press.

Jensen, K. O. and Holm, L. (1999). Preferences, quantities and concerns: socio-cultural perspectives on the gendered consumption of foods. European Journal of Clinical Nutrition 53 (5), 351359.

Kelder, S. H., Perry, C. L., Klepp, K. I., and Lytle, L. L. (1994). Longitudinal Tracking of Adolescent Smoking, Physical Activity, and Food Choice Behaviors. American Journal of Public Health 84 (7), 1121-1126.

Kemm, J. R. (1987). Eating patterns in childhood and adult health. Nutrition and Health 4 (4), 205-215.

Kime, N. (2008). Children's eating behaviours: the importance of the family setting. Area 40 (3), 315-322.

Koehler, J. and Leonhaeuser, I.-U. (2008). Changes in Food Preferences during Aging. Annals of Nutrition and Metabolism 52, 15-19.

Köster, E. P. (2009). Diversity in the determinants of food choice: A psychological perspective. Food Quality and Preference 20 (2), 70-82.

Kotler, P. and Bliemel, F. W. (1995). Marketing-Management: Analyse, Planung, Umsetzung und Steuerung. Stuttgart: Schaffer-Poeschel.

Kroeber-Riel, W., Weinberg, P., and Gröppel-Klein, A. (2009). Konsumentenverhalten. 9. Auflage. München: Vahlen.

Krystallis, A., Barcellos, M. D. d., Kügler, J. O., Verbeke, W., and Grunert, K. G. (2009). Attitudes of European citizens towards pig production systems. Livestock Science 126 (1-3), 46-56.

Kuhlmann, E. (1983). Consumer Socialization of Children and Adolescents. A Review of Current Approaches. Journal of Consumer Policy 6 (4), 397-418. 
Larson, N. I., Neumark-Sztainer, D., Harnack, L., Wall, M., Story, M., and Eisenberg, M. E. (2009). Calcium and Dairy Intake: Longitudinal Trends during the Transition to Young Adulthood and Correlates of Calcium Intake. Journal of Nutrition Education and Behavior 41 (4), 254-260.

Lassen, J., Sandøe, P., and Forkman, B. (2006). Happy pigs are dirty! - conflicting perspectives on animal welfare. Livestock Science 103 (3), 221-230.

Levitt, S. D. and List, J. A. (2008). Economics - Homo economicus Evolves. Science 319, 909910.

Lien, N., Lytle, L. A., and Klepp, K.-I. (2001). Stability in Consumption of Fruit, Vegetables, and Sugary Foods in a Cohort from Age 14 to Age 21. Preventive Medicine 33 (3), 217-226.

Louie, J. C. Y., Flood, V. M., Hector, D. J., Rangan, A. M., and Gill, T. P. (2011). Dairy consumption and overweight and obesity: a systematic review of prospective cohort studies. Obesity Reviews 12 (7), e582-e592.

Louviere, J. J., Hensher, D. A., and Swait, J. D. (2000). Stated Choice Methods: Analysis and Applications. Cambridge: Cambridge University Press.

Mau, G., Schramm-Klein, H., and Reisch, L. (2014). Consumer Socialization, Buying Decisions, and Consumer Behaviour in Children: Introduction to the Special Issue. Journal of Consumer Policy 37 (2), 155-160.

Mensink, G., Richter, A., Vohmann, C., Stahl, A., Six, J., Kohler, S., Fischer, J., and Heseker, H. (2007). EsKiMo - Das Ernährungsmodul des Kinder- und Jugendgesundheitssurveys (KiGGS). Neu-Isenburg: Springer Gesundheits- und Pharmazieverlag.

Moisander, J., Markkula, A., and Eräranta, K. (2010). Construction of consumer choice in the market: challenges for environmental policy. International Journal of Consumer Studies 34 (1), 73-79.

MRI (2008). Ergebnisbericht, Teil 2: Nationale Verzehrsstudie II. Max Rubner-Institut. URL: http: //www.bmelv.de/SharedDocs/Downloads/Ernaehrung/NVS_ErgebnisberichtTeil2.pdf? _ _ blob=publicationFile (visited on Feb. 18, 2013).

Nu, C. T., MacLeod, P., and Barthelemy, J. (1996). Effects of age and gender on adolescents' food habits and preferences. Food Quality and Preference 7 (3-4), 251-262.

Padel, S. and Foster, C. (2005). Exploring the gap between attitudes and behaviour: Understanding why consumers buy or do not buy organic food. British Food Journal 107 (8), 606-625.

Pieniak, Z., Verbeke, W., Scholderer, J., Bruns $\varnothing$, K., and Olsen, S. O. (2007). European consumers' use of and trust in information sources about fish. Food Quality and Preference 18 (8), 10501063.

Prendergrast, J., Foley, B., Menne, V., and Isaac, A. K. (2008). Creatures of Habit? The Art of Behavioural Change. URL: http://www.smf.co.uk/wp-content/uploads/2008/04/PublicationCreatures-of-Habit-The-Art-of-Behavioural-Change.pdf (visited on Sept. 13, 2014).

Reinaerts, E., Nooijer, J. d., Candel, M., and Vries, N. d. (2007). Explaining school children's fruit and vegetable consumption: The contributions of availability, accessibility, exposure, parental consumption and habit in addition to psychosocial factors. Appetite 48 (2), 248-258.

Reisch, L. A. and Gwozdz, W. (2010). Einfluss des Konsumverhaltens auf die Entwicklung von Übergewicht bei Kindern: Ein Überblick. Bundesgesundheitsblatt - Gesundheitsforschung - Gesundheitsschutz 53 (7), 725-732.

Reisch, L., Eberle, U., and Lorek, S. (2013). Sustainable food consumption: an overview of contemporary issues and policies. Sustainability: Science, Practice, \& Policy 9 (2), 1-19. 
Robinson, J. S. (1978). Special milk program evaluation and national school lunch program survey.

U.S. Department of Agriculture, Food and Nutrition Service.

Salamon, P, Weible, D, Bürgelt, D, Christoph, I. B., Peter, G, Gonzalez-Mellado, A., Rothe, A., and Weber, S. A. (2012). Endbericht: Ökonomische Begleitforschung zum BundesmodelIvorhaben "Schulmilch im Fokus", Projekt des BMELV. Johann Heinrich von Thünen-Institut. URL: http://www.ti.bund.de/media/institute/ma/Downloads/Endbericht___OEkonomische_ Begleitforschung _zum _ Bundesmodellvorhaben___Schulmilch _ im _ Fokus.pdf (visited on Feb. 23, 2015).

Salamon, P., Buergelt, D., and Christoph-Schulz, I. (2014). "Societal expectations and structural change in agriculture: how can the sector cope with it?" In: System Dynamics and Innovation in Food Networks 2014. Ed. by U. Rickert and G. Schiefer. Innsbruck-Igls, Austria: Universität Bonn, ILB Press, forthcoming.

Schulze, A., Wolter, F., and Unger, R. (2009). Bildungschancen von Grundschülern: Die Bedeutung des Klassen- und Schulkontextes am Übergang auf die Sekundarstufe I. Kölner Zeitschrift für Soziologie und Sozialpsychologie 61, 411-435.

Solomon, M. R., Bamossy, G., Askegaard, S., and Hogg, M. K. (2010). Consumer Behaviour: A European Perspective. Prentice Hall/Financial Times.

Story, M., Neumark-Sztainer, D., and French, S. (2002). Individual and environmental influences on adolescent eating behaviors. Journal of the American Dietetic Association 102 (3, Supplement), 40-51.

Sweeting, H. (2008). Gendered dimensions of obesity in childhood and adolescence. Nutrition Journal 7 (1), 1-14.

Thøgersen, J. (2005). How may Consumer Policy Empower Consumers for Sustainable Lifestyles? Journal of Consumer Policy 28 (2), 143-178.

Trommsdorff, V. and Teichert, T. (2011). Konsumentenverhalten. 8. Auflage. Stuttgart: Kohlhammer.

Vanhonacker, F., Verbeke, W., Van Poucke, E., Pieniak, Z., Nijs, G., and Tuyttens, F. (2012). The Concept of Farm Animal Welfare: Citizen Perceptions and Stakeholder Opinion in Flanders, Belgium. Journal of Agricultural and Environmental Ethics 25 (1), 79-101.

Varian, H. R. (1984). Grundzüge der Mikroökonomik. Second edition. New York, London: W. W. Norton \& Company.

Verbeke, W. (2005). Agriculture and the food industry in the information age. European Review of Agricultural Economics 32 (3), 347-368.

Verbeke, W., Vanhonacker, F., Sioen, I., Van Camp, J., and De Henauw, S. (2007). Perceived Importance of Sustainability and Ethics Related to Fish: A Consumer Behavior Perspective. Ambio 36 (7), 580-585.

Verbeke, W., Pérez-Cueto, F. J. A., Barcellos, M. D. d., Krystallis, A., and Grunert, K. G. (2010). European citizen and consumer attitudes and preferences regarding beef and pork. Meat Science 84 (2), 284-292.

Vereecken, C., Huybrechts, I., Maes, L., and De Henauw, S. (2008). Food consumption among preschoolers. Does the school make a difference? Appetite 51 (3), 723-726.

Vereecken, C. A., Van Damme, W., and Maes, L. (2005). Measuring Attitudes, Self-efficacy, and Social and Environmental Influences on Fruit and Vegetable Consumption of 11- and 12-Year-Old Children: Reliability and Validity. Journal of the American Dietetic Association 105 (2), 257-261. 
Vermeir, I. and Verbeke, W. (2006). Sustainable Food Consumption: Exploring the Consumer "Attitude - Behavioral Intention" Gap. Journal of Agricultural \& Environmental Ethics 19 (2), 169-194.

Weber Cullen, K., Baranowski, T., Rittenberry, L., Cosart, C., Hebert, D., and Moor, C. (2001). Child-reported family and peer influences on fruit, juice and vegetable consumption: reliability and validity of measures. Health Education Research 16 (2), 187-200.

Weindlmaier, H. and Fallscheer, T. (1997). Schulmilchversorgung in Deutschland: Situation, Problembereiche, Ansatzpunkte für eine Erhöhung des Distributionsgrades. Sonderveröffentlichung Technische Universität München.

WHO (2003). Obesity and Overweight. World Health Organisation. URL: http://www.who.int/ dietphysicalactivity/media/en/gsfs_obesity.pdf (visited on Sept. 15, 2014).

WHO (2014). Obesity and Overweight. Website ed. by World Health Organisation. URL: http: //www.who.int/mediacentre/factsheets/fs311/en/ (visited on Sept. 11, 2014).

Wingensiefen, S., Maschkowski, G., Höllmer, J.-P., Simons, J., and Hartmann, M. (2012). Schulobstprogramm in NRW: Analyse der Umsetzung, Evaluation und Identifizierung zentraler Erfolgsfaktoren. Forschungsbericht Nr. 171. Landwirtschaftliche Fakultät der der Universität Bonn, Schriftenreihe des Lehr- und Forschungsschwerpunktes "Umweltverträgliche und Standortgerechte Landwirtschaft".

Young, W., Hwang, K., McDonald, S., and Oates, C. J. (2010). Sustainable Consumption: Green Consumer Behaviour when Purchasing Products. Sustainable Development 18 (1), 20-31.

Zander, K., Isermeyer, F., Bürgelt, D., Christoph-Schulz, I., Salamon, P., and Weible, D. (2013). Erwartungen der Gesellschaft an die Landwirtschaft. Abschlussbericht. Münster: Stiftung Westfälische Landwirtschaft. URL: http://www.ti.bund.de/media/institute/ma/Downloads/SWL_ Zander_etal_2013.pdf (visited on Feb. 23, 2015). 
Appendices 


\section{A Further Publications}

\section{In the area of preferences for school milk products}

Weible, D., Buergelt, D., Christoph, I. B., Peter, G., and Salamon, P. (2012). Economic background of families - is it vital for food decisions? A case study of school milk orders in Germany, Poster. Joint Conference of the AAEA and EAAE "Food Environment: The effect of Context on Food Choice" on May 30-31, 2012, Tufts University, Boston, MA.

Salamon, P., Weible, D., Buergelt, D., Christoph, I. B., and Peter, G. (2012). Individual and context factors determine gender-specific behaviour: the case of school milk in Germany. Joint Conference of the AAEA and EAAE "Food Environment: The Effect of Context on Food Choice" on May 30-31, 2012, Tufts University, Boston, MA.

Peter, G, Salamon, P, Christoph, I. B., Weible, D., and Bürgelt, D (2012). "Eine LOGITAnalyse zur Differenzierung von Käufern und Nicht-Käufern von Schulmilch in Deutschland." In: Schriften der Gesellschaft für Wirtschafts- und Sozialwissenschaften des Landbaues e.V.. Ed. by A. Balmann, T. Glauben, M. Graubner, M. Grings, N. Hirschauer, F. Schaft, and P. Wagner. Hohenheim: Landwirtschaftsverlag Münster, pp. 249-260.

Weible, D, Buergelt, D, Christoph, I. B., Peter, G, Rothe, A., Salamon, P, and Weber, S. A. (2011). School milk demand in Germany: The role of individual as well as contextual factors preliminary results. EAAE 2011 Congress "Change and Uncertainty; Challenges for Agriculture, Food and Natural Resources" from August 30 to September 2, 2011, ETH Zurich, Zurich, Switzerland.

Weible, D. (2011). "Schulmilchanbieter - welchen Einfluss haben sie af die Nachfrage nach Schulmilch in Nordrhein-Westfalen?" In: Schriften der Gesellschaft für Wirtschafts- und Sozialwissenschaften des Landbaues e.V.. Ed. by P. Weingarten, M. Banse, H. Gömann, F. Isermeyer, H. Nieberg, F. Offermann, and H. Wendt. Braunschweig: Landwirtschaftsverlag Münster, pp. 473475 .

Gonzalez-Mellado, A. A., Christoph, I. B., Salamon, P, Peter, G, Weber, S. A., and Weible, D. (2011). "Sinkende Schulmilchnachfrage in Deutschland - woran kann es liegen?" In: Schriften der Gesellschaft für Wirtschafts- und Sozialwissenschaften des Landbaues e.V.. Ed. by P. Weingarten, M. Banse, H. Gömann, F. Isermeyer, H. Nieberg, F. Offermann, and H. Wendt. Braunschweig: Landwirtschaftsverlag Münster, pp. 47-59. (Dieser Beitrag wurde auf der 50. Jahrestagung der GEWISOLA ausgezeichnet als "eines der besten eingereichten Konferenzpapiere eines wissenschaftlichen Themas im Rahmen der Jahrestagung 2010")

Christoph, I. B., Peter, G, Rothe, A., Salamon, P, Weber, S. A., and Weible, D (2010). School milk demand - interaction between policy and other factors: some preliminary findings of a 
regional project. 1st Joint EAAE/AAEA Seminar "The Economics of Food, Food Choice and Health" on September 15-17, 2010, Freising, Germany.

Salamon, P., Pfau, C., Grillenberger, M., Christoph, I. B., Strassburg, A., Weber, S. A., Peter, G., Gonzalez, A., Bonfig, J., and Weible, D. (2010). School milk demand: design and first results of the German federal research project 'Focus on school milk'. Landbauforschung 60 (1), 1-10.

\section{In the area of preferences for attributes of school milk products}

Christoph-Schulz, I. B., Bürgelt, D., Peter, G., Salamon, P., and Weible, D. (2012). "The small difference: How does gender affect preferences for school milk?" In: Microcosm of economic psychology. Ed. by A. Gasiorowska and T. Zaleskiewicz. Warsaw, Breslau: Warsaw School of Social Sciences and Humanities, pp.65-75.

Christoph, I. B., Peter, G., Rothe, A., Salamon, P., Weber, S. A., and Weible, D. (2011). School milk consumption in Germany - what are important product attributes for children and parents?, Poster. EAAE 2011 Congress "Change and Uncertainty; Challenges for Agriculture, Food and Natural Resources" from August 30 to September 2, 2011, ETH Zurich, Zurich, Switzerland.

Christoph-Schulz, I.B., Buergelt, D., Peter, G., Rothe, A., Salamon, P., Weber, S. A., and Weible, D. (2011). Children's milk consumption: How to attain sustainability? Poster at the 5. International Consumer Science Research Conference "Consumer Behaviour for a Sustainable Future" on July 18-20, 2011, Bonn, Germany.

Christoph-Schulz, I. B. and Buergelt, D. and Peter, G. and Rothe, A. and Salamon, P. and Weber, S. A. and Weible, D. (2011). "Children's school milk consumption: How realistic are lexicographic preferences?" In: Proceedings of the 2011 Conference of the International Confederation for the Advancement of Behavioral Economics and Economic Psychology. Ed. by S. Lea, D. Crelley, D. Modic, D., A. Butler, and D. Gordon. University of Exeter, Exeter, Great Britain: The Washington Singer Press.

\section{In the area of preferences for the sustainability attribute of fish products}

Buergelt, D., Christoph-Schulz, I. B., Salamon, P., and Weible, D. (2013). "Impacts of sustainability labels on consumers' purchasing decisions for fish". In: The ethics of consumption: The citizen, the market, and the law. Ed. by H. Röchlingsberg and P. Sandin. Uppsala, Sweden: Wageningen Academic Publ., pp. 39-45.

Zander, K., Bürgelt, D., Christoph-Schulz, I. B., Salamon, P., and Weible, D. (2013). "Nachhaltigkeitskennzeichnungen bei Wildfisch aus VerbraucherInnenperspektive". In: Jahrbuch der Österreichischen Gesellschaft für Agrarökonomie. Ed. by M. Eder, J. Kantelhardt, S. Pöchtrager, and M. Schönhart. Universität für Bodenkultur Wien, Wien: facultas.wuv Universitätsverlag, pp. 91-100.

Zander, K., Bürgelt, D., Christoph-Schulz, I. B., Salamon, P., and Weible, D. (2013). Siegel haben für die Kaufentscheidung eine untergeordnete Bedeutung. Fischmagazin 09/2013. 


\section{In the area of preferences for pig production systems}

Efken, J., Christoph-Schulz, I., Weible, D., Käsbohrer, A., and Tenhagen, B.-A. (2014). Der Markt für Fleisch und Fleischprodukte. German Journal of Agricultural Economics 63 (Supplement), $58-72$.

\section{In the area of animal husbandry}

Christoph-Schulz, I. B., Buergelt, D., Salamon, P., Weible, D., and Zander, K. (2012). How to capture and deal with divergent expectations of consumers, producers, citizens, processors, retailers and rest of society regarding animal husbandry. 10th Wageningen International Conference on Chain and Network Management (WICaNeM) on May 23-25, 2012, Hof van Wageningen, Wageningen, The Netherlands.

Christoph-Schulz, I. B., Buergelt, D., Salamon, P., Weible, D., and Zander, K. (2012). "A holistic approach to consumer research on exceptions regarding animal husbandry". In: System Dynamics and Innovation in Food Networks 2012. Ed. by U. Rickert and G. Schiefer. Innsbruck-Igls, Austria: Universität Bonn, ILB Press, pp. 292-304.

\section{Final reports}

Zander, K., Isermeyer, F., Bürgelt, D., Christoph-Schulz, I., Salamon, P., and Weible, D. (2013). Erwartungen der Gesellschaft an die Landwirtschaft. Abschlussbericht. Münster: Stiftung Westfälische Landwirtschaft. URL: http://www.ti.bund.de/media/institute/ma/Downloads/ SWL_Zander_etal_2013.pdf (visited on February 23, 2015).

Salamon, P, Weible, D, Bürgelt, D, Christoph, I. B., Peter, G, Gonzalez-Mellado, A., Rothe, A., and Weber, S. A. (2012). Endbericht: Ökonomische Begleitforschung zum Bundesmodellvorhaben "Schulmilch im Fokus", Projekt des BMELV. Johann Heinrich von ThünenInstitut. URL: http://www .ti. bund . de/media / institute / ma / Downloads / Endbericht__OEkonomische_Begleitforschung_zum_Bundesmodellvorhaben_-_Schulmilch_im_Fokus. pdf (visited on Feb. 23, 2015).

Christoph, I. B., Salamon, P., Bürgelt, D., Peter, G., Peter, G., Weible, D., Rothe, A., and Weber, S. A. (2012). Endbericht: Ökonomische Begleitforschung zum BundesmodelIvorhaben "Schulmilch im Fokus" - Teilprojekt 4: Akzeptanz und Zahlungsbereitschaft für neue Schulmilchprodukte, Projekt des BMELV. Johann Heinrich von Thünen-Institut. URL: http: //www.ti.bund.de/media/institute/ma/Downloads/vTI_Schulmilch_- _Teilprojekt_4.pdf (visited on Sept. 11, 2014). 


\section{B Curriculum Vitae}

\section{Daniela Weible}

Date and place of birth: 17 November, 1984, Bietigheim-Bissingen (Germany) Email: daniela_weible [at] web [dot] de

\section{Education}

04/2012-11/2014 PhD Program for Agricultural Sciences in Göttingen (PAG) at the Faculty of Agricultural Sciences, Georg-August University, Dissertation: "Consumer preferences for food products and production systems - Empirical evidence of choice behaviour and attitudes"

10/2007-12/2009 Master of Science in Food Economics, Justus Liebig University Giessen Master thesis: "Das Angebot von Schulmilch in Nordrhein-Westfalen: Eine empirische Analyse" (The supply of school milk in North Rhine-Westphalia: an empirical analysis)

10/2004-09/2007 Bachelor of Science in Ecotrophology, Justus Liebig University Giessen Bachelor thesis: "Der Markt für fair gehandelte Agrarprodukte: Entwicklung und Determinanten" (The agricultural market for fair trade products: development and determinants)

$06 / 2004$

Abitur / general qualification for university entrance, Alfred-Amann-Gymnasium Bönnigheim

\section{Work experience}

01/2010-present

05-10/2009

09/2007-04/2009

08-09/2006

$03 / 2006$

$09 / 2005$

$08 / 2005$
Scientific employee in consumer research, Johann Heinrich von Thünen Institute, Institute of Market Analysis, Brunswick

Master thesis at the Institute of Market Analysis and Agricultural Trade Policy, Johann Heinrich von Thünen Institute, Brunswick

Student assistant at the Institute for Agricultural Policy and Market Research, Justus Liebig University Giessen

Internship in quality management \& customer service, NaturataSpielberger AG, Marbach

Internship in health promotion \& prevention, Ludwigsburg county health authority

Internship in nutrition \& diabetes consulting, Bietigheim hospital

Internship in hospital kitchen \& purchasing, Ludwigsburg hospital 


\section{Danksagung}

Der "letzte Schliff" meiner Arbeit ist abgeschlossen und damit der richtige Zeitpunkt gekommen, Danke zu sagen. Zum Gelingen dieser Arbeit haben zahlreiche Personen beigetragen. Diesen möchte ich allen ganz herzlich Danken! An allererster Stelle gilt mein Dank meinem Doktorvater PD Dr. Martin Banse, der mir die Idee überhaupt erst in den Kopf gesetzt und es mir ermöglicht hat, dieses Vorhaben neben den ganzen Projekt-, Konzept-, Strategie- und Thünenarbeiten zu verwirklichen. Ein ebenso großes Dankeschön geht an Dr. Petra Salamon, für ihre Geduld und den "mahnenden Blick", der dafür gesorgt hat, dass ich auf der Zielgeraden bleibe und mich nicht in anderen spannenden Themen verliere. Jede Menge Vertrauen und Freiheiten durfte ich erfahren, die ich sehr zu schätzen gelernt habe. Zudem bedanke ich mich bei Herrn Prof. Dr. Roland Herrmann für die Zweitbetreuung, die eine Verbindung zu meiner Studienzeit in Gießen herstellt und für mich etwas wertvolles ist.

Besonderer Dank gebührt ebenfalls meinen Kollegen und Kolleginnen aus dem Schulmilchteam und der Verbrauchergruppe sowie allen MA'lern. Dabei denke ich vor allem an viele gute Gespräche und Diskussionen sowie die herzliche, motivierende, hilfsbereite, konstruktive und somit einmalige Atmosphäre im Institut. Ich danke Inken für die Gespräche zum Rahmen meiner Arbeit und Sandra für das kurzfristige, zeitaufwändige Korrekturlesen.

Ein herzliches Dankeschön geht auch an meine Eltern und Simone, die trotz der vielen Kilometer, die zwischen uns liegen, zu jeder Zeit ein offene Ohr für mich haben. Hannes danke ich für sein Verständnis, Rückhalt und seine unermüdlichen Aufmunterungsversuche, auch in "hoffnungslosen" Zeiten. 